\title{
Reflecting On the TESOL Practicum: A Case Study
}

\author{
By \\ Michelle A. Wardman
}

A thesis submitted to the Faculty of Graduate Studies and Research in partial fulfillment of the requirements for the degree of

\section{Master of Arts}

\author{
School of Linguistics and Language Studies \\ Carleton University \\ Ottawa, Ontario, Canada
}

September 2009

CCopyright 2009, Michelle A. Wardman 


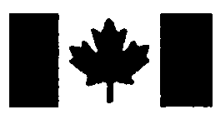

\author{
Library and Archives \\ Canada \\ Published Heritage \\ Branch \\ 395 Wellington Street \\ Ottawa ON K1A ON4 \\ Canada
}

Bibliotheqque et

Archives Canada

Direction du

Patrimoine de l'édition

395 , rue Wellington

Ottawa ON K1A 0N4

Canada
Your file Votre refférence
ISBN: 978-0-494-60271-3
Our file Notre reférence
ISBN: $978-0-494-60271-3$

\section{NOTICE:}

The author has granted a nonexclusive license allowing Library and Archives Canada to reproduce, publish, archive, preserve, conserve, communicate to the public by telecommunication or on the Internet, loan, distribute and sell theses worldwide, for commercial or noncommercial purposes, in microform, paper, electronic and/or any other formats.

The author retains copyright ownership and moral rights in this thesis. Neither the thesis nor substantial extracts from it may be printed or otherwise reproduced without the author's permission.
AVIS:

L'auteur a accordé une licence non exclusive permettant à la Bibliothèque et Archives Canada de reproduire, publier, archiver, sauvegarder, conserver, transmettre au public par télécommunication ou par l'Internet, prêter, distribuer et vendre des thèses partout dans le monde, à des fins commerciales ou autres, sur support microforme, papier, électronique et/ou autres formats.

L'auteur conserve la propriété du droit d'auteur et des droits moraux qui protège cette thèse. Ni la thèse ni des extraits substantiels de celle-ci ne doivent être imprimés ou autrement reproduits sans son autorisation.
In compliance with the Canadian Privacy Act some supporting forms may have been removed from this thesis.

While these forms may be included in the document page count, their removal does not represent any loss of content from the thesis.
Conformément à la loi canadienne sur la protection de la vie privée, quelques formulaires secondaires ont été enlevés de cette thèse.

Bien que ces formulaires aient inclus dans la pagination, il n'y aura aucun contenu manquant. 


\begin{abstract}
This case study explores connections between reflective language teaching and a constructivist model of teacher learning while documenting the lived experiences of 14 pre-service teachers during their second of two practicum placements. How a bottom-up, constructivist model of teacher learning plays out in practice is discussed at length. Specifically, features such as age, gender, and previous language teaching experience (PLTE) are examined to determine if they influence the learning-to-teach experiences of 14 CTESL students engaged in online, in-person, individual and group reflection. Four stages of data were collected: 1) a document analysis of the practicum course syllabus and a one-on-one interview with the practicum course instructor; 2) a questionnaire completed by 14 CTESL students; 3) one-on-one interviews with four CTESL students; and 4) a group interview with the same four participants. These different forms of data collection allowed for triangulation of data sets. PLTE was found to be the most significant feature in this study, affecting CTESL students' experience of their practicum placements in three distinct areas. Importantly, PLTE was also linked to the occurrence of hindsight reflection, a form of reflection uniquely linked to pre-service teachers who came into the language teacher education (LTE) program with prior teaching experience. Implications for LTE-related research and pedagogy are discussed.
\end{abstract}




\section{Acknowledgements}

Many individuals were of immense help in the undertaking of this thesis. I'd like to give due thanks, first, to my supervisor, David Woods: your words of encouragement, feedback, and above all, your relaxed demeanour throughout this learning process is exactly what I needed.

To other SLaLS graduate faculty members who have made my M.A. experience such a positive one: thank you. In particular, I would like to thank Janna Fox for her contagious enthusiasm for the research process, her insightful comments on a much earlier draft of this thesis, and for making SPSS a whole lot less daunting (thanks also to her graduate students for sharing their insights on Stage 2 data). And thanks to Joan Grant, who keeps SLaLs running so smoothly.

I'd like to extend a big thank you to the 14 CTESL students who participated in this study and, in particular, to "Alima", "Karen", "Marek", and "Elaine", who so generously shared their time and thoughts with me in Stages 3 and 4. This thesis could not have existed without you. I'd like to also thank the practicum course instructor for allowing me into her classroom and for agreeing to be interviewed by me not once, but twice.

And, on a more personal note: thank you to Karen, Pixie, and Isabelle for your enduring friendship. Thanks to fellow grad student Janna Holmes for making grad school fun! To Paul, thank you for your patience. "Mummsies" and Bryan, thank you for the encouragement. Last but not least, I'm sending a big thank you across the Atlantic to Grandpa Evelyn, who first sparked my interest in words, languages, and writing. 


\author{
Abbreviations \\ LTE $=$ Language Teacher Education \\ $\mathrm{GTE}=$ General Teacher Education \\ $\mathrm{TL}=$ Teacher learner \\ ELT $=$ English Language Teaching $\quad$ OR \\ $=$ Enhanced Language Training \\ $\mathrm{ESL}=$ English as a Second Language \\ $\mathrm{EFL}=$ English as a Foreign Language \\ $\mathrm{FSL}=$ French as a Second Language \\ TESOL $=$ Teaching English to Speakers of Other Languages \\ TESL $=$ Teaching English as a Second Language \\ CTESL $=$ Certificate in Teaching English as a Second Language \\ CELTA $=$ Certificate in English Language Teaching to Adults \\ PLTE $=$ Previous language teaching experience \\ LINC $=$ Language Instruction for Newcomers to Canada \\ EAP $=$ English for Academic Purposes \\ L1 $=$ First Language Spoken \\ L2 = Second Language Spoken \\ SLA $=$ Second Language Acquisition
}




\section{List of Tables}

Table 2.1: Evolution of Reflective Practice: From Individual to Collaborative 9

Table 2.2: Reflective teaching questions: Pedagogical and Critical 19

Table 2.3: Shift from Behaviourist to Constructivist Model of Learning 24

Table 2:4: Top-down versus Exploratory model of Teacher Learning (in Theory) 24

Table 2.5: Reflective Activities for both Pre-Service and In-Service Teachers 33

Table 2.6: Two Student Teachers' Experiences with Action Research 36

Table 2.7: Teacher Development Groups for Prospective and Practicing Teachers $\quad 48$

Table 3.1: Research Design $\quad 52$

Table 3.2: Demographic Profile of Stage $3 \& 4$ Participants 66

Table 3.3: Core Features of Focus Group vs. Stage 4 Group Interview 68

Table 4.1: Example of Coded Data from Stage 2 Questionnaire 77

Table 5.1: Comparison of Practicum Course Syllabus with Scholarly Sources 78

Table 5.2: Overview of Reflective Assignments Required of CTESL students $\quad 79$

Table 5.3: Practicum Course Objectives: Interview vs. Syllabus 81

Table 6.1: Bio-Data collected from 14 CTESL students 108

Table 6.2: Likert-Scale Responses that Generated Follow-Up Questions 111

Table 6.3: Correlations for Question 17 and 20 113

Table 6.4: Correlations for Question 21 and $23 \quad 114$

Table 6.5: TLs' Primary Reason for Obtaining the CTESL 124

Table 6.6: CTESL Students' Future ELT-Related Aspirations 126

Table 6.7: CTESL Students' ELT-Related Concerns in September 2008

Table 6.8: CTESL Students' ELT-Related Concerns in February 2009

TabIe 6.9: What Did 14 CTESL Students Value the Most? 131

Table 7.1: Demographic Profile of Four TLs Interviewed in Stage 3 and $4 \quad 137$

Table 7.2: The Experience of Web-CT Online Reflection: Two Perspectives 151

Table 7.3: Two Different Reflective Styles 162

Table 8.1: Additional Information on Respondent 2 188 


\section{Graphs / Figures}

Box plot 1: Impact PLTE has on difficulty experienced linking theory with practice 116

Box plot 2: Impact PLTE has on intensity of value felt re: observing host teachers 118

Box plot 3: Impact PLTE has on amount of feedback desired by student teachers $\quad 120$

Box plot 4: Age factor and the value students placed on learning from peers 122

Figure 8.1: Three Teacher Learners Reflecting Across a Continuum 194 


\section{Table of Contents}

$\begin{array}{lc}\text { Abstract } & \text { i } \\ \text { Acknowledgements } & \text { ii } \\ \text { Abbreviations } & \text { ii } \\ \text { List of Tables } & \text { iv } \\ \text { Graphs / Figures } & \text { v } \\ \text { Table of Contents } & \text { vi }\end{array}$

$\begin{array}{ll}\text { Chapter 1: Introduction } & 1\end{array}$

Chapter 2: Literature Review $\quad 7$

- The Evolution of Reflective Practice $\quad 7$

- Definitions of Reflective Teaching 10

- Rationale for Reflective Teaching: Why is it needed? 20

- Models of Adult Learning and Teacher Education 21

- Constructivist Learning, Reflective Practice and LTE: What does it look like? 32

- Teacher Development for both Novice and Experienced Educators 43

Chapter 3: Methodology

- Research Approach and Design 50

- Stage One: Document Analysis and Instructor Interview 53

- Stage Two: Designing the Questionnaire 55

- Stage Three: One-on-one interviews with CTESL Students 62

- Stage Four: Group Interview with CTESL Students 67

Chapter 4: Analysis

- Stage 1: Document Analysis and Interview with Practicum Instructor 72

- Coding System used for all Transcribed Text: Stages 1, 3, and 4

- Coding Questionnaire Data from Stage 2

Chapter 5: Results from Stage 1

- Stage 1 Practicum Course Syllabus: Findings 78

- Stage 1 Interview with Practicum Course Instructor: Findings 80

- Practicum Course Objectives 80

- Lack of Time Issues 83

- Benefits and Challenges of Different Reflective Assignments 86

- The Instructor's View of Reflective Teaching 98

- The Instructor's Own Reflections 101

- The Instructor's Perceptions of CTESL Students' Experiences 104

Chapter 6: Results from Questionnaire Data in Stage 2

- Bio-Data Information from Section 1 of Questionnaire 107

- Section 2: Findings from Likert Scale Responses 110 
- Findings from SPSS Data Analysis 112

- Findings from Responses to Open-ended Questions 123

- TLs' Primary Reasons for Obtaining the CTESL 124

- CTESL Students' Future ELT-Related Aspirations 125

- CTESL Students' ELT-Related Concerns in September 2008

- CTESL Students' ELT-Related Concerns in February 2009

- What 14 CTESL Students Valued the Most 130

Chapter 7: Results from Stage 3 and 4

- Why the Practicum Placement is an Essential Part of CTESL 139

- Why Observation is an Essential Part of Teacher Development 143

- The Value of Learning with and from Peers 147

- The Pros and Cons of Online Reflection 150

- Issues Linking Educational Theory with Practice 154

- Lack of time Issues 158

- Experiences with Reflective Teaching 159

$>$ Hindsight Reflection: The Impact of PLTE 164

- Stage 4: Findings from the Group Interview 166

- Group Response to Baby Bird Metaphor Prompt 178

Chapter 8: Triangulation of Data Sets and Discussion

- Summary of Triangulated Data Sets 182

- Concerns of 14 TLs: Links to Conway \& Clark's (2003) Work 185

- Investigating the case of an Outlier: Respondent 2 187

- TLs' Motivation for Certification: Distinct from B. Ed Students? 191

- PLTE and the Significance of Hindsight Reflection 193

- Refection across a Continuum: Different Stages of Teacher Development 194

Chapter 9: Conclusion

- Research Questions Revisited 196

- The Reflective Process for Novice vs. Experienced Teachers 201

- Reflection: Not always Constructive 204

- Limitations of Study 205

- Implications for LTE Programs and Further Research 206

References $\quad 213$

$\begin{array}{ll}\text { Appendices } & 220\end{array}$

- Appendix A: Ethics Certificate 220

- Appendix B: Situating my Role as Researcher 221

- Appendix C: Stage 2 Questionnaire 226

- Appendix D: Recruitment Letter given to CTESL Students 231

- Appendix E: Information and Consent Letter for CTESL Students, Stage 2 


\section{Chapter 1: Introduction}

This thesis addresses the relative absence of literature on the TESOL practicum experience while documenting the lived experiences of pre-service teachers during their second of two practicum placements. Specifically, I explore how a constructivist, inquiry-based model of teacher learning - one that places value on both individual and collaborative reflection - plays out in practice. I do so by documenting the lived experiences of one group of CTESL undergraduate and postgraduate students at an Ontario university as they engage in online, inperson, individual, and collaborative means of reflection during their second of two practicum placements. I report on whether these teacher learners find greater value in individual reflection, collaborative reflection, or a combination thereof. Additionally I report on whether they appear invested in English language teaching (ELT) as a long-term career objective. Doing so is important as reflective teaching is frequently cited as an integral part of professional development for both novice and experienced teachers (Farrell 2007; Richards \& Ho 1998; Richards \& Lockhart, 1994). Given that reflective teaching is often cited as having professional development value and appears to play a central role in many language teacher education (LTE) programs (Farrell 2007), it is timely to study the experience of reflective teaching from the perspective of pre-service teachers while inquiring into their ELT-related career objectives. Identifying whether or not features such as age, gender, and previous teaching experience can be seen to influence how receptive individual teacher learners are to different types of reflection is also timely.

\section{Research Questions:}

The following research questions directed the focus of my thesis and undertaking of original research as I sought to gain insight into the lived experiences of one group of undergraduate and postgraduate CTESL students: 


\section{Research Questions:}

1. With respect to their teaching concerns, how closely do the experiences of this group of CTESL students resemble Conway and Clark's (2003) model of teacher development?

2. What are their ELT-related career aspirations? Related to this, what are their primary motivations for obtaining the CTESL?

3. Do the CTESL students see value in their practicum placements? If yes, how so?

4. What are their appraisals of the four different types of practicum course reflection: face-to-face, online, individual, and collective?

5. Do features such as age, gender, and previous language teaching experience (PLTE) appear to influence how receptive individual teacher learners are to the four types of reflection outlined above?

\section{Rationale for pursuing Thesis:}

In the past 10 years, several scholars have noted the absence of research and literature in the area of TESOL teacher education and the learning processes that pre-service teachers go through while completing their teaching practicum placements (Beaumont, 2004; Crookes, 2003; Freeman \& Johnson 1998). In light of the fact that the practicum has become an established and integral part of many language teacher education (LTE) programs for two decades now (Stoynoff, 1999), the absence of research in this particular area of ELT is surprising. Indeed, it would seem that, as Beaumont (2004, p.10) suggests, "TESOL teacher education has taken a backseat to other aspects of English language teaching and research" and that, as language teachers, learners, and researchers, we need to encourage more "discussion of what constitutes teacher education". as well as "the processes that teachers go through when learning to teach". Further, Crookes (2003) indicates that "how S/FL teachers develop is still a topic little understood, and the practicum remains an under-theorized and under-researched area" (p.2). 
While much has been written on the importance of reflective language teaching in the past 25 years (Cruickshank \& Applegate 1981; Farrell 2007; Richards 1990; Richards \& Ho 1998; Richards \& Lockhart, 1994,) documented and descriptive feedback from student teachers with regard to the impact and relevance of reflection and the learning processes that they go through during their practicum placements has been marginal at best. Currently, the most descriptive and extensive body of literature on the topic of teacher learners' practicum experiences relates to short-term, intensive, one-month training programs such as the Certificate in English Language Teaching to Adults (CELTA) - the principal teacher training certificate course accredited by Cambridge University in the U.K. - which are typically only one month long (Brant, 2006; Ferguson \& Donno, 2003; Senior, 2006). However, even those writing on the topic of intensive one-month certification courses such as the CELTA have lamented the "dearth of published research" into "the phenomenon" of pre-service teacher learners' experiences (Ferguson \& Donno, 2003, p.26).

Despite the value of research on short-term TESOL programs that gives voice to preservice teachers' learning experiences, it is imperative to recognize that, due to the time constraints of a 4-week training program and the standardized model of learning that takes place, actual program encouragement of individual and collective reflection remains largely a novelty. Parker (1991) questions how "four week courses, given their brevity" can possibly be associated with a process-driven model of LTE that values critical reflection (p.151, italics added). He suggests that one-month long courses, because of their brevity, inevitably favour a productdriven approach.

Similarly, Brandt (2006) and Ferguson and Donno (2003) assert that, by receiving explicit or implicit pressure to emulate their trainers and learn to teach "the CELTA way", trainees are not engaged in an exploratory model of learning that places value on inquiry or 
collaborative reflection. By following a standardized, transfer model of learning where experimentation is described by one candid trainer as "dangerous", Brandt (2006) argues that trainers are encouraging "a mechanistic, compliant response that limits opportunities for insight and stifles initiative" (p.362, italics added). Furthermore, Ferguson and Donno (2003) suggest that one-month TESOL certification courses are geared more toward individuals interested in teaching EFL for only a few years, rather than those teaching ESL or EFL as a career, because "a considerable number. . leave TEFL teaching within a few years, having used the certificate for purposes of foreign travel" (p.30).

When we stop to consider that one-month teacher training courses do not make up a large "proportion of the total number of English language teachers trained annually" (Ferguson and Donno, 2003, p.26), the even greater dearth of published research on the phenomena of learning to teach by those engaged in longer LTE programs is clearly problematic. What then, of the teacher learner who is interested in teaching ESL (or EFL) for more than a few years and has chosen to commit to 8 months or a full year of LTE? Although modest in volume, research has begun to emerge that gives voice to these pre-service teachers and the learning processes they go through during their practicum (Johnson, 1992 and 1996; Crookes, 2003; Carter 2008). Following suit, I hope to add, on a small scale, to this developing area of study.

\section{Theoretical Framework:}

The proposed thesis is situated in the following two theoretical bases: 1) progress from a narrow definition of individual, solitary reflection in the 1980 s to a contemporary, broader understanding of reflective teaching that has a clearly defined social component; and 2) concepts of an exploratory, constructivist model of learning that has been applied to language teacher education programs as a means of encouraging long-term professional development in pre- 
service teachers. In the following chapter, I demonstrate how these two educational movements have significantly shaped LTE programs in recent years.

\section{Personal Connection: Situating My Role as Researcher}

Farrell (2007) has noted that all of his research on reflective language teaching draws on qualitative techniques, and, as such, he cannot separate himself from his research but inevitably is "part of the process." Providing the reader with an overview of how he came to be interested in reflective practice, Farrell includes a "tree of life" visual that details his formal and informal learning experiences that span over 50 years. It is in this tradition that I provide a brief sketch, below, that outlines my personal connection to the TESOL practicum research area.

I have been teaching ESL and EFL collectively for 10 years. In my final year of undergraduate studies in 1999, I began tutoring ESL students on campus and volunteered alongside a LINC instructor for several months, providing assistance in class as needed. At that point, I had no formal teacher training and no theoretical knowledge of SLA. After graduating in 2000, I went to South Korea for six months to teach EFL. I had the best intentions and took my work seriously, but had no sense of how my teaching practice was effective or could be improved. When I returned to Ontario, I immediately found work teaching ESL, despite the fact that I was not TESL certified. After almost two years of teaching ESL, I realized I needed some type of language teacher training and so decided to obtain a CELTA in Toronto. Soon after, I went to Japan and taught EFL for a year. I returned to Ontario and then, after three years of teaching ESL, realized that something was still missing. Wanting to develop further as a TESOL professional, I applied to an Ontario M.A. program in Linguistics and Language Studies and was accepted. I began my M.A. in September 2007 and it was at this time that I decided to complete courses to qualify for TESL Ontario certification. 
My understanding of the CTESL program featured in this study is situated and stems from my own experience of going through two very different practicum programs. More specifically, it is situated in the sense that I have been able to compare my 8-month-long CTESL course and practicum experiences in the 2007 to 2008 academic year with the much briefer but more intensive 4-week CELTA program experience in 2002. To illustrate how my understanding of the CTESL program is situated, and for theoretical purposes only, I have completed the questionnaire administered in Stage 2 of this study (see Appendix B).

\section{Organization of Thesis}

The remainder of this thesis is organized in the following way:

\begin{tabular}{|c|c|}
\hline Chapter 2 & $\begin{array}{l}\text { Consists of a literature review on reflective teaching, models of teacher } \\
\text { learning and language teacher education (LTE) programs, as well as } \\
\text { professional teacher development }\end{array}$ \\
\hline Chapter 3 & $\begin{array}{l}\text { Describes the research methodology used in this study, steps taken to gain } \\
\text { access to research participants, and research instruments used in all four } \\
\text { stages of data collection. }\end{array}$ \\
\hline chaptert & $\begin{array}{l}\text { Describes the analytical tools used and steps taken to analyze data from all } \\
\text { four stages. }\end{array}$ \\
\hline $\mathrm{Ch}$ & $\begin{array}{l}\text { Presents results from Stage 1, involving a practicum course outline } \\
\text { document analysis and interview with the practicum course instructor }\end{array}$ \\
\hline $\mathrm{Ch}$ & $\begin{array}{l}\text { Presents results from Stage } 2 \text {, involving responses to both closed and open- } \\
\text { ended questions on the questionnaire completed by } 14 \text { CTESL students. }\end{array}$ \\
\hline 策 & $\begin{array}{l}\text { Presents results from Stage } 3 \text { and } 4 \text {, involving one-on-one interviews with } 4 \\
\text { CTESL students and a group interview with the same } 4 \text { participants }\end{array}$ \\
\hline Chapt & $\begin{array}{l}\text { Presents triangulation of data sets and a discussion of findings from the } \\
\text { four stages of data collection }\end{array}$ \\
\hline Ghapter 9 & $\begin{array}{l}\text { Summarizes key issues, identifies limitations to the study and presents } \\
\text { implications for future research }\end{array}$ \\
\hline
\end{tabular}




\section{Chapter 2: Literature Review}

In this chapter I provide a review of literature on the topic of reflective teaching, models of teacher learning and language teacher education (LTE) programs, as well as professional teacher development. More precisely, this chapter is divided into the following six sections: 1) The evolution of reflective practice; 2) Definitions of reflective teaching; 3) Rationale for reflective teaching; 4) Models of teacher learning; 5) Constructivist learning, reflective practice, and LTE: what does it look like in practice?; and 6) Teacher development for novice and experienced teachers. The purpose of this literature review is to provide the reader with sufficient background information on the above-mentioned topics in order to better situate the case study discussed in the remainder of this thesis.

\section{1) The Evolution of Reflective Practice}

For more than two decades now, reflective teaching has been recognized as forming - or needing to form - a fundamental part of teacher education programs, including LTE programs (Richards \& Ho, 1998). But the concept of reflective teaching has been around for much longer than a decade. It can be traced back to over 70 years ago, when educator John Dewey first encouraged reflective teaching alongside principles of "open-mindedness, responsibility and wholeheartedness" (Farrell, 2007). Moving forward 50 years, and a renewed interest in reflective practice was sparked by Donald Schon in the 1980s with The Reflective Practitioner (1983) as well as Educating the Reflective Practitioner (1987). Schon asserted that individual reflection needed to form a central part of professional practice. While his contribution to spurring discussion and research on the topic of reflective practice cannot be overlooked, it is equally important to recognise that Schon's concept of reflection is nevertheless limited in its description 
of a solitary, introspective act, one that does not involve a community of other, similarly reflective practitioners.

Extending Schon's call for reflective practice further, Bartlett (1990) and Ur (1996) maintain that a combination of both individual and collective form of reflection is needed if teacher learners are to commit to long-term professional development. As Ur (1996) states, while individual reflection is useful, "it enables you to draw on your own experience only" and while it is "indeed the basic and primary source of professional learning ... there comes a point when it is not enough" (p.321). Bartlett expresses a similar viewpoint by reminding us that classroom teaching, as a very social, interactive process, is naturally suited to collegial reflection. Locating teaching in a broader socio-cultural context, Bartlett (1990) calls for teachers to reflect critically both individually and collectively in order to extend "one's insights about oneself as teacher to oneself as an individual member of a larger community" (p.210). Note how Bartlett states that an individual teacher committed to professional development can be seen as a member of a larger community of practitioners.

More recent extensions on the model of reflective teaching continue to point to advantages of collegial reflection. Crookes (2003), Farrell (2007), and Richards \& Farrell (2005) all describe benefits to forming what they call teacher development groups (TDGs) and teacher support groups (TSGs). Farrell (2007) notes that language teachers belonging to a TDG often experience increased confidence in their overall teaching abilities. By providing members with a "non-threatening environment" in which teachers can "develop new knowledge and skills and gain supportive feedback from peers", TDGs are seen as a valuable source as they enable members to "generate more ideas about classroom issues than can one individual" working on his/her own (Farrell, 2007, p.121). In other words, TDGs allow groups of teachers to come 
together and "begin to function as a community of professionals rather than individuals working in isolation" (Richards \& Farrell, 2005, p.51, italics added).

Table 2.1: Evolution of Reflective Practice: From Individual to Collaborative

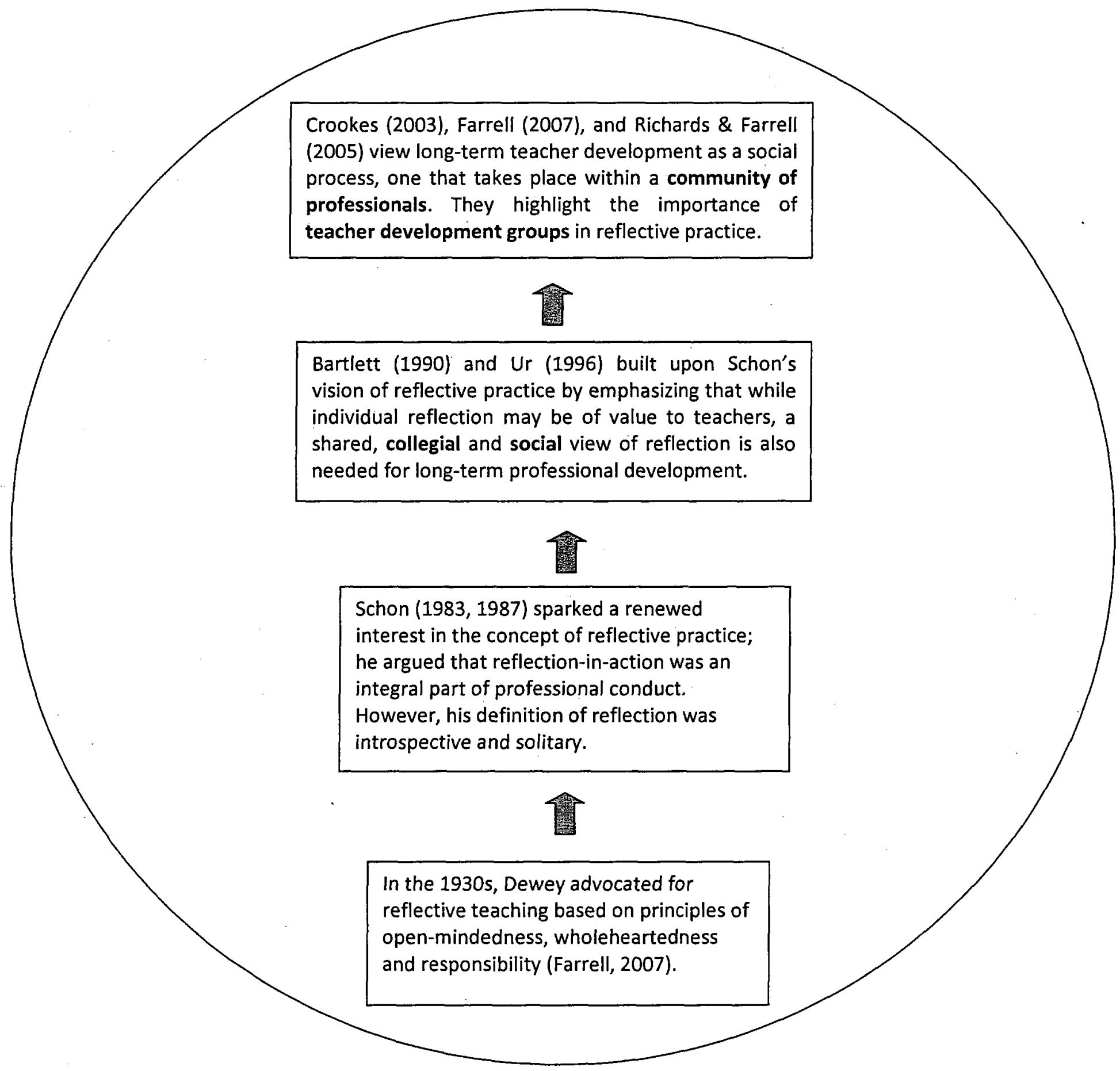




\section{2) Definitions of Reflective Teaching}

It is fitting to now look at what exactly is meant by the term reflective teaching. As Tabachnick and Zeichner (1991) noted almost 20 years ago, the notion that teacher educators ought to encourage their students to become reflective practitioners "has emerged as the new zeitgeist in North American teacher education" and yet "the criteria that have become attached to reflective practice are diverse" (p.1, italics added). This, they maintain, has meant that "important differences between specific practices are masked by the use of the common rhetoric" (p.1, italics added). Even more significantly, the above authors assert that this very "generic" concept of reflective teaching has been "employed by teacher educators of every ideological persuasion" and tends to "offend no-one" (p.2). Problematic is the fact that questions about "what it is that teachers should be reflecting about" remain "unanswered" and thus, "in some extreme cases, the impression is given that as long as teachers reflect about something", the main goal of encouraging reflective practice has been met (p.2, italics added).

To understand how generically the term reflective practice has been employed in the past and how, in recent years, the term has been described in increasingly detailed ways specific to the teaching profession, let us begin by looking at the highly influential work of Donald Schon. The Reflective Practitioner (1983) is so frequently cited that it is almost impossible to read a scholarly article, essay or book on the topic of reflective teaching without seeing multiple references to Schon. While scholars such as Bartlett (1990) have noted the limitations of Schon's work - namely that his description of reflective practice fails to take into account the social aspects of reflection - there are other limitations that need to be addressed, specifically within the context of pre-service teacher education and professional teacher development. 


\section{Schon's Influence on Reflective Teaching: Limitations need to be addressed}

Before addressing some of the limitations of Schon's view of reflective practice, I would like to emphasize that his work is relevant to my thesis simply because it provides a starting point reference for reflective practice in the early 1980s. In other words, his work functions as a base-line of sorts that provides insight into how reflective practice may have been viewed 30 years ago compared to how it is viewed today by many teacher educators.

Schon asserted that up until the early 1980s (the point at which he wrote The Reflective Practitioner), the dominant, most influential model of professionalism was that of technical rationality. Schon (1983) employed this term to mean that "professional activity is based on scientific theory and technique" (p.21). He indicated that in the early 1980s professionalism was "still mainly identified with technical expertise" (p.69). Schon described "major professions" (such as engineering) that are more likely to fit within the standard model of technical rationality; they are often considered unambiguous and operate within "stable institutional contexts" (p.23). Each major profession is likely to have a systematic knowledge base that is "specialized, firmly bounded, scientific, and standardized" (p.23). Conversely, minor professions (such as teaching) are more likely to encourage a type of "professional pluralism" that allows room for "uncertainty, complexity, [and] instability" (p.21) where each practitioner's perspective on work-related experiences is often unique.

In other words, professional pluralism is at odds with the model of technical rationality because there are no one- size-fits-all technical solutions to problems; instead, the professional course of action will vary from practitioner to practitioner. It is interesting to note a link between a previously methods dominated approach to language teacher education (the Audio-Lingual Method, The Silent Way, etc.) before the 1980s and the gradual shift towards a 'post-methods' era of teacher education since that time (Richards, 1998). In the 1980s, Schon was pushing for 
professional pluralism at the same time that educators were advocating for a more context-based approach to language teacher education. Noteworthy is the fact that in 1983 , at the time of writing, Schon stated that "reflection-in-action is not generally accepted - even by those who do it - as a legitimate form of professional knowing" (1983, p.69).

Schon argued that reflection-in-action, the ability to reflect in the moment of professional action, is a fundamental part of professional pluralism. He suggested that reflection-in-action is necessary in order to deal with instances where things don't go according to plan, when our actions lead to "surprises, pleasing and promising or unwanted" (p.61-62, italics added). Hence both positive and negative moments are grounds for reflection-in-action but the common denominator is the element of surprise. Whereas the model of technical rationality sees uncertainty as a threat to professional practice, for the reflective practitioner, uncertainty offers an opportunity to stop (in the moment) and reframe the experience. In Schon's words, "the practitioner allows himself to experience surprise, puzzlement, or confusion in a situation which he finds uncertain or unique" (p.68). Notice the use of the verb allows, which points to the element of choice in reflection-in-action. Note also the solitary aspect of this process and the absence of sharing reflections on practice with colleagues.

It is important to realize that the type of reflection that Schon described is in-the-moment reflection, distinct from reflecting for practice before one is engaged in teaching or reflecting on practice after one has finished teaching. This is true for all references to reflection that Schon makes in his 1983 book. The only exception to this is his acknowledgement that practitioners need to be able to reflect on their reflection-in-action after the fact in order to be able to communicate this process to others in attempts to make their tacit, intuitive, and "on-the-spot" knowledge explicit. Schon suggests that if the practitioner "cannot describe his reflection-inaction, he cannot teach others to do it" (p.243, italics added). But Schon does not explore this 
issue further. There is no discussion of the doubtful ability to "transfer" or "teach" others how to reflect. However, in his subsequent book, Educating the Reflective Practitioner (1987), Schon does suggest that experienced practitioners model their "knowing-in-action" to students by voicing these reflections, as they occur in the moment of practice, out loud.

As Bartlett (1990) points out, a key limitation of Schon's 1983 book is that the reflective conversation, advocated throughout the book, takes the form of inner dialogue and does not require the input of other practitioners. Thus when Schon (1983) describes a reflective practitioner engaged in a reflective conversation, this conversation does not take place with peers but rather "with a situation that he treats as unique and uncertain" (p.163, italics added).

\section{More Limitations that Need to be Addressed}

There are still other limitations of The Reflective Practitioner (1983) that have yet to be addressed but certainly need to be within the context of pre-service teacher education. First, Schon's 1983 book is written to persuade those already established in their careers to become reflective practitioners and does not relate to the emerging professional's need to develop a reflective practice. Secondly, The Reflective Practitioner does not address specific issues related to teaching but rather engages in a kind of philosophical discussion about the prevailing influence of technical rationality with regard to the way practitioners from the fields of architecture, psychoanalysis and city planning view their profession. It is not until the last 30 pages that Schon, very briefly, discusses reflective teaching.

Schon's subsequent book, Educating the Reflective Practitioner, while containing much of the same content as The Reflective Practitioner, does address the issue of a reflective practicum in the final chapters. However, while the discussion of a reflective practicum would suggest greater links to the field of teacher education, it is in this second book that we begin to 
see further limitations of Schon's conceptualization of reflective practice as it pertains to prospective teachers.

Referencing the often tacit knowledge of experienced professionals adept at reflecting-inaction, Schon asserted that this knowledge needs to be made explicit if students are to benefit from the practitioner's many years of expertise. Using an architectural design program as the "prototype" for a reflective practicum, Schon (1987) suggested that practicum students need to learn from their "studio master's demonstration[s]" (p.120, italics added). Problematic is the fact that while advocating the importance of a constructivist view of professional practice for experienced professionals where "perceptions, appreciations, and beliefs are rooted in worlds of our making", Schon failed to extend this constructivist view to student learning (p.36).

Rather than adopting a constructivist view of learning for the practicum student, Schon advocates what he terms reflective imitation, a process whereby the student is expected to learn from imitating the studio master. In his words:

Once she [the practicum student] has entered into an initial contract with the studio master . . . she must be willing to try out his approach to designing . . . [and] when it comes to the studio master's demonstrations, she is asked to take up a stance of reflective imitation - even though she is very likely to feel an abhorrence of imitation (Schon, 1987, p.120, italics added).

To lend support to his proposed reflective imitation process, Schon makes the following point: "in the United States, an apprentice machinist usually learns his trade by imitating just what he sees the master machinist do" (p.121). Yet Schon fails to acknowledge that studying to be a machinist entails a set of pre-determined, specifically technical skills; and that this process is noticeably different from other lines of work, such as counselling or teaching. His idea of reflective imitation is, without doubt (as will be demonstrated later in this chapter), indicative of a transmission model of learning. Schon asserts that his proposed model of reflective imitation depends on "a willingness to do as the studio master is doing and, at the same time, reflect on 
what one does" (p.121, italics added). Interestingly, Schon does not raise the question of how the program-directed (rather than student-directed) need to imitate a master teacher may limit the practicum student's ability to think, and therefore reflect, for and by him or herself.

\section{Reflective Teaching Practice: Four Profession-Specific Definitions}

The previous section provided an overview of Schon's frequently cited work while drawing attention to the limitations of that work within the context of a constructivist model of teacher education. The following section provides four definitions of reflective practice that all relate to teacher education. I begin with two fairly generic descriptions of critical reflection and then proceed to provide two increasingly detailed definitions.

Here is one of the earliest definitions of critical reflection that is associated with a constructivist model of language teacher education:

Critical reflection encompasses the ability to make informed comparisons between the ideal demonstration of methods, techniques, and strategies as presented in the pre-service methods course, and how those same instructional procedures may be adapted in an authentic classroom situation. Students need to develop the ability to systematically analyze situations, instructional actions and learners' reaction to gauge effectiveness of practice being implemented ... Critical reflection arises out of sound theoretical and pedagogical base; being able to perceive (anticipate) the variables in the teaching and learning context from a multi-dimensional perspective (Whitson \& Bodycott, 1991, p.129-130).

Notice how the above definition of critical reflection, written almost 20 years ago, focuses largely on the difference between theoretical knowledge as it is presented in the "pre-service methods course" and the degree to which this knowledge can be applied in the practical "authentic classroom situation". Note also how that the above definition is fairly general. It does not provide insight into what aspects of instructional actions student teachers might benefit from reflecting on, but rather limits the foci of reflection to the effectiveness of the teaching practice and the ability to be forward-thinking about one's practice. 
Moving forward three years, and Richards and Lockhart (1994) offer the following:

Critical reflection involves examining teaching experiences as a basis for evaluation and decision-making and as a source for change. It involves posing questions about how and why things are the way they are, what value systems they represent, what alternatives might be available, and what the limitations are of doing things one way as opposed to another (p.4).

Here we are provided with some insight into the broader implications of teaching, namely that it can be viewed as value-laden. The importance of being inquisitive about one's practice, of posing questions, is also addressed. However the above definition is still quite general and leaves many questions unanswered about what reflective teaching might actually look like in practice.

Farrell (2007) succeeds in providing a more detailed portrait of what reflective teaching may look like in practice. He provides an overview of the differences between reflection-inaction, reflection-on-action, and reflection-for-action. In his words:

There are said to be three major types, or moments, of reflective practice where teachers can undertake reflection. The first moment happens during the event, such as classroom teaching and in called reflection-in-action. The second moment is thinking about the event after is has happened and this is called reflection-on-action. While the third moment is where teachers think about future actions and this is called reflection-for-action ... [it] is different from the previous types of reflection in that it is proactive in nature" (p. 5-6, italics added).

Farrell (2007) adds that critical reflection is different to a simple after-class musing such as 'wow, that activity went really well. I'll have to try that again' because teachers 'need to know why a class was responsive or not responsive" (p.7). Similarly, Farrell indicates that language teachers need "to reflect on their actual classroom practices to see if there is an alignment between their stated beliefs and their classroom practices" (p.35).

Larrivee (2008) provides additional insight into what reflective teaching might look like in practice. Similar to Farrell (2007), she outlines three different types of reflective moments: reflection in-, on-, and for-action. And, like Farrell (2007), she references the enduring nature of 
John Dewey's work on reflective practice in the 1930s. Specifically, Larrivee notes that the three essential characteristics of 1) open-mindedness; 2) taking responsibility; and 3) wholeheartedness that Dewey advocated over 70 years ago "are still considered the foundation of reflective practice" today (p.91). Larrivee (2008) describes open-mindedness as "being open to other points of view, appreciating that there are many ways to view a particular situation or event" (p.91). Responsibility is about "taking ownership for the consequences of one's actions ... owning the many positive and negative ways our actions might influence others" (p.91). And, finally, wholeheartedness means "thoroughly committing oneself to seeking better solutions to perplexing concerns"' (p.91).

However, Larrivee (2008) goes further than Farrell (2007) and previous scholars in that she suggests that teacher reflection can be understood to occur across a continuum. After reviewing existing literature on reflective practice, Larrivee (2008) noted that the term reflection is often used "to describe a vast array of practices, ranging from mere thinking about a single aspect of a lesson to considering the ethical, social, and political implications of teaching practice" (p.89). She concluded that three levels of reflection seemed to be consistently at play. The three levels of reflection are as follows:

1. Surface reflection

2. Pedagogical reflection

3. Critical reflection

$\overrightarrow{\text { surface pedagogical critical }}$

Larrivee (2008) asserts that the term reflective practice "incorporates all of these levels" outlined above (p.90). However she also indicates that "there is an implicit distinction in quality of reflection" between more "trivial" forms of reflection at the surface level and more profound, in-depth reflection at the critical level (p.90, italics added). She maintains that, for many 
educators, "critical reflection represents the zenith or ultimate aim" (p.89). Notice how, in the following excerpt, Larrivee very precisely defines these three levels of reflection:

At the surface level of reflection, teachers' reflection focus on strategies and methods used to reach pre-determined goals. Teachers are concerned with what works in the classroom rather than with any consideration of the value of such goals as ends in themselves. At the level of pedagogical reflection, teachers reflect on educational goals, the theories underlying approaches, and the connections between theoretical principles and practice. Teachers engaged in pedagogical reflection strive to ... foster consistency between espoused theory (what they say they do and believe) and theory-in-use (what they actually do in the classroom). At the critical level of reflection, teachers reflect on the moral and ethical implications and consequences of their classroom practices on students. Critical reflection involves examination of both personal and professional belief systems. Hence, self-reflection is an embedded dimension of critical reflection ... self-reflection entails deep examination of values and beliefs, embodied in the assumptions that teachers make and the expectations they have for students. Teachers who are critically reflective focus their attention both inwardly, at their own practice, and outwardly, at the social conditions in which these practices are situated (p.90).

Larrivee (2008) emphasizes that teachers need to consciously work toward this final stage of reflective practice, that of critical reflection. She provides the following example of the limitations associated with teachers who are only engaged in surface-level reflection:

For example, teachers engaging in surface reflection may question how to limit the transition time between reading groups but may never question the larger issue of whether reading groups should exist (pedagogical reflection) or even if that structure limits the potential for some students with different cultural backgrounds (critical reflection) (p.91, italics added).

Due to the amount of detail that Larrivee provides in her description of reflective practice (which encompasses all three levels of reflection), I believe her definition is the most helpful and provides the greatest amount of insight about what reflective teaching might look like in practice.

To further contextualize Larrivee's three levels of reflective practice, I have compiled a series of reflective questions from four scholars (Bartlett, 1990; Richards \& Lockhart, 1994; and Farrell, 2007) writing on the topic of reflective teaching and have created Table 2.2, which 
categorizes each question according to Larrivee's (2008) definition for both pedagogical and critical reflection. Table 2.2 clearly demonstrates that some reflective questions are limited to pedagogical level reflection whereas others are noticeably more critical.

Table 2.2: Reflective teaching questions: Pedagogical and Critical Pedagogically reflective questions 14 Critically reflective questions:

1. How might I teach differently?

2. What criteria do I use to evaluate my teaching?

3. What kind of learning activities do I employ?

4. What kinds of interaction occur in my classroom?

5. What kind of grouping arrangements do I use and how effective are they?
1. What is my role as a teacher?

2. Is the teacher I am the person I am?

3. Where did the ideas I embody in second language teaching come from historically?

4. Whose interests do these ideas serve?

5. Do I wish to uncover the 'hidden curriculum' - the inconsistencies - in my teaching?

Note that the two levels of reflection are at times inter-connected. For example, the first pedagogically reflective question - how might I teach differently - might be posed after a teacher realizes that his/her classroom practices do not reflect the learning needs of his/her learners because they are not culturally appropriate. As such, the question would become critically reflective. Consider the following example: an ESL teacher, accustomed to using a communicative language teaching (CLT) approach in Canada, decides to teach EFL in China to students exposed to a remarkably different culture of learning, and then decides to continue to use the CLT approach despite evidence from learners that this is not how they want to learn. Later on, the teacher revisits this decision. Hence the question of how might I teach differently might appear to be pedagogically reflective but could certainly have critically reflective roots. 


\section{3) Rationale for Reflective Teaching: Why is it needed?}

Why is reflection considered to be so important for pre-service and practicing teachers?

In this section I share answers that four scholars have given in response to this question. I begin with the simplest rationale and then proceed with increasingly detailed reasoning.

Ghaye and Ghaye (1998) maintain that being a reflective teacher "is about admitting that practice can always be improved in some way" and that reflection-on-action enables teachers to take moments of their teaching experience and re-frame "the problematic aspects of it so that it becomes workable" (p.3). The rationale for reflective teaching is therefore quite simple: "it can provide teachers with the courage and intellectual capacity to turn insight into improved action" (p.3, italics added). Thus reflection-on-action is connected to reflection-for-action and is understood to be both necessary and of value because it results in improved teaching practice. In other words, deliberate reflection-on-action leads to a more effective teaching practice.

Larrivee (2008) provides a more in-depth rationale. She identifies two central reasons for why reflective practice is needed:

Perhaps the most important reason for teachers to develop as reflective practitioners is to deal more consciously with the inevitable dilemmas and tradeoffs involved in everyday decisions that affect the lives of students ... An equally compelling reason for advocating that teachers be reflective practitioners is that it frees them from routine and impulsive acts, enabling them to act in a more deliberate and intentional manner ... when teaching becomes so habitual that it is tantamount to a mechanical act it can be the path to teacher burnout" (p.88, italics added).

Notice how the first reason is associated with teacher accountability - that teachers need to reflect on their practice in order to become aware of how their everyday decisions affect the lives of their students. Conversely, the second reason is associated with teacher resiliency - teachers need to be able to step back and reflect on the big picture aspects of their practice in order to gain perspective and avoid teacher burnout. 
Interestingly, Farrell (2007) also refers to the idea of teacher burnout and the preventative role that reflective practice can play. In his words:

... experience is not enough for effective teaching, for we do not learn as much from experience alone as we learn from reflecting on that experience ... teachers who do not bother to reflect on their work become slaves to routine and their actions are guided mostly by impulse, tradition and/or authority rather than informed decision making ... such continuous repetitive actions can also lead to burnout (p.2).

Note that both Farrell (2007) and Larrivee (2008) have both drawn from the work of John Dewey when referencing the concept of unreflective teachers being slaves to routine and impulsive acts. Note also that both scholars emphasize the need for teachers to consciously reflect on their teaching experiences in order to make informed decisions about their future practice, thereby teaching in a more grounded, accountable, and intentional way.

Farrell (2007) further maintains that for those teachers who are willing to engage in "systematic reflection of their own teaching beliefs and practices" (p.55), they are likely to experience the following benefits:

- Deeper insights and knowledge about teaching which can, in turn, increase the effectiveness of one's practice

- Increased confidence in teaching-related actions and decisions

- Increased ability to develop strategies for intervention and change

- A cathartic experience for both practicing and novice teachers

(Farrell, 2007, p.7)

\section{4) Models of Adult Learning and Teacher Education}

In the past 30 years, much has been written on the topic of adult learning and teacher education. Numerous scholars have noted that, beginning in the mid-1970s and extending to today, a shift in pedagogical perspectives has taken place where educators have moved from a behaviourist, transmission model of adult learning and teacher education to a constructivist, 
exploratory model of learning (Beaumont, 2004; Crandall, 2000; Farrell, 2007; Freeman \& Cornwell, 1993; Freeman \& Johnson, 1998; Richards, 1998; Lee, 2004; Sarasin 1998; Woodward, 1991). In other words, we have moved away from a passive model of learning where student teachers receive knowledge transmitted to them by an expert espousing concepts of best practices. We have moved toward an active, engaged model of learning where students are increasingly held responsible for their own learning through reflection and inquiry and, throughout this process, are required to make connections to their everyday life.

Whereas with the transmission model of learning, an instructor lecturing would typically form the knowledge-base of what was "transmitted" to students, with the constructivist model, the knowledge-base may be "constructed" from any number of sources, such as from other students, the student him or herself, as well as from the instructor. As Scrivener (1994, p.4, italics added) notes, teacher learners and language learners alike will invariably "make use of whatever knowledge and experience" they already have accumulated before they enter a new classroom as any "new learning is constructed over the foundation of our own earlier learning." Hence each student teacher brings a wealth of previous life, work, and educational experiences into LTE and GTE programs that he/she can then draw upon and share with his/her peers in the pooling of collective knowledge.

Learning to teach thus becomes a social act that mirrors the multi-dimensional, constantly evolving nature of the ES/FL classroom itself. In this way, an argument can be made that a constructivist model of learning better prepares teachers for the 'real world' - one that is largely unpredictable - by encouraging students to be inquisitive, reflect critically on their practice individually and with peers, hone communication skills, and develop problem-solving skills.

Other scholars, commenting on this pedagogical shift, have described this movement as a shift from a product-based model of teacher learning to a process-driven model (Parker, 1991; 
Richards, 1990; Woodward, 1991). Almost twenty years ago, Richards (1990) noted that a product or methods-based approach to LTE involves a "predetermined, packaged deal" for student teachers, one that "incorporates a static view of teaching" and, as such, is not able to prepare teachers for "the real world" of teaching, one that is complex and ever-changing (p.35, italics added). Richards further asserted that a product-approach to LTE is based on the assumption that student teachers "cannot be trusted to teach well" and that, "left to their own devices" they will "invariably make a mess of things" (p.35). He also emphasized that this prescriptive, methods-driven approach is associated with a "top-down" model of LTE, whereas an exploratory, constructivist model of teacher learning is decidedly "bottom-up". Richards (1990) also underlines the importance of learning to teach as a life-long endeavour.

Writing on the topic of how LTE programs were once delivered under the product-or best methods approach to teaching, Freeman (in Richards, 1998: viii, italics added) writes:

Until the second half of the 1980 s, education was essentially defined as training or whatever we knew or thought was important about teaching second languages. The complexities of how that knowledge of teaching might be learned or taught were not a central question.

Freeman also noted that even in the early 1990 s, when scholars had begun to examine "teacher education in its own right", the idea that "learning to teach might itself be a process worth examining and theorizing about had not yet fully taken hold" (in Richards, 1998: viii).

It is worth mentioning that scholars writing on constructivist and process-driven models of learning are essentially describing the same trend towards a more student-centered, exploratory concept of learning. We can also conceptualize this movement as a shift from teacher training to teacher education where training is seen as product-driven and teacher education views teacher learning as a "long-term, complex, developmental process" (Freeman \& Johnson, 1998, p.402, italics added). Drawing on the work of numerous scholars (Beaumont, 
2004; Crandall, 2000; Farrell, 2007; Freeman \& Johnson, 1998; Richards, 1998; Lee, 2004;

Sarasin 1998; Woodward, 1991), I have created Tables 2.3 and 2.4 that combine numerous aspects of this shift regarding the role of the instructor and that of the student teacher:

Table 2.3: Shift from Behaviourist to Constructivist Model of Learning

\begin{tabular}{|ll|}
\hline Behaviourist Model & Constructivist Model \\
\hline Training & $\begin{array}{l}\text { Education } \\
\text { Product }\end{array}$ \\
Short-term goals & Pong-term development \\
Instructor as 'expert' or 'master teacher' & Instructor as facilitator \\
Passive student learning & Active student learning \\
Knowledge is predetermined \& & Knowledge is situated \& mutually \\
decontextualized & constructed \\
Best practices defined & Post-method, critical stance, teacher \\
\& to be imitated & chooses approaches appropriate to context \\
Dependence on instructor & Range of input: lecture, group discussions, \\
lecturing for input & critical reflection via journals, portfolio, etc. \\
\hline
\end{tabular}

Table 2:4: Top-down versus Exploratory model of Teacher Learning (in Theory)

$$
\bigcirc=\text { Teacher Learner }
$$

TPS = Teaching practicum site

\section{TOP-DOWN, TRANSMISSION MODEL}



EXPLORATORY, INQUIRY-BASED MODEL

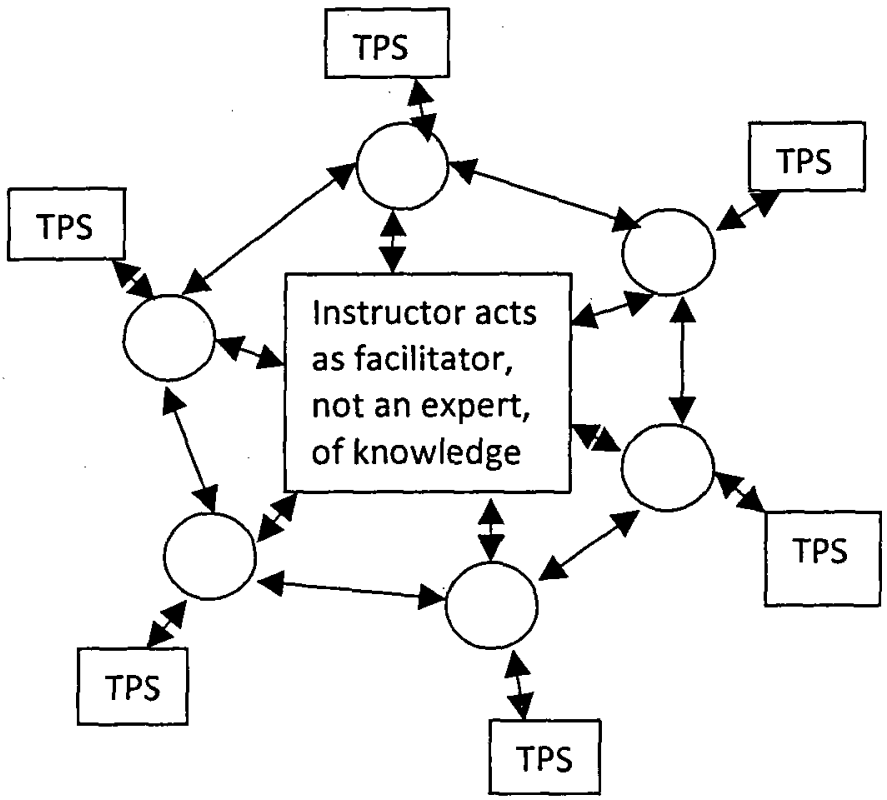


While it is heartening to read about models of teacher learning that mirror the dynamic, socio-cultural reality of ES/FL classrooms, we would be wise to step back and ask: to what degree is this model possible, not in theory, but in practice? What factors, if any, work against the actualization of this model? I have identified two potential answers to the above questions. First, there are underlying issues related the teacher educator him or herself; secondly, there are issues related to the demographic profile of student teachers participating in any LTE program.

First, beginning with the teacher educator: while an instructor may support the notion of a constructivist model of LTE in theory, how they actually teach in practice may be markedly different. In support of this idea, I present the persistent use of the term master teacher in both past and recent LTE-related literature. The term master teacher has been employed by the same teacher educators who purportedly support a bottom-up model of LTE and practice reflective teaching. In the following section I will identify why such terminology is problematic within the context of a constructivist, exploratory model of adult learning.

\section{Master Teacher: No Place in a Bottom-Up Model of LTE}

Beginning with scholars writing in the late 1980s and moving to scholars writing into the $21^{\text {st }}$ century, I will illustrate how the term master teacher has been consistently employed by the very same teacher educators who purportedly support a constructivist model of LTE programs and practices. I will indicate why the use of this term is problematic. Also, I will provide examples of how this terminology has been employed by teacher educators who fail to directly quote their student teachers in their descriptions of the learning-to-teach process and who instead rely on extensive paraphrasing. Of greater concern is the occurrence of pedagogical appropriation by teacher educators regarding what student teachers were recorded as having said. 
As indicated earlier in this chapter, the movement from a transmission to a constructivist model of language teacher education has been well-documented. What has yet to be documented, however, is the persistent use of the term master teacher to describe the role of any teacher with more previous language teaching experience than that of a novice teacher. The term master teacher has been employed to describe the role of the collaborating/host teacher at the practicum placement site as well as the role of the practicum supervisor.

Twenty years ago, Brinton and Holten (1989) presented a number of recurring themes gleaned from 20 MA student teachers' weekly journal entries completed during a 10 week TESL practicum at UCLA. However, while the researchers looked at over 150 journal entries by 20 teacher learners (TLs) in the process of coding and analyzing their data, they only quoted 3 student teachers directly and briefly in their article. Their goal of analyzing the entries of the 20 MA student teachers was to gain insight into the student teachers' "evolving perceptions of themselves as teachers" by "categorizing and quantifying" (p.344) their perceptions and by documenting how these perceptions changed over the 10 week period. However, the TLs were never directly surveyed on this particular subject. Given that only three of the $20 \mathrm{MA}$ student teachers are quoted in the 1989 article, it is not too great a stretch to assert that the student teachers' voices go largely unheard. Equally interesting about this article, and perhaps not coincidently, is the fact that the authors employ the term master teacher to describe the role of the host or cooperating teacher.

In their concluding remarks, Brinton and Holten (1989) mention that their student teachers appear interested in "mastering the art of language teaching" (p. 350, italics added). This statement presumes that the reader shares the authors' view that the "art of teaching" is something that can be clearly defined, observed, learned, and subsequently mastered. There is no reference to the concept of becoming a critical reflective practitioner or links to future 
professional development. The dialogue journals take place between the student learner and supervisor only and there is no report of discussions involving other student teachers. Based on the descriptions provided in the article, there appears to have been no attempt to set up collaborative learning between TLs. As such, it can be argued that this article is located more toward the transmission end of the language teacher education spectrum where the student teacher's role is largely passive as they follow a standard "apprenticeship" model of the learningto-teach process.

Similarly, just over 20 years ago, Richards and Crookes (1988) presented an apprenticeship model of language teacher education while indicating support for a processdriven or constructivist model. They described a learning-to-teach model whereby "a novice teacher is apprenticed to a master teacher and expected to learn some of the master teacher's skills through observing, working with, and, in many cases, getting feedback from the master teacher" (p.20, italics added). However, there is no mention of what, if any, certification standards, teaching performance indicators or how many years' teaching experience are required in order for a cooperating teacher to earn the title master teacher. The pivotal question of whether many years' teaching experience translates into a more effective, critically reflective and accountable teaching practice is never addressed. What is fascinating about this article is that the authors provide an overview of the differences between a process- versus product-based teacher education program and indicate that assumptions about "how teacher development is thought to occur"(p.11) invariably influence the objectives set out by TESOL program planners, yet they do not seem aware of the transmission or transference aspect inherent in their description of an apprenticed learning-to-teach model.

Equally fascinating is the fact that Graham Crookes, one of the co-authors of the above mentioned 1988 article, continues to use the term master teacher fifteen years later. On the topic 
of the anxiety that student teachers often experience when being observed by their practicum supervisors, Crookes (2003) writes:

Classroom observation is an archetypal feature of teaching practice, and probably the most common feature across practica. It is also one which induces anxiety, particularly when, as is most common, the observer is a master teacher or administrator (p.29).

Somewhat ironically, only eight pages earlier, Crookes maintains that a teacher with many years' teaching experience may not necessarily be as reflective or committed to his/her practice as a newly certified teacher who is critically reflective, resulting in:

The familiar distinction between a teacher who has twenty years' experience and the teacher who has one year of experience 20 times (p.21).

Again, the reader is not provided with any insight as to what conditions need to be met in order for an experienced teacher to earn the title master teacher. However, it is doubtful that the above-mentioned teacher with 20 years' experience would be labelled as such. But what is clear is that the term master teacher is ambiguous. By contrast, the term cooperating teacher is far more descriptive and does not suggest being in possession of a superior knowledge-base when compared to other, less experienced teachers. Interestingly, though Crookes (2003) employs the term master teacher, he indicates that when working with student teachers, he resists the notion of students having to raise their hands in class to share their opinions, as "it reinforces a hierarchical relationship that I'm trying to get away from" (p.39, italics added).

\section{A Case of Pedagogical Appropriation}

Six years after their 1989 article, Brinton and Holten (1995) reported on a similar study in 1995 that took place at UCLA. The study spanned a 10-week period involving MA student teachers who had completed dialogue journals with input from their practicum supervisors. What is remarkably different about this 1995 article is the extensive use of direct quotations from the 
student teachers themselves rather than relying almost exclusively on paraphrased descriptions of journal entries. In this respect, the authors succeed in giving voice to the learning-to-teach experiences of three novice teacher learners.

However, Brinton and Holten (1995) still appear to maintain residual ties to the idea of mastering the art of teaching, rather than fully accepting the notion of learning-to-teach as a highly complex and life-long developmental process. In their concluding remarks, the authors note that the three student teachers - Luke, Kay and Sigrid - all seem concerned with "identifying areas to be mastered in their teaching" (italics added, p.25). But this is not how Kay, one of the TLs quoted in the article, describes it. Kay indicates that she needs "to develop an awareness" of modeling techniques that she has observed her mentor teacher using successfully ( $\mathrm{p} .25$, italics added). Yet the authors describe Kay's desire to develop this awareness as being much further along an apprenticeship model of learning to teach: they assert that Kay is commenting on "her successful or unsuccessful mastery" of her mentor's teaching techniques (p.25). This is an unfortunate case of what I will term pedagogical appropriation: the words the authors use do not reflect Kay's developmental stance on learning to teach, nor do they reflect the views of the practicum supervisor. The practicum supervisor indicates that the techniques that Kay is concerned about, particularly those related to pacing, can only be expected to develop "with time and experience" (p.25). As such neither Kay nor her practicum supervisor appears preoccupied with mastering particular set of teaching techniques. Also worth noting is that the collaborative exchange of dialogue journals only takes place between the TL and practicum supervisor: there is no mention of collaborative reflection among student teachers.

\section{Master Teacher: Is the term really so problematic?}

The assertion that master teacher is only a word, just a term, and is not at odds with a constructivist model of teacher learning needs to be challenged. First, as language teacher 
educators, working with language, there needs to be an awareness of any bias - pedagogical, socio-cultural or otherwise - in the language used by teacher educators, pre-service teachers, and in-service teachers. Second, this awareness has already resulted in two frequently cited shifts: 1) a shift in focus from teacher training to teacher education and 2) a shift away from describing ES/FL students toward describing ES/FL learners. And a third shift has occurred: more than 15 years ago, Richards and Lockhart (1994) emphasized the inclusive nature of the term teacher learners to describe both prospective and practicing teachers. The authors employed this term to demonstrate that learning to teach is a life-long process. I would argue that the same degree of mindfulness and critical reflection needs to be present when using any word to describe the role of practicum supervisors and collaborating teachers. It is clear that every teaching situation is different and that teaching cannot be reduced to a discrete set of skills or methods to be imitated and then mastered (Farrell, 2007). Hence the idea that experienced teachers can become masters in a field of work that is perpetually changing is at once perplexing and problematic.

\section{Other Potential Obstacles to a Constructivist Model of LTE}

If we consider the influence that prior learning experiences has on pre-service teachers' experience (Crandall, 2000; Freeman \& Johnson, 1998), the diversity of needs and backgrounds that often constitute the student teacher population (Woodward, 1991), and the short-term appeal of teaching EFL overseas for certain CTESOL graduates (Ferguson \& Donno, 2003), we may want to ask whether all or merely some pre-service students are interested in long-term professional teacher development. We cannot assume that students who have committed to 8 months of teacher education immediately recognize TESOL as a profession or plan to continue to develop and be recognized as an ELT professional in the long term. Hence it is possible that not all teacher learners will be equally invested in a bottom-up, constructivist model of LTE. The following section outlines different aspects of diversity among TESOL student teacher groups in 
order to strengthen the argument that it is unrealistic to assume that all pre-service teachers will be equally invested in ELT as a career.

Addressing the concept of student teacher diversity, Sheilds and Janopoulos (1995, p.12) identified three distinct TL groups engaged in the TESOL practicum featured in their study: 1) Non-native speakers of English who already have previous EFL teaching experience and wish to obtain the CTESOL from a North-American university; 2) Native speakers of English who want to teach EFL overseas; and 3) Native speakers and to a lesser degree, non-native speakers, who want to teach in government-funded ESL programs and need certification to do so.

Within the specific context of a TESOL/TESL program here in Ontario, I think a fourth category needs to be added: 4) teacher learners who come into an LTE program with previous language teaching experience (PLTE) who may or may not speak English as their first language but who plan to teach in Ontario (or elsewhere in Canada) upon graduation.

Additional examples of TESOL student teacher diversity can be found in Woodward's (1991, p.65) summary of the myriad of factors that may shape any given pre-service LTE group. Woodward identifies the following factors as influential in shaping student teacher groups: age, gender, previous teaching experience, educational background, course expectations, needs, goals, view of their role in the course, motivation, learning style, and energy level. I would add to this list the importance of previous language learning experiences.

Numerous scholars have asserted that previous learning experiences can have an enduring influence on the way pre-service teachers view teaching and how they develop as teachers (Crandall, 2000; Crookes, 2003; Johnson, 1992). They assert that this is because, after "years of being in classrooms and watching what teachers do", TLs are likely to "teach in similar ways as they were taught" (Johnson, 1992, p. 43). But previous learning experiences should be considered important because students often do consciously reflect on what they did and did not 
like about their former teachers; the assumption that teacher learners are doomed to repeat the behaviours that they have observed without staged intervention on the part of a teacher educator is somewhat simplistic. It also suggests a behaviourist model of how people learn. Fortunately, other scholars have acknowledged that TLs can be consciously driven to teach in radically different ways from the way they were taught. Quoting from a TL's journal, Carter (2008, p.40) gives the following example: "I know the name of every single student I teach - that's because I spent most of my secondary school life being referred to as "young lady."

When we stop to reflect on the myriad of factors that make each TESOL student teacher group distinct, it becomes clear that adult pre-service TESOL teachers studying at North American universities seldom represent a homogeneous group but, rather, make up a diverse student population. This distinction is important because the question of whether all pre-service TESOL teachers are equally invested in teaching ELT as a career remains unanswered. Answers to this question will have implications for the design and implementation of LTE programs that encourage pre-service teachers to be critically reflective about their practice (due to the oft-cited link between reflective teaching and long-term professional teacher development).

\section{5) Constructivist Learning, Reflective Practice and LTE: What does it look like?}

For well over a decade, there has been a push in both general teacher education (GTE) and language teacher education (LTE) programs to encourage student teachers to become reflective practitioners (Farrell, 2007; Ghaye \& Ghaye, 1998; Richards \& Lockhart, 1994). According to Farrell (2007), the central goal of LTE programs should be to "provide students with the tools to reflect so that they can continue to develop as teacher after the teacher education course" (p.22). He also notes that reflective language teaching is, by definition, "a bottom-up 
Table 2.5: Reflective Activities for both Pre-Service and In-Service Teachers

\begin{tabular}{|c|c|c|c|c|c|}
\hline & Reflective Activity & Individual? & Collaborative? & Time-Consuming? & Link to Real World? \\
\hline 1. & $\begin{array}{l}\text { Teaching } \\
\text { Journals }\end{array}$ & $\checkmark$ & potentially & potentially & potentially \\
\hline 2. & $\begin{array}{l}\text { Viewing Film of } \\
\text { Experienced Teachers }\end{array}$ & $\checkmark$ & potentially & potentially & $\checkmark$ \\
\hline 3. & $\begin{array}{l}\text { Observing Teachers } \\
\text { in Real Time }\end{array}$ & $\checkmark$ & potentially & potentially & $\checkmark$ \\
\hline 4. & $\begin{array}{l}\text { TLs Viewing Film of } \\
\text { Themselves }\end{array}$ & $\checkmark$ & potentially & potentially &  \\
\hline 5. & $\begin{array}{l}\text { Learning a second or } \\
\text { additional language }\end{array}$ & $\checkmark$ & potentially & potentially & $\checkmark$ \\
\hline 6. & $\begin{array}{l}\text { Case Study } \\
\text { Discussion }\end{array}$ & $\checkmark$ & $\checkmark$ & not usually & potentially \\
\hline 7. & $\begin{array}{l}\text { Participating in } \\
\text { Online List-Serv }\end{array}$ & $\checkmark$ & $\checkmark$ & potentially & $\checkmark$ \\
\hline 8. & Micro-Teaching & $\checkmark$ & $\checkmark$ & not usually & $\checkmark$ \\
\hline 9. & $\begin{array}{l}\text { Mini Ethnography } \\
\text { of ESL Learner }\end{array}$ & $\checkmark$ & $\checkmark$ & potentially & $\checkmark$ \\
\hline 10. & $\begin{array}{l}\text { Forming a Teacher } \\
\text { Development Group }\end{array}$ & $\checkmark$ & $\checkmark$ & potentially & $\checkmark$ \\
\hline 11. & Action Research & $\checkmark$ & $\checkmark$ & potentially & $\checkmark$ \\
\hline
\end{tabular}

${ }^{1}$ Reflective activities covered in the above table have been pooled from my literature review, specifically from: Bailey, Curtis \& Nunan (2001); Carter (2008); Farrell (2007); Freeman and Cornwell (1993); Johnson (1994); Numrich (1996); Richards and Farrell (2005); Richards (1998); and Richards and Lockhart (1994). The above list is not meant to be exhaustive but does cover frequently cited LTE reflective activities.

${ }^{2}$ Observing teachers in real time might include experienced and/or novice teachers 
approach to teacher professional development" (p.9). As such it is pre-service and experienced language teachers themselves "who make a difference" in their efforts to make sense of and improve their practice, and "not methods or expert opinions" (p.175).

But the question of what reflective teacher education programs might look like in practice has yet to be answered in this thesis. Thus, in Table 2.5, on the previous page, I have provided an overview of frequently referenced reflective activities cited in LTE and GTE literature.

Note the categories in Table $\mathbf{2 . 5}$ indicate if the activity is 1) time-consuming; 2) has clear links to the 'real world' of classroom teaching; and 3) if it involves individual or collaborative reflection. Note also that all of the individual-based reflective activities can potentially be adjusted to have a collaborative angle. For example, individual journals can become collaborative by initiating dialogue journaling between or among other teacher learners.

Farrell (2007) notes that his objective of encouraging student teachers to be reflective about their current and future teaching practice is accomplished by employing a range of reflective activities, including action research. He defines action research in the following way:

It focuses on researching an issue of interest to the teacher and usually takes place inside the classroom to determine what is currently occurring. Action research involves the teacher systematically collecting information about this issue and then acting on the information to make improvements to the issue. In order to help teachers collect information related to their action research project, they can use reflective tools such as teaching journals, classroom observations, narrative analysis and group discussions (p.104).

Thus, action research can be understood to involve at least a four-stage process of 1 ) identifying a teaching or learning issue to be researched; 2) collecting data on the particular issue of interest; 3) analyzing and reflecting on the data collected; and 4) using this information to then take action in order to improve one's teaching practice. It is important to note that the language teacher is 
not necessarily alone in undertaking action research, but rather, in many instances, will choose to work with a colleague (Farrell, 2007).

\section{Action Research in Practice}

Here is an example of action research in practice: an in-service language teacher invites a colleague to record her teaching (using a digital video recorder) so that she can later observe 1) the non-verbal communication she uses with students, generated through her posture, eye contact, intonation, gestures, etc; and 2) her use of conversational fillers such as "okay" "so" and "um". Or she may want to isolate a different aspect of her teaching, such as the type of questions she asks students; how much teacher-talk occurs in her class; how much L2 is used; interactions that occur between learners, and so on. If the colleague agrees to take the time to record part of her lesson, he may ask her to do the same for him. They may or may not be interested in collecting data on the same aspect of their classroom practices, but they can certainly use each other as sounding boards after watching viewed footage of themselves and taking extensive notes. Note that action research does not require the use of audio-visual equipment. It can be as low-tech as keeping a teaching journal over a period of time and sharing journal entries with a trusted colleague in order to pool insights about a particular aspect of teaching practice.

Action research is not used exclusively by in-service teachers but has been used in teacher education programs by pre-service teachers as well. Kitchen and Stevens (2008) describe their experience of using action research with their student teachers. They introduced action research to their students in order to address "the persistent concerns of pre-service teachers regarding the tensions between educational theory and classroom practice" (p.9). They felt that action research, "with its emphasis on reflection and inquiry for the purpose of taking positive action" would assist students in linking educational theory and practice and help create links between pre-service and in-service teaching (p.9). Note that action research was one of several 
reflective practices that their students engaged in. Other practices included "reflecting on critical incidents during practice teaching; examining case studies; and undertaking critical analysis of educational readings" (p.9).

Fittingly, both Kitchen and Stevens (2008) engaged in critical reflection "about their experiences as teacher educators during the [action research] project and at its conclusion" with one of the authors writing journal entries for the duration of the school year (p.22). Student teachers were asked to write a final report that summarized their experience with action research (each student had chosen their own area of research to undertake) and how they felt in their role as teacher-researcher. While more than 75 per cent of the TLs indicated that they found the project beneficial and were able to better connect theory to practice as a result of their action research, approximately 20 per cent indicated that they had concerns. Compare the following two pre-service teacher's experiences and note the reflective language used by the student on the left:

\section{Table 2.6: Two Student Teachers' Experiences with Action Research}

One student teacher s positive experience with One student teacher's negative experence with Waction research

"I think that the process of reflection and investigation that accompanies an action research project forces a teacher to examine new ways of teaching and learning - both of which are important in the process of life-long learning" (p.20, italics added).
"The action research was essentially useless. A research paper would have served us much better. We do not have the experience or the time to worry about it [action research] in the practicum" (p.21).

What is most refreshing about Kitchen and Stevens' (2008) article is that, as teacher educators, they are critically reflective about their own teaching practice. For them, the negative comment from the student teacher outlined above suggested that for some pre-service teachers, there is "little place for action research" in a teacher education program (p.21). Reflecting on the comment further, they then wondered about the "possibility that pres-service teachers, who have 
no formal experience as classroom teachers, are not yet equipped with the knowledge and experience to be action researchers" (p.22). Again, the authors point out that, for the majority of their students, the action research project was highly beneficial, noting that two students went on to present their work at an educational research conference the subsequent year. However, both teacher educators felt the need to reflect on all their students' experiences in order to "continue the iterative process of improving our practice and enhancing the action research project" (p.25). Both indicated they had "benefited professionally" from the reflecting on the project and felt this growth better positioned them "to help our future students" (p.25).

\section{The Power of Observation: Teacher Learners Comment}

Bailey, Curtis, and Nunan (2001) note that, for over 30 years, video recording has been consistently used in LTE and GTE programs as an observation tool to enable student teachers to see themselves from the perspective of language learners. Describing a video recording as an "estrangement device", the authors maintain that video allows teachers to "create more distance" between themselves and their teaching and to watch themselves "with the kind of objectivity that is usually possible only when viewing someone else" (p.118). The authors assert that video recordings are an invaluably reflective tool for pre- and in-service teaches for two reasons: 1) they reveal a great deal about teachers' non-verbal state at the time (such as energy level and overall mannerisms); and 2) they can provide teachers with "a powerful prompt for stimulated recall" (p.118): The authors recommend that TLs focus on a particular aspect of their teaching practice when watching recorded footage of themselves, such as how they respond to students' comments or the type of questions they may ask learners.

Worth noting is the fact that two of the three above-mentioned authors have themselves experimented with the video recorded self-observation process. Kathi Bailey and Andi Curtis note that "the details captured by the camera" allowed them to experience "vivid recollections of 
what we had done and even of how we had felt during that particular lesson" (Bailey, Curtis, \& Nunan, 2001, p. 121). Although Kathi had been teaching for over 20 years at the time of the recording and knew her subject matter very well, she was able to discover new aspects about her teaching practice by watching herself on video. While watching the video, she made "a few pages of notes" for future reference which included the following two insights:

I say 'Okay?' quite a lot . . . As the workshop went on, I began to feel as if I say it too much and that it feels empty as an invitation to the participants to speak. I want to develop some alternatives ... I [also] noticed that each time I put the students into groups I gave instructions and signalled a clear start to the group work but I didn't set any time parameters (p.125).

Johnson (1994) provides insight into the impact that self-observation can have on the developing practice of pre-service TESOL teachers. As part of a study that looked at the instructional practices of prospective language teachers, Johnson had student teachers videotape one another teaching and then had each TL review their recorded teaching. Each TL was asked to watch the videotape of themselves and "provide stimulus recall comments" with their practicum supervisor. These recall comments were audio-recorded and then later transcribed for the purposes of the study. The following is an example of the think-aloud commentary that occurred when Gretchen, one of the TLs in the study, reflected on what she was seeing:

I feel like I'm answering my questions for them. If they don't give me what I want, I just tell them the answer. I didn't realize I was doing this, but it sure is clear here. I'm beginning to realize that when I do this, it just cuts them off. No wonder they don't volunteer. I guess I wouldn't either if I knew that the teacher was going to tell them the answer anyway (Johnson, 1994, p.446).

From the above excerpt we can see how, in the process of watching video footage of her teaching, Gretchen is better able to create distance from her own teaching and put herself in her students' shoes. She identifies with not wanting to answer questions that are almost rhetorical in nature in that they are consistently asked and answered by her, the teacher. 
There are still other documented accounts of TLs deriving benefit from observing themselves. For example, one teacher learner, more than one year after completing his TESOL course, noted the following: "Of tremendous value was the video recording. Much more should be made of this. Over one year after the course I still refer to my tapes" (Brandt, 2006, p. 359).

Two other comments from prospective teachers illustrate how "much of what happens in teaching is unknown to the teacher" (Richards and Lockhart, 1994, p. 3). Consider the following comments that TLs made after watching themselves on videotape: "I had no idea I did so much talking and didn't let students practice" and "My pacing was terrible. I didn't give students enough time to practice one task before going on to another" (Richards and Lockhart, 1994, p.3). And consider the following comment, from a different study involving pre-service teachers:

I have now seen two of my videotapes and I don't shut up for a second. OK, this obviously something of an exaggeration - but I talk excessively and I don't give enough wait time (Numrich, 1996, p.136).

There is significantly less documented commentary from TLs on the topic of observing their host teachers at their practicum sites. However, the following quote, from a prospective teacher in a GTE program in the early 1990s, does shed some light on the issue of how much of an impact observing host teachers may have on pre-service teachers, particularly for those with no previous teaching experience to draw from:

As I taught during my internship, I recall being aware of my mentor's teaching style and techniques and attempting to emulate them. I remember finding myself consciously thinking about his approach and I stood teaching, in front of the class ... I still struggled though, to be more like my mentor teacher. A teacher's teaching style reflects that teacher's personality and, because I could not comfortably acquire my mentor's personality, my struggle continued. I finally came to realize that one can acquire some of another teacher's techniques by watching and recording information about that teacher's behaviour and then practicing that behaviour, but because a teacher's teaching style is unique, a student teacher will have to develop his or her own teaching style (Knowles, Cole \& Presswood, 1994, p. 42). 
Worth noting is that the novice TL in the above example attempted to follow an apprenticeship model of learning-to-teach suggested by Schon (1987) but eventually came to the realization that, despite how much he admired his host teacher, and despite the fact that he was able to adopt some of his teaching techniques, ultimately, he needed to develop his own teaching style. What is interesting about the above excerpt is the lack of critical reflection that has occurred in the observation process. If we recall Larrivee's (2008) three levels of reflection, we can see how the above quoted student teacher has reflected, both on the surface-level and to some degree, pedagogically. But the critically reflective question of whether or not the teaching techniques his host teacher employed were appropriate for that particular group of learners has not been asked. It may well be that critical reflection is better suited to pre-service teachers who come into a teacher education program with some previous teaching experience of their own to reflect upon.

On the topic of observing more experienced teachers, Richards (1998) maintains that this form of observation is of utmost importance in any LTE program. He writes that: "observation of experienced teachers has always played an important role in teacher education" and can arguably help pre-service teachers to "develop a repertoire of strategies and techniques" while "distinguishing between effective and ineffective classroom practices" (p.141). It would seem that TESL Ontario shares this viewpoint, as their website indicates that in order to be qualified for certification, CTESL graduates must have been placed in a practicum that "consists of a minimum of 30 hours of observation and a minimum of 20 hours of supervised teaching" (p.2, Instructor Certification Application Package, www.teslontario.org).

As such, observation hours are not just a central part of many teacher education programs; in the case of TESL Ontario, a higher number of observation hours is required compared to that of required practice teaching hours before certification can be issued. Further, the TESL Ontario website indicates that observation is a pre-requisite to practice teaching: 
"TESL students must first observe classes that they will teach", advising that observation hours "must be done in two or more settings" (p. 3 of the same document). Hence we see support for the idea, as Crookes (2003) outlines, that "some sort of progression from observation, through assistance, to possibly full responsibility for the discharge of actual lessons" is the prevailing model in the majority of practicum settings (p.222).

\section{Journal Writing: widely promoted but not without limitations}

At first glance, it would seem that teachers tend to start and maintain a teaching journal for two practical reasons: 1) they want to record teaching events and ideas in order to recall and reflect upon them at a later date; and 2) they understand the process of writing may itself "trigger insights about teaching" and is thus a source for reflection-for-action (Richards \& Lockhart, 1994, p.7). Yet reflective writing is complex in that there are numerous ways that it can be used in teacher education programs as well as by in-service teachers. On the one hand, journal writing can be a decidedly individual and private process: a teacher writes about aspects of his/her teaching practice for his/her own reference and benefit only. On the other hand, journal writing can become a collaborative project involving peers or colleagues. In pre-service programs, journal dialogues frequently occur between student teacher and course instructor or practicum supervisor (Carter, 2008; Holten \& Brinton, 1995). But there are still other uses of journal writing in pre- and in-service teacher education programs. In cases where teachers are required to study a second or additional language, journal writing is often used to document their language learning experiences (Bailey, Curtis, \& Nunan, 2001).

However, the practice of having pre-service language teachers share their journal reflections with each other and respond, either anonymously or openly (by, say, writing their response on paper or online) is seldom documented. This is curious, given the amount of time 
that is required on the part of a course instructor to maintain a journal dialogue with a whole class of individual students, versus the drastically less amount of time required for students to dialogue with one another. And, when we consider the constructivist model of teacher learning currently advocated by many teacher educators, the lack of documented occurrence of dialogue journals between pre-service teachers is that much more curious.

Worth noting is the fact that while many scholars have identified numerous benefits associated with journal writing for both pre-service and in-service teachers (Brinton \& Holten, 1995; Brock, Wong, \& Wu, 1993; Carter, 2008; Johnson, 1994; Numrich, 1996; Richards \& Lockhart, 1994; Ur, 1996), still others have acknowledged that there are limitations to this form of reflection that need to be considered (Bailey, 1990; Farrell 2008; Richards, 1998). For example, while Richards (1998) asserts that teacher educators are "generally positive about the use of journals" (p.54) he also notes a number of limitations associated with journal writing:

1. The process can become time consuming for the student teacher;

2. The process may feel artificial for those who are not accustomed to journal writing;

3. Some students may lack the discipline and motivation to write journal entries on a regular basis;

4. From the perspective of the instructor, the analysis and interpretation of students' journal writing can be difficult;

5. Maintaining a dialogue journal process where the instructor responds to each student's writing for each journal entry can be time consuming for the instructor.

Similarly, Bailey (1990), who lists many advantages to journal writing, also advises teacher educators to include journals only "as an option among several possibilities," emphasizing that this particular genre of writing be voluntary, not forced (p.225, italics added). Her rationale is simple: not all student teachers are comfortable writing within this particular genre and to force individuals to keep a teaching journal is not in line with an inquiry-based, constructivist model of teacher education. 


\section{6) Teacher Development for both Novice and Experienced Educators}

In Chapter 1, I indicated that one of my research questions relates to Conway and Clark's (2003) model of teacher development. In this section I provide an overview of their work while making a connection between a bottom-up approach to LTE and the need to have both preservice and in-service teachers share their individual reflections with other TLs.

\section{Conway and Clark's Adaptation of Fuller's Model of Teacher Development}

Conway and Clark's (2003) model of teacher development, adapted from Fuller's work in 1969 and 1975, provides one conceptual framework through which the learning-to-teach process of novice teachers can be viewed. Before describing how Conway and Clark adapted Fuller's model of teacher development, let us first review the original Fuller model. According to Conway and Clark (2003), Fuller's 1975 model is based on the premise that teacher learners typically experience three stages of concerns as they learn to teach, beginning with:

1) Concerns about self (inward focus); then moving toward

2) Concerns about specific teaching tasks and situations (outward, but not yet concerned with big picture issues); and finally moving toward

3) Concerns about the impact they as teachers have on their students (outward focus, with big picture issues in mind)

In addition to providing a summary of Fuller's model, the two authors note the enduring impact this model has had on teacher education research and practice for over two decades. They also reference scholars who have since critiqued Fuller's model of teacher development.

In their adaptation of Fuller's model, Conway and Clark (2003) interviewed 6 Michigan State University TLs who were in the process of completing two semesters of practicum placements and course work. The authors extended Fuller's model to encompass both hopes and fears as a means of documenting the six teacher learners' development as novice teachers over the course of a year. Their rationale for documenting TL's hopes as well as their fears was to 
provide "a more balanced and expansive view of prospective teachers' actual experience and anticipations about learning to teach than a concerns-only focus" (p.468, italics added).

Findings from the study revealed an observable movement from four of the six teacher learners from self (inward) to task (outward) to student (outward, big picture). Conway and Clark (2003) note that these concerns shifted according to the stage of the TLs' internship. For example, in the middle internship period, TLs appeared most concerned with curriculum and instruction issues. The authors speculated that this pedagogical focus was likely linked to the fact that the student teachers were immersed in practice teaching at that time. However, contrary to the Fuller model, the TLs they studied still reported inward-focused hopes and fears "prominent even late in the Intern year" while also reporting outward-related hopes and fears (p.470).

On closer examination, the authors realized that the exact nature of these inward hopes and fears were related to development of self-as-teacher. Rather than focusing on concerns about self for survival (how can I meet the course requirements, create a good lesson plan, etc.), the TLs were focused more on "professional development ... of self-as-teacher" (p.474). Given that the TLs they studied expressed outwardly focused concerns far earlier than the Fuller model predicted they would, the authors argue that Fuller's model does not reflect "the pace and developmental direction of expressed concerns among pre-service teachers" (p.475). The authors also suggested that the Fuller model is too linear and does not reflect the cyclical and bidirectional nature of learning to teach, because TLs do often think about both inward and outward related issues, and many continue to do so throughout the course of their careers.

Further, Conway and Clark (2003) highlight the behavioural model of learning to teach prominent in the 1970s, which they argue likely influenced Fuller's linear model. They suggest that a social constructivist model that informs many contemporary teacher education programs is more likely to foster critical reflection among teacher learners. In other words, the "inward focus 
among Intern teachers is necessary, valuable, and reflects a move toward reflective practice as the professional self is constructed over time" (p.475, italics added). Moreover, this image of the professional self can be revisited at any stage of a teacher's career and "be fruitfully revitalized". In this way, the need, as outlined in Fuller's 1975 model, for TLs to transcend the inward focus of concerns and move toward outward concerns is challenged and, within the context of reflective teaching, no longer bears the same relevance.

One limitation of Conway and Clark's (2003) study is that the authors do not acknowledge that, because their study is so small (only 6 participants), their findings cannot be generalized to other settings. This is unfortunate because in order to critically assess Fuller's model and refute it with empirical evidence, a larger study is needed.

However, despite this limitation, the value of Conway and Clark's work should be recognized, for two reasons. First, they have succeeded in extending Fuller's 1975 model to encompass both teacher-related concerns and aspirations, providing a more holistic perspective of the learning-to-teach process. Secondly, their findings suggest that reflective teacher learners, at any stage of their career, may well engage in a cyclical and bi-directional process of learning from their teaching, reflecting both inwardly and outwardly on their practice.

\section{Long Term Teacher Development: A Bottom-Up, Collaborative Process}

As outlined earlier in this chapter, a constructivist model of teaching learning is inherently bottom-up. This bottom-up model is applicable to the teacher development of both prospective and practicing teachers. As Farrell (2007) notes: "the need for ongoing teacher development has been a recurring theme in the field of second language teaching" and is reflection of "the fact that not everything a language teacher needs to know can be provided at pre-service level, and also that the knowledge base of teaching is constantly changing" (p.174, 
italics added). He further asserts that language teacher education programs that support a constructivist model of teacher learning recognize that teachers are "capable of constructing and sustaining their own professional practice" both now and in the future (p.175).

In describing this bottom-up approach to teacher learning, scholars have, in recent years, emphasized a need to have the reflections of individual teachers be shared with other teachers in a collaborative, supportive manner both in pre-service and in-service teacher education settings (Bailey, Curtis, \& Nunan, 2001; Farrell, 2007; Ghaye \& Ghaye, 1998). Whereas Ghaye and Ghaye (1998) focus on the value of teachers sharing their reflections with others, other scholars (e.g. Farrell, 2007) have provided specific details on how teachers can systematically set time aside to form and participate in their own teacher development groups (TDGs).

Over ten years ago, Ghaye and Ghaye (1998) asserted that pre-service teachers need to be given opportunities to reflect not just individually, but also collaboratively with their peers. They indicated that this could be achieved by engaging in what they termed a reflective conversation. A reflective conversation involves, at minimum, two teacher learners: the "owner of the teaching experience and a significant other" (p.21). The "other" party could be a fellow student teacher, a host teacher, a practicum supervisor, or course instructor. In their words:

In professional development and particularly in the context of becoming a qualified teacher, reflective conversations, seen in the act of collaborative meaning-making, are an important educational activity. Collaborative knowledge building like this is the driving force for further leaning. Through the communication, exploration, challenge and justification of the teacher's 'lived experiences', shifts in perspective, attitude and values may arise. . . Knowledge generated through reflective conversations is a creative and constructivist process (p.22).

Note how the act of sharing individual reflections with others is seen as an act of collaborative knowledge building that is understood to be the driving force for further learning. Ten years later, and the perspectives of Ghaye and Ghaye (1998) are echoed by other scholars. 
Larrivee (2008) asserts that if a reflective practitioner exclusively engages in individual reflection and does not share with peers, his or her "potential for personal growth" is greatly limited (p.95). She maintains that by sharing reflections, teachers are able to generate more ideas and insights about their practice as well as the practice of others:

In order to gain perspective, it often takes another person to mirror back experiences and perceptions. Exposure to different viewpoints is critical to fostering reflection by providing opportunities to listen to more sides than one, to entertain plausible alternatives, and to recognize the possibility of error even in our most cherished beliefs. Structured conversations with peers can open up a new way of seeing things. In the absence of such feedback, reflection can merely validate and perpetuate one's own views (p.95).

It is important to note that the reflective conversations that Larrivee (2008) describes are structured, meaning that they are focused on a particular aspect of reflection and serve a particular purpose. They are not arbitrary, trivial or about venting teaching frustrations; rather they involve two professionals (or more) making critical reflections about their teaching practices public, with the intent to learn with and from one another.

Similar to Larrivee (2008), Crookes (2003) notes that "teachers do learn from each other, and may possibly learn better when they have more opportunities to interact in a mutually supportive fashion" (p.7). For this reason, he contends that teacher education programs need to address "the social aspects of teacher learning" and expose TLs to social practices they can use long after their formal training is over (p.7). Crookes (2007) and Farrell (2008) both suggest that pre-service teachers who are exposed to the concept of a teacher development group (TDG) while completing their practicum are better prepared to engage in collaborative learning as inservice teachers. Table 2.7, on the following page, outlines core features of what a TDG looks like in practice, based on the criteria provided by Farrell (2007) and Crookes (2003). Also outlined are key aspects of the TDG that may be applied in a pre-service teacher context: 
Table 2.7: Teacher Development Groups (TDGs) for Prospective and Practicing Teachers

\begin{tabular}{|c|c|c|}
\hline Criteria & Teacher Development Group (TDG) & Adapted TDG for LTE Context \\
\hline How initiated: & $\begin{array}{l}\text { Are always voluntary and teacher- } \\
\text { initiated; they are not mandated by } \\
\text { employers }\end{array}$ & $\begin{array}{l}\text { Organized by course instructor; but input from } \\
\text { TLs re: the size of groups, and points of focus } \\
\text { could be considered }\end{array}$ \\
\hline Purpose: & $\begin{array}{l}\text { To share and/or collaborate on } \\
\text { teaching experiences, theories, } \\
\text { research ideas, resources, and overall } \\
\text { knowledge-base in order to continue to } \\
\text { develop as reflective teacher learners }\end{array}$ & $\begin{array}{l}\text { SIMILAR; with an added emphasis on current } \\
\text { practicum experiences; links between } \\
\text { educational theory and teaching practice could } \\
\text { be one of many points of focus to be explored }\end{array}$ \\
\hline $\begin{array}{l}4 \\
4 \\
\text { sized }\end{array}$ & $\begin{array}{l}\text { Small number of participants: as few } \\
\text { as } 2 \text { but generally no more than } 8\end{array}$ & $\begin{array}{l}\text { More than two students might be } \\
\text { recommended for greater range of input and } \\
\text { less than } 8 \text { for greater ease for group members } \\
\text { to organize themselves (arrange meeting } \\
\text { times, etc.) }\end{array}$ \\
\hline Meeting place: & Members meet in person or online & TLs could meet in person and online \\
\hline Duration: & Short or long-term & Pre-determined according to program length \\
\hline
\end{tabular}

Thus, TDGs can be adapted for LTE and GTE programs without compromising the collaborative nature of the standard model.

I would like to conclude this literature review with a quote that illustrates the importance of reflective teaching as a life-long process. The quote is from Kitchen and Stevens (2008), two teacher educators previously cited in this chapter. Commenting on their own reflective process that they went through while their B. Ed. TLs completed their research projects, they noted that:

As we sought to encourage pre-service teachers to become proactive through reflection and inquiry into their practice, we committed ourselves to inquiring into our teacher education practices (p.9).

Worth remembering is that one of the researchers from the above excerpt kept a reflective teacher journal throughout the action research project. Also worth noting is that both teacher 
educators met on a regular basis before, during and after the project to engage in reflection for and on action.

What is most significant about the above quote is that the two authors have provided a clear case of a parallel learning process known as loop input (Woodward, 1991). This term has been used to describe parallel structures between ESL learners and student teachers and/or TESL educators. In some cases the parallel structure is seen on two levels; for example, the parallel process of both a student teacher and teacher educator engaged in journal writing, analyzing case studies, or peer observation to further develop their teaching practice. In other instances, parallels can be seen on all three levels, where an ESL student might also be engaged in journal writing to say, better understand their own language learning experiences or language learning needs.

The significance of the above example of loop input should not be overlooked. It speaks to the importance of two issues that will function as a backdrop to the remainder of this thesis. First, reflective teacher educators and pre-service teachers are not separated by terminology such as master teacher but rather are connected by one central term: teacher learner. Second, and related to this first point, is the idea that teacher learning is a life-Iong process. As numerous scholars cited in this chapter have indicated, this life-long process involves purposeful, forwardthinking critical reflection, as well as inquiry, experimentation and exploration. 


\section{Chapter 3: Methodology}

In this chapter, I describe the research methodology used in my study. After describing the overall research approach and design, I outline the steps taken to gain access to my research participants. I then describe the research instruments used in all four stages of my study while providing a rationale for why these particular instruments were used. I also provide background information on four research participants who participated in Stage 3 and 4 of this study.

\section{$\underline{\text { Research Approach and Design }}$}

Adopting an exploratory case study approach (Johnson \& Christensen, 2000; Merriam, 1998), data was collected in order to better understand a particular case (the practicum course and placement experience) by a particular group of individuals (CTESL undergraduate and postgraduate students) at a particular point in time (during their second of two practicum placements). As Merriam and Simpson (1994) explain, case studies are particularistic, often focusing on a "particular situation, event program, or phenomenon" with the goal of providing readers with a "rich description of the phenomenon under study" (p.109).

My central goal in collecting data from my selected participants, the CTESL students, was to document their lived experiences while they were in the midst of their second semester of full-time study and their second practicum placement. More specifically, I wanted to document their past and current teaching concerns after they had begun their second practicum placement. Drawing on the work of Conway and Clark (2003), I also wanted to document the aspirations of this particular group of CTESL teacher learners.

In terms of the role of reflective teaching in their learning-to-teach processes, I hoped to gain insight into their appraisal of different types of reflection that formed a core part of the CTESL program: in-person, online, individual and group. Additionally, I wanted to find out if 
certain features such as age, gender and previous language teaching experience (PLTE) influenced TLs' experiences of their practicum course and placements. More generally, I wanted to give voice to their experiences as teacher learners who were placed in a number of ESL community settings, interacting with a range of adult ESL learners. With the intent to understand the practicum experience from more than one perspective and to understand the reflective activities being asked of the 2008-2009 CTESL students, I set out to interview the practicum course instructor as well. By pooling these different data sources, I hoped to generate a richer data set so that I might "see" my participants with greater clarity.

I pursued the above mentioned objectives via a four-stage data collection process: Stage 1 involved document analysis of the practicum course syllabus as well as a semi-structured interview with the course instructor; Stage 2 involved distributing a questionnaire to the CTESL group of undergraduate and postgraduate students; Stage 3 involved one-on-one semi-structured interviews with four CTESL students; and Stage 4 involved a group interview with all four CTESL students. It is important to note that data from each stage informed the scope and nature of data collected in each subsequent stage. For example, data from Stage 1 allowed me to step back and consider the relevancy of my initial research questions and prompted me to revise them

Stage 2 , involving the questionnaire, provided a big picture analysis of the practicum experiences of the CTESL students as a group. The questionnaire responses from both the closed and open-ended questions helped shape the focus of questions that I then asked in Stage 3. Stage 3 in turn provided me with a final point of focus for Stage 4. The following diagram, Table 3.1, illustrates how each stage in my research design informed and complemented the next: 
Table 3.1: Research Design

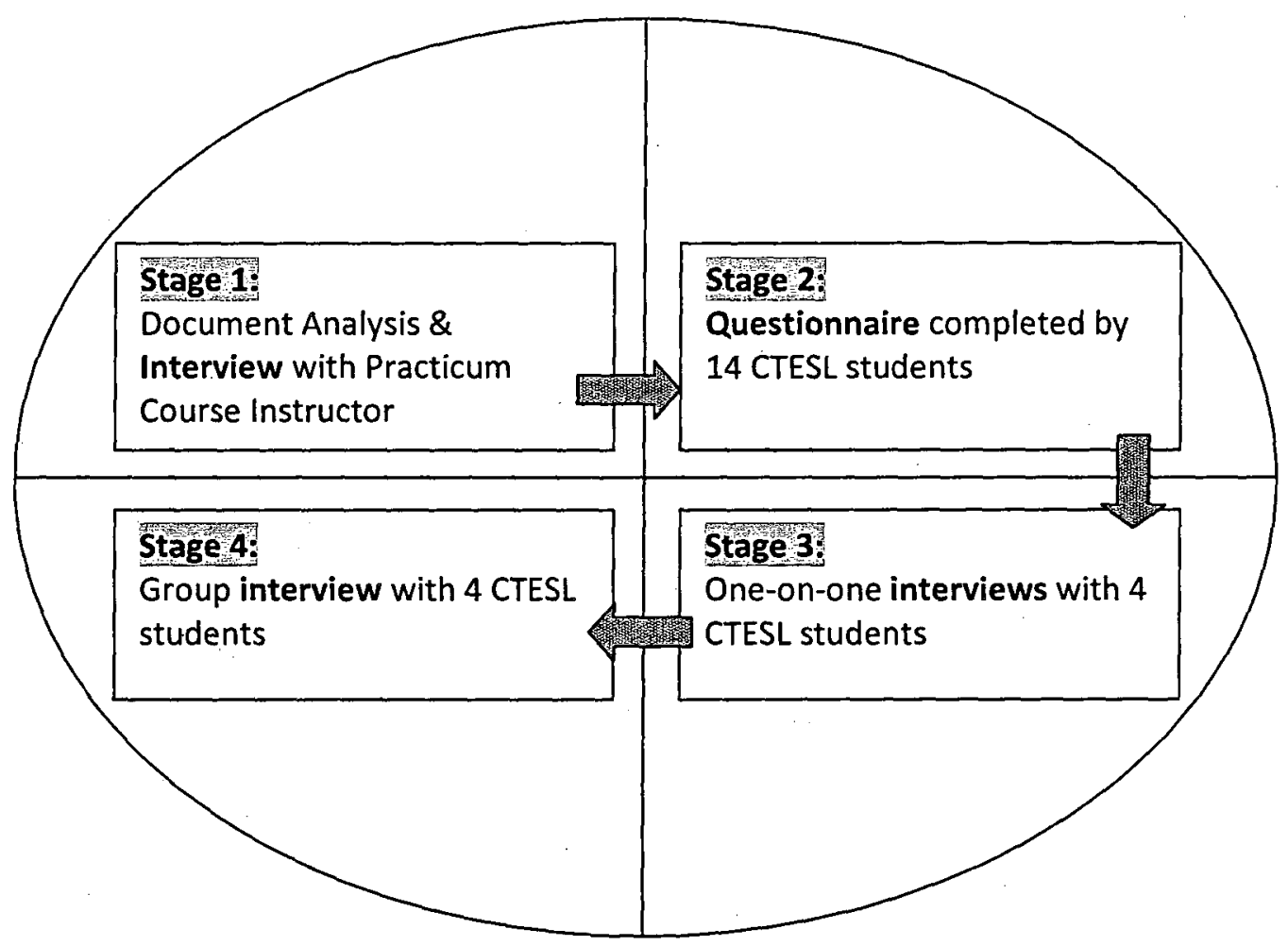

As can be seen from Table 3.1, qualitative interviews were the main research instrument in this study, used in Stage 1, 3 and 4. These interviews allowed me to "gain in-depth knowledge from participants about particular phenomena, experiences or sets of experiences" (DeMarrais, 2004, p.52, italics added). On the topic of case study research, Hays (2004) explains that "interviews are one of the richest sources of data in a case study and usually the most important type of data to be collected" (p.228, italics added). The other sources of data in my study, that of document analysis and questionnaire, were used to provide additional context and direction for the interviews that I conducted, something that Hays (2004) recommends doing. 


\section{Gaining Access}

Before collecting data, I needed to gain access to the students of the practicum course and ask the instructor to participate in my study. In late November 2008, I obtained Ethics Clearance ${ }^{3}$ from the university, allowing me to conduct original research on campus. In December 2008 I emailed the course instructor to provide an overview of my study and request an in-depth interview. I also requested an electronic copy of her course outline and asked to visit her practicum class the following semester with the intent to recruit student participants for Stage 2, 3, and 4 of my study. The instructor agreed to be interviewed by me in January 2009 and also gave me permission to visit her practicum class in February 2009 for recruiting purposes.

\section{Stage One: Document Analysis and Instructor Interview}

Once the course instructor agreed to participate in my study, I began Stage 1 of my research design. I analyzed the practicum course instructor's syllabus in order to better understand the requirements - particularly reflective activities - that were being asked of the CTESL students as they completed their course work. I compared the type of reflective activities required of the TLs with the range of reflective activities frequently cited in LTE literature (see Chapter 2, Table 2.5 for a matrix of these activities). As Hays (2004) explains, a major strength of case study research is the "opportunity to use many different sources of data" which often take the form of interviews, observations, and written documents such as "a school plan document" (p. 229, italics added). Hays recommends that researchers seek "multiple sources and multiple methods" of data collection in order to develop a more comprehensive understanding of the case being studied (p.229). As I analyzed the syllabus, I highlighted key sections and wrote questions that I anticipated asking the instructor during the interview.

\footnotetext{
${ }^{3}$ See Appendix A
} 
In preparation of one-on-one interviews in Stage 2 and 3 of this study, I found the work of Demarrais (2004), Merriam (1998) and Kvale (1996) to be especially helpful. These authors provided insight on many aspects of interviewing, such as the importance of avoiding leading questions $^{4}$ and using a range of probes $^{5}$; the value of brief and clear interview questions, active listening, and establishing rapport with participants; and the concept of providing participants with a transcript review ${ }^{6}$ at later date. Before interviewing student participants in Stage 3 of my study, I revisited the work of the above mentioned scholars.

To prepare the interview guide for my interview with the course instructor, I referred to the notes I had taken when analyzing the practicum course syllabus. The interview guide helped me bridge my initial research questions with areas of interest related to the practicum course syllabus. I then conducted a semi-structured interview with the practicum course instructor to determine her pedagogical reasons for including different types of reflective activities in her course. I also used this opportunity to ask about her experiences teaching the practicum course over several years. I chose a semi-structured interview approach because I wanted to have a certain degree of flexibility in the order and scope of my questions while maintaining a research focus throughout the interview process.

The semi-structured interview with the course instructor took place on January 9, 2009 and lasted one hour. The instructor graciously agreed to be interviewed two weeks later to

\footnotetext{
${ }^{4}$ For example, "Why do student teachers need be reflective?" would be a leading question had the participant not already indicated this was his/her own viewpoint; it would lead the participant to adopt the researcher's opinion.

${ }^{5}$ Probes are most frequently used to ask for elaboration and clarification (Drew, Hardman, \& Hosp 2008). For example, "Can you explain what you mean by _?" is a probe that asks the participant to elaborate on his/her previous comment.

${ }^{6}$ A transcript review is exactly what the name suggests: a typed word document of the transcribed interview made accessible for the participant to review. He/she can then verify that his/her views and words used have been accurately conveyed and transcribed; this also provides an opportunity for the respondent to elaborate on, clarify, or edit his/her comments. A transcript review is also known as member checking, which is understood to enhance the internal validity of a study (Merriam, 1998).
} 
answer more interview questions that had emerged during that first interview. I recorded both interviews using a SONY microcassette recorder. The recordings were then transcribed before starting Stage 2 of my study. I sent the transcribed interview text to the instructor for her review and further elaboration. The instructor did not elaborate on any of her transcribed comments.

In preparation of Stage 2, I reflected on both my syllabus document analysis and preliminary analysis of my two interviews with the course instructor as well as my research questions. These reflections then influenced the questions asked in stage 2 of my data collection.

\section{Stage Two: Designing the Questionnaire}

The questionnaire administered in Stage 2 was used to augment my findings from Stages 1, 3 and 4. This questionnaire provided a big-picture analysis of individual and group experiences as well as a demographic portrait of each student teacher, enabling me to "see" my participants more clearly, both individually and collectively, as a group. Data from completed questionnaires in Stage 2 functioned as a backdrop against which data obtained in Stages 1, 3 and 4 were contextualized. Although questionnaires are often employed in quantitative studies involving a large number of participants with the objective of producing findings that can be generalized to other settings, this was never my objective. From the outset my intention was to select a purposeful and small sample, rather than a random and large sample.

Before designing the questionnaire, I consulted the work of several scholars writing on the topic of survey design, most notably Nardi (2006), Hutchinson (2004), de Vaus (2002), and Drew, Hardman, and Hosp (2008). These scholars helped me to appreciate the complexity of survey design and develop an understanding of biased or leading questions; question ordering; choosing appropriate intensity measures ${ }^{7}$; the direction of statements $^{8}$; and the need to

\footnotetext{
${ }^{7}$ Intensity measures measure the intensity of a respondent's opinion; In my questionnaire I chose a 6-point likert scale rather a 4-point scale because I wanted to more precisely measure the intensity of respondents' opinions
} 
demonstrate respondent sensitivity in terms of survey length and layout as well as questions asked and wording used. My goal was to ask questions in a clear, direct manner; I also wanted to ensure the survey would take a reasonable amount of time for respondents to complete.

Based on my familiarity with the CTESL program from the year before, I had some insight into what types of filtering questions should be included on the questionnaire. For example, in Section 1, question 7, I included a filter question as I anticipated that some CTESL students would come into the program with PLTE. As can be seen in the following example, I included arrows to direct the respondent to the section that was relevant to them:

Q7. Did you have any previous language teaching experience when you started the CTESL program in September $2008 ?$

Yes:



Q8. How many years of language teaching experience did you have in September 2008?

Please check the section that applies to you. Less than 1 year 1 to 2 years 2 to 3 years - 3 to 4 years 4 to 5 years
No: (Please proceed to Section 2, page 3)
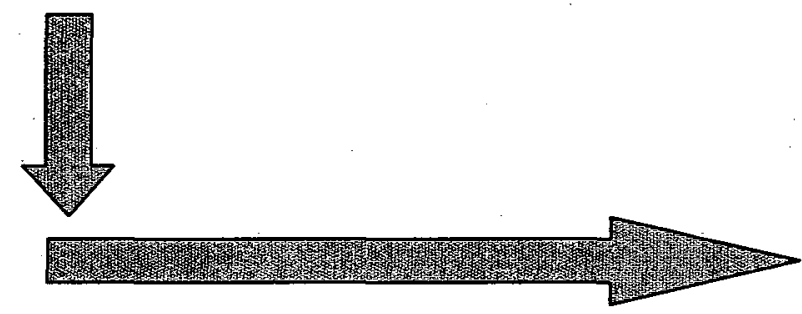

\section{閶}

Q9. Indicate the type of language teaching experience you had coming into the CTESL Program (circle all that apply).

- ESL (here in Canada or any English-speaking country such as England or the USA)

- EFL (in any country where English is not a first language such as Japan or China)

- Other (please explain)

\footnotetext{
${ }^{8}$ If all likert scale questions are worded positively, there is a risk that respondents will develop an automatic, reflex habit of consistently circling 2 or 3 (or any other number) that has recurred earlier in their questionnaire. By adjusting the wording of questions so that they do not all reflect a positive theme, it is thought that the respondent is more likely to stay engaged and not resort to providing automatic responses.
} 
Q10. Do you currently hold any teaching certificates? If yes, please circle all that apply.

- B.Ed. If no, please proceed to Section 2

- CELTA

- Other (please indicate name and duration of certification

My goal, as Nardi (2006) advises, was to enable respondents to provide answers candidly and accurately. For example, on the topic of designing likert-scale questions, Nardi suggests that if the direction of statements is mixed (by ensuring that not all questions related to a particular set of opinions will lead respondents to always "agree" or "disagree"), we can reduce the occurrence of response bias $^{9}$ and reduce the likelihood that respondents will answer according to what he/she feels is socially desirable (p. 76-80). I also took advantage of this concept of mixed directionality by asking similar questions but posed in a different direction as a strategy to measure internal respondent reliability ${ }^{10}$. For example, the questions below measure the same construct (feeling pressure to teach a certain way) but employ different directionality of wording:

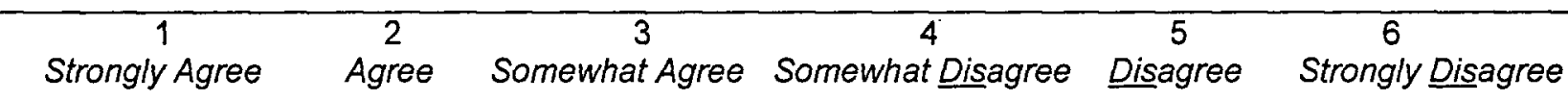

17 During my practice teaching, I sometimes feel pressure to teach a particular way.
1
2
3
4
5
6

20. Ifeel free to experiment and try out new ideas in my practice teaching.

1

2

3

4

5

6

\footnotetext{
${ }^{9}$ Response bias tends to occur when respondents "answer most questions in the same way, such as simply checking 'disagree' for all the questions" (Nardi, 2006, p. 78)

${ }^{10}$ Internal respondent reliability measures how reliable each respondent is when answering questions. In other words, on questions that measure the same construct, how consistent are the participant's responses? See question \# 17 and \# 20 above.
} 
These two questions appeared on two separate pages. I intentionally spaced them apart as I thought this would more effectively determine internal respondent validity.

As can be seen in the above example, I also chose a six-point scale with no neutral category. Nardi (2006) and Johnson \& Christensen (2000) provide the following rationale for omitting a neutral category: respondents will be forced to express their opinion on the likert-scale statement, rather than being given the option to remain non-committal. I was not concerned that the CTESL student respondents would not have an opinion on any of the 15 likert-scale questions as each statement was relevant to their practicum course requirements and practicum placements. As Johnson and Christensen (2000) note, "a key to effective questionnaire construction is understanding your research participants" (p.129). For this reason they recommend trying "to develop an empathetic understanding, or an ability to 'think like' your potential research participants" (p.129). In this respect I feel I had an advantage as I had already completed the CTESL program the previous academic year and, having interviewed the practicum course instructor prior to distributing the questionnaire, had a sense of how their course requirements were similar or different to my own CTESL student experiences.

I employed a six-point scale which included strongly agree and strongly disagree because I wanted to measure how intensely the respondents felt about each statement. I chose a likert-scale going from strongly agree to strongly disagree as this was the direction of agreement shown in questionnaire examples provided by Nardi (2006), de Vaus (2002), and Johnson and Christensen (2000). However, I am aware that some researchers prefer to use the reverse order, beginning with strongly disagree and moving across to strongly agree. In fact, this was the case for the study by Romano (2005) who looked at how well a teacher education program was meeting the needs of pre-service elementary school teachers. This questionnaire was helpful to me because several of the likert-scale statements related to reflective assignments asked of the 
student teachers. Although I chose a likert-scale agreement that had a reverse order to the one Romano used, I did adapt several of her questions and used them in my questionnaire ${ }^{11}$

\section{Demographic Information: Best Requested At Outset of Questionnaire}

Several scholars writing on the topic of questionnaire development recommend asking respondents to provide demographic information at the end and not the beginning of the questionnaire (De Vaus, 2002; Davies, 2007; Nardi, 2006). However, I found their rationale for this to be either completely absent or wanting. If researchers are expected to ask "easily answered questions" at the outset and progress from "concrete to abstract" and place open-ended questions toward the end (de Vaus, 2002, p. 110-111), it does not appear logical to then switch back and have the questionnaire end by asking simple, concrete, bio-data based questions. Nardi (2006) does shed some light on the issue, however, by suggesting that "after some fatigue or impatience in having to fill out a survey, most respondents prefer to end the session just checking boxes that are simple to answer" $(2006$, p. 85$)$.

My critical response to this is twofold: first, if researchers make it a priority to locate and ask respondents with a similar profile to the target respondents to complete the questionnaire and keep a record of the time, these same researchers can better predict the length of time the survey will take to complete and can thus avoid respondent fatigue. From this point they can a) decide if they need to reduce the survey to demonstrate greater respondent sensitivity; and b) inform the research participants how long the survey generally takes to complete. Second, when distributing a questionnaire to adults who have numerous years' experience filling out forms for health, work, tax, housing, legal, and educational purposes where they are routinely asked to provide personal demographic information at the outset, it seems odd to request that these adults go

\footnotetext{
${ }^{11}$ See Appendix $\mathrm{C}$ for copy of questionnaire; note that questions 11,12 , and 13 were adopted from Romano (2005).
} 
against convention and provide the same type of information at the end of a questionnaire. For these reasons, I deliberately chose to ask demographic questions at the beginning of my questionnaire.

The questionnaire was divided into three sections. Section 1 asked demographic-related questions such as gender, age range, as well as previous teaching and language learning experiences. Section 2 asked the CTESL students to respond to 15 likert-scale statements. Section 3 consisted of four open-ended questions that asked respondents to comment on 1) what they had found most valuable in their practicum course experience so far, including their placement; 2) what concerns they had experienced at the outset of the program in September 2008 with regard to their first practicum placement; 3) what future concerns they had about teaching English; and 4) what aspirations they had regarding teaching English. I included these open-ended questions because I wanted to give voice to the experiences of CTESL students during their second practicum placement. I wanted these TLs to "answer in their own words" so that I might "see or hear respondents' actual words" (Hutchinson, 2004, p. 293). However, I also knew that open-ended questions were more time-consuming for the respondent to answer and more difficult to code than closed-ended questions; for these reasons I limited them to four.

\section{Pilot Testing the Questionnaire}

Prior to visiting the practicum course in February 2009 for recruiting purposes, I asked three fellow M.A. students who had recently graduated from the CTESL program to complete the questionnaire. This was not a pilot study, but rather was a pilot test intended to measure the effectiveness of my research instrument. As Drew, Hardman, and Hosp (2008) explain, a pilot test involves "asking a few individuals to complete the questionnaire before the actual study begins" and should "be conducted with individuals who are similar to the respondents in the sample" (p.171). Asking the three M.A. students to complete the questionnaire and provide me 
with feedback allowed me to assess if my questionnaire was sufficiently brief, contained "culturally and developmentally appropriate content" was "presented in a clear, unambiguous format" (Hutchinson, 2004, p.289). If these conditions were met, I knew I would be able to "yield the highest response rates and the most trustworthy data" (Hutchinson, 2004, p.289).

All three M.A. students were asked to document the amount of time the questionnaire took for them to complete and to write notes on the questionnaire after they had completed it to indicate if any sections seemed ambiguous or problematic in any other way. The issue of timing was important because it is believed that "the less effort required" and "the shorter a questionnaire is", the "more likely a respondent is to complete and return [it]" (Drew, Hardman, \& Hosp, 2008, p.126). All three students indicated that it took them approximately 15 minutes to complete the questionnaire, which I felt was a good indicator of appropriate length. Two of the three students made suggestions for how to change the wording on two different questions to increase the transparency of what was being asked. I followed their advice, revised the questionnaire, and then made copies ready for distribution.

\section{Distributing the Questionnaire: Class Visit}

On February 9, 2009, I visited the CTESL students in the last 30 minutes of their practicum course. I began by providing an overview of my study and then indicated that I hoped to recruit them to participate in my study. I made sure to inform the M.A. students in the group that I was not be seeking their participation in my study because of my previously established connection with several of them which I felt might influence my objectivity as a researcher. Both the instructor and I emphasized that participation was voluntary. Before distributing the questionnaires in plain, unmarked envelopes, I explained that both I and the instructor would leave the room in order to respect the privacy of those students who did or did not want to complete the questionnaire. I informed the group that the questionnaire would take 
approximately 15 minutes to complete. I explained that each envelope contained a recruitment letter ${ }^{12}$, two copies of a consent and information letter $^{13}$ and the questionnaire. I also explained that I was interested in recruiting students for Stage 3 of my study, involving one-on-one interviews, and that the questionnaire would ask them to indicate their willingness to participate further in my study. The envelopes were then distributed and I informed the group that I would return 20 minutes later, emphasizing again that those who did not wish to participate could simply return the envelope to the desk at the front of the class and leave class early.

When I returned 20 minutes later, only one student, who had just finished completing the questionnaire, remained in the class. Of the 17 undergraduate and postgraduate students present that day, 14 chose to participate in Stage 2 of my study. I was very pleased with this high response rate. Additionally, four students indicated that they were interested in participating in Stage 3 of my study. In the following two weeks, I began a preliminary analysis and basic coding of data from each questionnaire. My analysis of data from this questionnaire then influenced the scope and content of questions that I asked in stage 3 .

\section{Stage Three: One-on-One interviews with CTESL Students}

Stage 3 involved one-on-one semi-structured interviews with four student teachers who had indicated on the questionnaire that they would be willing to participate further in my study. All four teacher learners provided their university email address so that I could contact them to arrange for a 30-40 minute one-on-one interview. My goal was to document, through one-on-one interviews, how certain CTESL students perceived their practicum experiences and the CTESL program as a whole, as well as their ongoing development as both novice and experienced

\footnotetext{
${ }^{12}$ See Appendix D

${ }^{13}$ See Appendix E
} 
teachers. And I wanted to dig deeper to come up with some possible answers for patterns that had emerged in my initial Stage 2 data analysis.

As an M.A. student who had completed the CTESL program just one year prior, I was aware of the need to avoid over-identification with student participants during Stage 3 and 4, the interview process. My knowledge and understanding of the practicum experience is situated and originally stems from having gone through the CTESL process myself. For this reason, from the outset of this case study I wanted to be mindful of any potential researcher bias I might have or be susceptible to. Davies (2007) cautions researchers who "already feel at home" in the field they have chosen to research to "work hard at being open to interpretations and patterns that differ from (their) own prior assumptions" (2007, p.157).

Having read the work of Silverman and Marvasti (2008), I understood that there is "no golden key to validity", but that I could, as a qualitative researcher, increase the validity of my findings by "actively seeking out and addressing anomalies and deviant cases" (p.259-264). Rather than cherry-picking data that supports a researcher's initial research hypothesis or emerging theories, a critical examination of all data, known as comprehensive data treatment, is needed (ibid). I reminded myself of the need to seek out experiences different to my own during all four stages of the research process.

To prepare questions to include in my interview guide for Stage 3, I read over the completed questionnaires from Stage 2. Drawing from this preliminary form of data analysis, I was able to identify which areas of emerging importance I felt needed to be explored further in Stages 3 and 4. I employed an informal or simpler version of the constant comparison method (Silverman \& Marvasti, 2008) by comparing the demographic portrait of each respondent (gleaned from the first section of each completed questionnaire) against the group as a whole. A very basic theme of group diversity emerged when looking at the age range of the CTESL 
undergraduate and postgraduate students: six were in the 20-24 range; one was in the 25-29 range; three were in their 30s; two were in their 40s; and two were in the 50 plus range.

This age range diversity is important because I noticed the same kind of diversity in the CTESL students who had agreed to be interviewed in Stage 3: one was in the 25-29 range; one was in the 30-34 range; one was in the 35-39 range and one was in the 50 plus category ${ }^{14}$. All four of the participants already had an undergraduate degree; although, in the case of the oldest student teacher, she was completing her second undergraduate degree in Linguistics. Regrettably, none of the youngest (in the 20-24 year-old range) undergraduate students volunteered to participate in Stage 3. It is worth noting that three of the four student teachers who agreed to be interviewed had previous language teaching experience (PLTE).

After contacting each of the four CTESL students by email to thank them for their time and agreeing to be interviewed, I set up an interview schedule, providing each participant with a range of dates and times to choose from. The first interview took place on February 24, 2008, and the last interview took place on February 27, 2008. All four interviews took place on campus in the same private room that I had reserved ahead of time. I began each individual interview by thanking the student participant for volunteering their time and then gave them the information letter and consent form to sign.

The one-on-one interviews with four CTESL students allowed me to follow-up on individual responses from the questionnaire completed in Stage 2 that I felt warranted further investigation. For example, I noted that all 14 respondents indicated on their questionnaires that they valued observing their host teacher(s) teach in their classroom, with a range going only from strongly agree to agree. In Stage 3, I decided to probe further to find out what in particular was most valuable about this observation process for the four TLs who had agreed to be

\footnotetext{
${ }^{14}$ See Table 7.1 on page 135 for a demographic profile of the 4 TLs in Stage 3 and 4
} 
interviewed. Another area I wanted to investigate further was the agreement of all 14 respondents who indicated that they found talking about their practicum experiences with other students to be beneficial. In Stage 3, I saw an opportunity to find out why these four TLs valued sharing their practicum experiences with their CTESL peers.

Two other areas that I wanted to explore further were the range of responses concerning students' experiences of online learning and their ability to link educational theory with practice teaching. When asked if they found the online discussion group to be beneficial and whether they had experienced difficulty linking educational theory with practice, responses ranged from strongly agree to strongly disagree. As well, my decision to follow-up on these questionnaire responses was connected to my research question concerning students' appraisal of different forms of reflection as well as their experience of collaborative learning.

Each interview began with educational and work-related questions to provide me with a clearer picture of each student participant and to determine what he or she individually brought to the CTESL program. Given the program's focus on collaborative learning, I felt it was important to gather this type of background information. In other words, if a constructivist model of learning was employed, where student teachers were actively responsible for constructing meaning in a collaborative environment, I needed to know more about the individuals constructing the collective knowledge-base. Also, following the tradition of gathering rich qualitative data, asking participants to describe their educational background and previous work experiences enabled me to "see" four of my student participants more vividly. The following table provides a brief sketch of the demographic profile of participants in Stage 3 and 4 : 
Table 3.2: Demographic Profile of Stage $3 \& 4$ Participants

\begin{tabular}{|c|c|c|c|c|}
\hline Pseudonym & Gender & Age & Education & Previous Teaching Experience (PTE) \\
\hline Karen & Female & $25-29$ range & $\begin{array}{l}\text { B.Ed. } \\
\text { B.A. in History }\end{array}$ & $\begin{array}{l}3.5 \text { years teaching grade } 1-8 \text { and core } \\
\text { French in Ontario }\end{array}$ \\
\hline Marek & Male & $30-34$ range & B.A. Comparative Lit & $\begin{array}{l}4 \text { years teaching EFL in Asia, mostly } \\
\text { children }\end{array}$ \\
\hline Alima & Female & $35-39$ range & $\begin{array}{l}\text { B.A. English Lit } \\
\text { M.A. English Lit }\end{array}$ & $\begin{array}{l}5 \text { years teaching English Lit to high } \\
\text { school students in the Middle East }\end{array}$ \\
\hline Elaine & Female & 50 plus & $\begin{array}{l}\text { B. Engineering } \\
\text { B.A. (in progress) }\end{array}$ & No PTE \\
\hline
\end{tabular}

Each interview was semi-structured, allowing me to ask some of the same questions to all participants while in other instances pursue particular areas of interest as they emerged. Questions consistently asked of all four CTESL students include: 1) their educational and work background; 2) how their second practicum placement compared to their first placement; 3) what they had learned from observing their host teachers; 4) their experience of online versus inperson discussion groups; 5) their experience of individual reflection; 6) insights on their own experiences as language learners; and 7) their future career goals.

The four semi-structured interviews were recorded using the same SONY microcassette that had been used with the course instructor. However I also took extensive short-hand notes during each interview as I realized I would not have the time to finish transcribing all four interviews before starting the group interview. I also spent approximately 30 minutes after each interview filling in my short-hand notes with observational details about the exchange that had taken place, something that Kleiber (2004) recommends doing. Prior to the group interview 
which took place on March 11,2009, I reviewed my notes that I had written during and after each interview. I analyzed and synthesized answers from these questions as well as from other questions that emerged during the interview process to come up with preliminary findings and compared them to themes that had emerged in Stage 2 from the questionnaire responses. This in turn led me to revise questions for my final stage of data collection, the group interview.

\section{Stage Four: Group Interview with CTESL Students}

In Stage 4, the final stage of data collection, I conducted a semi-structured group interview. Each participant from Stage 3 had been contacted by email to ask if they would be interested in participating in a group interview. Fortunately, all four participants indicated they were. My main goal in interviewing CTESL students in a group setting was to gain further insight into the collaborative nature of learning that forms the core of the CTESL program. By arranging a group environment, I could effectively "listen in" to the conversation of four TLs as they discussed issues related to their program, reflective teaching and practicum experiences. As Kleiber (2004) notes, in this group environment, researchers are able to gather data "not available through individual interviews or surveys" because of the unique social interaction between research participants (p.97).

While I employed many of the strategies and organizational features of a focus group, the research design of Stage 4 should be considered a group interview, not a focus group. This concept of bringing a group of people together for research purposes in a setting other than the standard focus group is outlined by Stewart, Shamdasani and Rook (2007). They describe alternative group methods such as the nominal group technique (NGT) which retains aspects of the focus group structure but is notably different in the sense that participants may not actually meet one another. Although not as different as the NGT approach, the group interview method that I employed for Stage 4 is still distinct from the standard focus group. Table 3.3 illustrates 
three differences between the two interviewing methods, namely the size of the group as well as the number of groups involved in the study. Table $\mathbf{3 . 3}$ also outlines several areas in common.

Table 3.3: Core Features of Focus Group vs. Stage 4 Group Interview

\begin{tabular}{|c|c|c|}
\hline Core Features & Focus Groups in General ${ }^{15}$ & Group Interview in this Thesis \\
\hline Size of the group & $\begin{array}{l}\text { Typically } 6 \text { to } 12 \text { people but can include as } \\
\text { few as } 4\end{array}$ & 4 \\
\hline Number of groups total & $\begin{array}{l}\text { Typically at least } 3 \text { and continued until } \\
\text { saturation point has been reached and/or as } \\
\text { resources allow }\end{array}$ & 1 \\
\hline $\begin{array}{l}\text { Number of questions } \\
\text { asked to members }\end{array}$ & $\begin{array}{l}12 \text { as uppermost limit for a } 2 \text {-hour group; } \\
\text { sometimes as few as } 5 \text { or } 6\end{array}$ & 8 (hence, similar) \\
\hline Main Objective & $\begin{array}{l}\text { To discover a range of opinions, ideas or } \\
\text { feelings that a purposefully sampled group } \\
\text { has about a particular topic and/or sub- } \\
\text { topics; reaching a group consensus is not } \\
\text { the objective }\end{array}$ & $\precsim$ SAME \\
\hline Advantages & $\begin{array}{l}\text { Group dynamic offers a synergy and } \\
\text { spontaneity unlike } 1 \text {-on-1 interviews or } \\
\text { surveys }\end{array}$ & $\precsim$ SAME \\
\hline Disadvantages & $\begin{array}{l}\text { Participants may portray themselves as } \\
\text { being more reflective and thoughtful than } \\
\text { they actually are (Krueger \& Casey, 2009) }\end{array}$ & $\begin{array}{l}\text { Small size of the group means that not as } \\
\text { many opinions were voiced }\end{array}$ \\
\hline
\end{tabular}

As can be seen in the advantages section of Table 3.3, the strength of both group methods is the aspect of spontaneity and synergy that a group brings to the interview process.

Rather than a simple two-way conversation between researcher and research participant that occurs in one-on-one interviews, group interviews allow for exchanges to occur between and

\footnotetext{
${ }^{15}$ Information provided in the above table was taken from the following sources: Krueger and Casey (2009); Stewart, Shamdasani and Rook (2007); and Kleiber (2004).
} 
amongst participants. Krueger and Casey (2009) note that "as participants answer questions, their responses spark ideas from other participants. Comments provide mental cues that trigger memories or thoughts of other participants - cues that help explore the range of perceptions" (p.35). This interactive process where participants build upon each other's comments, also known as snowballing, conveniently allows the researcher to step back and observe the exchange of feelings, experiences and opinions as they emerge and are shared amongst participants.

\section{Rationale for Including a Group Interview in the Research Design}

Although the Stage 4 group interview required more transcribing, analysis and coding, I felt this additional time was justified from a research perspective, particularly given the collaborative nature of the CTESL program. It made sense to interview the pre-service teachers as a group for two main reasons. First, many of the activities the CTESL students are required to do involve a great deal of group work, consisting of brainstorming, lesson planning and sharing their practicum experiences. Knowing that these TLs had already been working together closely for several months, my approach was to build upon and take advantage of this existing group dynamic. Secondly, as noted above, the synergy and spontaneity of a group interview was very appealing to me. I wanted to see how ideas would "emerge from the group", and understood that "a group possesses the capacity to become more than the sum of its parts, to exhibit a synergy that individuals alone don't possess" (Krueger and Casey, 2009, p.19).

Admittedly, as noted in the disadvantages section of Table 3.3, it was possible that participants in the Stage 4 group interview might portray themselves as being more reflective than they actually were (Krueger \& Casey, 2009). My response to this concern is that this can be said of any interview process, be it individual or group. Also, my two different sources of data from Stage 1 and 2 allowed me to triangulate my findings across data sets, meaning that I did not rely exclusively on interview data when analyzing and reporting on my findings. 
Also noted in the disadvantages section of Table 3.3 is the idea that four participants make for a small group. However, as authors Kreuger and Casey (2009) suggest, a small group of research participants can be seen both positively and negatively, given that "small groups of four or five participants afford more opportunity to share ideas, but the restricted size also results in a smaller pool of total ideas" (p. 60, italics added). Fortunately a range of opinions was exchanged during the group interview; this range of opinion in turn provided me with greater insight into the experiences of CTESL students, from both a novice and experienced teacher perspective.

The group interview included the following steps: 1) I asked participants to read the information letter and sign the consent form; 2) I then began the group interview by thanking participants for their time; 3) I established some group rules, including the need for each participant to speak one at a time (to give each member a chance to speak without being interrupted), to ask for clarification at any point as needed, and not to feel pressured to answer questions if they did not feel comfortable; 4) I reminded the group that the objective of the group interview was not to reach a consensus and that differing viewpoints were welcome; and 5) I also gave a brief sketch of the type of questions I would be asking;

Following the suggestion of Kleiber (2004) and Krueger and Casey (2009), I began by asking a question relevant to all four participants to ensure that each participant would be involved from the outset. As Krueger and Casey (2009) explain, the objective of the opening questions is "to get everyone to talk early in the discussion" because "the longer it is before someone says something in a group, the less likely he or she is to say something" (p.38). I therefore began the group interview by asking how many of them had finished their second practicum placement. All four responded to this question, indicating how many hours they had 
remaining. Although the question was factual and simple to answer, I chose this as an opening question because it prompted each participant to think about their second practicum placement.

The remaining six questions asked during the group interview related to themes such as the participants sense of development as English teachers, the role of reflection in the CTESL program, the perceived value of discussing practica with peers as well as group work and their recent experience with an end-of-term poster session, a highly collaborative group activity. And, as Kleiber (2004) suggests, I asked the group for their input on results from the questionnaire to "assist in the interpretation of what respondents may have been thinking when they answered a question" (p.92). Specifically, I wanted their input on why they and eleven of their peers had all indicated that the practicum was an essential part of the CTESL program.

Finally, the second to last question that I posed involved a written prompt. I gave each participant a written excerpt from a teacher educator who had used a baby bird metaphor when describing the student teacher's learning-to-teach process. I gave the group a few minutes to write down or mentally compose their response to the written prompt. When the group was ready, I made sure to ask the least experienced teacher, Elaine, to share her thoughts with the group before asking to hear from the most experienced teacher, Alima, who had visually indicated that she was ready to share her thoughts. This decision was linked to my awareness of researcher bias, namely that from reviewing my one-on-one interview transcript notes, I had noted that Alima and I seemed to view several issues from a similar perspective. Also, I wanted to make sure that the one novice teacher in the group, Elaine, had a chance to speak before perhaps being influenced by others. At one point Alima asked me for my opinion, but I indicated that I would wait until the end of the discussion to share my thoughts. I did this because I did not want to influence the scope or direction of the continued exchange among participants. 


\section{Chapter 4: Analysis}

In the previous chapter, I described the research methodology used in my study and indicated that each of the four stages in my research design informed and complemented the next. I reported how preliminary analysis was undertaken during data collection for each of the four stages, indicating how notes taken both during and after each interview were continuously reviewed to identify emerging themes of importance, enabling me to narrow my research focus.

In this chapter, I describe the analytical tools used and steps taken to perform additional and more thorough analysis of data collected from all four stages.

\section{Stage 1: Document Analysis and Interview with Practicum Instructor}

My objective when analysing the practicum course syllabus was twofold: first, I wanted to develop a holistic feel for how the course was organized and to understand the overall course objectives; second, I wanted to develop an understanding of the types of reflective activities that were being asked of the CTESL students. From here, I compared the reflective activities outlined in the syllabus to what I had read about in the GTE and LTE literature. Examining the practicum course syllabus in this way enabled me to adjust my interview guide and ask more course specific questions to the instructor during the one-on-one interview. After the interview with the course instructor and prior to subsequent stages of data collection, I reviewed the syllabus to solidify my understanding of the course.

Further to my initial analysis of the interview with the course instructor, I used open coding (Bloomberg \& Volpe, 2008) to identify segments of the interview text to code. By open coding, I mean that sections of the transcribed text were labelled using terms employed by the instructor or a paraphrased version of what was said. Thus the codes were not pre-determined before I began analysing my interview data. I chose an open coding approach instead of 
predetermined categories as I wanted to avoid coding sections of text based on what I expected to find. As Bloomberg \& Volpe (2008) advise, the main purpose of a qualitative study is to tap into the experiences of participants, to "find out what their experience is and to endeavour to understand it from their perspective" (p.103). The authors assert that this is best achieved by allowing the codes to emerge (hence, open coding) from the words of the participants themselves.

\section{Coding System Used for all Transcribed Text: Stages 1, 3, and 4}

Sections of transcribed text for interviews with the course instructor in Stage 1, one-oneinterviews with CTESL students in Stage 3, and the group interview in Stage 4 were all coded using a bracketing system. Johnson and Christenson's (2004, p.503) provide a great example of what a bracketed system for segmenting coded text might look like, which I duplicate here:

Book learning

Experiental learning
[It's one thing to read about teaching in books; ] [It is another to actually go into a real classroom, with real students, and actually try to teach them something. Basically, I think there is something to learning by experience.]

As can be seen in the above example, the data is coded using brackets and is segmented according to meaning. The first segment, labelled Book learning, consists of one sentence. The second segment, Experiental learning, consists of two sentences. As Johnson and Christenson (2004) explain, "segmenting and coding go hand in hand because segmenting involves locating meaningful segments of data and coding involves marking or labelling those segments with codes or categories" (p.503, italics added). 
Similarly, Bloomberg \& Volpe (2008) indicate that coded text can encompass different types of segments, from single words to sentences to whole paragraphs. Importantly, this means that a qualitative researcher is not restricted to using the exact same unit of analysis when coding transcribed text. In this way, a meaningful unit may switch from being a sentence to two sentences. The researcher is not restricted by only one coding structure as the focus is on meaning, which is not pre-determined or confined to the sentential level.

When coding meaningful segments of transcribed data from the interview with the course instructor in Stage 1, I employed a similar bracketing system to the example provided above. Following the advice of Johnson and Christenson (2004), I also created a separate master list to record all the codes used in my research study, ensuring that this list included "each code followed by the full code name and brief definition of the code" (p.504). While using the words or paraphrased word of my participants, I also used abbreviated terms to save time, something that the above mentioned authors suggest doing. As well, next to the definition of each code, I created an additional column labelled links that was used to note consistencies and inconsistencies among participant comments from the questionnaire responses, one-on-one interviews and the group interview. These links helped me triangulate data sets. The master list was recorded in Microsoft Excel and enabled me to apply codes from earlier stages of data collection to new segments of text, which in turn allowed me to begin the data reduction process.

The codes recorded in the master list were both descriptive and inferential (Miles and Huberman, 1994), in the sense that I described exactly what participants had said or written and then, in some cases, created an additional code to make inferences about what was said. This inferential coding process often occurred after comparing and making links among different participants' comments. Miles and Huberman (1994) indicate that both descriptive and inferential coding of one segment of data text can be useful in an exploratory study as this type 
of dual coding legitimately represents "two necessary levels of analysis" (p. 65). Example 4.1 contains transcribed comments from the practicum course instructor and illustrates how a segment of data text was coded and recorded using descriptive codes. Example 4.2 shows how the segmented data was recorded in the Excel master list document.

\section{Example 4.1}

[It's important for the student teachers to make a connection with their mentors to be able to have an opportunity to learn from them] [It's sometimes a bit of a balancing act because many of the adult ESL teachers do have a lot of demands on them. They may be leaving right after the class, or they may be doing some prep for their afternoon class. So time is often a big issue. And, at the same time, the other demand on a mentor teacher is that their first priority is their own students in the classroom. And so the questions at the end of the class that they really want to answer are for their students, not necessarily the CTESL student]

Impo.of.st.mentor.connect

Obstacle.to.st.mentor.connect Lack.time.issue

\section{Example 4.2}

\begin{tabular}{|l|l|l|l|l|l|}
\hline Code & Codedescription & Code \# & Page (s) & Frequency & Links? \\
\hline Impo.of.st.mentor.connect & $\begin{array}{l}\text { Instructor } \\
\text { explains that } \\
\text { CTESL students } \\
\text { need to connect } \\
\text { with their host } \\
\text { teacher to be } \\
\text { able to learn } \\
\text { from them }\end{array}$ & 86 & $7(x 2)$ & 2 & $\begin{array}{l}\text { This idea is } \\
\text { supported by } \\
\text { Stage 2 data } \\
\text { from } \\
\text { questionnaire. } \\
\text { See coded } \\
\text { responses to } \\
\text { open-ended } \\
\text { question 1, } \\
\text { Section 3 }\end{array}$ \\
\hline
\end{tabular}

Finally, Example 4.3 on the following page shows an example of inferential coding with the inclusion of the code labelled Instructor.reflect.course; it is inferential in the sense that the instructor did not explicitly state that she had reflected on the course but it is clear from her description that this has occurred. The inclusion of this inferential code is important given the focus on reflective teaching in the practicum course and the nature of my research questions. 


\section{Example 4.3}

[As the CTESL instructor, and depending upon how many years you've been doing it, you can become quite distant from the actual reality of the classroom. I think it's wonderful for us to be back there and to see the reality.] [I can then think about what it is that might be important to include in the curriculum, issues that I might want to reference either through additional readings or discussions in the classroom or thinking about, 'Right, maybe we should bring that person in as a guest speaker.'] [You have to be grounded. The only way to be grounded in this particular field is to be in the adult ESL classroom].

Value.pract.site. visit Instructor.reflect.course

Need.to.be.grounded.instructor

All subsequent interviews with the CTESL students were coded using the same system of open coding; however, in some cases I used existing codes that had emerged during Stage 1 and Stage 2 data coding and in other instances, saw the need to create new codes. After I had finished coding all data text from all four Stages, including participants' comments on the completed questionnaires, I began making thematic connections between codes and where appropriate, grouped similar codes together and collapsed more detailed codes into larger themes. In this way, I continued the data reduction process.

\section{Coding Questionnaire Data from Stage 2}

To code the data from the completed questionnaires, I used two different analytical tools. Before entering data generated from the likert-scale responses into a Statistical Package for the Social Sciences (SPSS) database, I assigned each respondent a number, beginning with 1 and ending with 14. For the bio-data information such as student participants' gender, age, program type, L1, and previous language teaching experience (PLTE), coded numbers were assigned to each response (for example, 1 for female and 2 for male). This numerical data was then entered into an SPSS database. Next, students' responses on the likert-scale questions, ranging from 1 (strongly agree) to 6 (strongly disagree) were recorded. From here I was able to analyse 
correlations between the range of responses to likert-scale questions and features such as age and PLTE. I then created box-plot graphs to illustrate significant findings. These findings are described in detail in Chapter 6.

A second analytical tool was used to code responses to the four open-ended questions in Section 3 of the questionnaire. First, I typed up the participants' responses in a word document. I used an open coding system to segment participant responses; however, many of the responses were quite similar and thus were coded using the same labels. The text generated from the four open-ended questions was much easier to code than the transcribed one-on-one interviews as there were only four responses to code and these were provided in a written format, not orally.

As with the coded text from the transcribed interviews, I added codes from Stage 2 to the existing Excel master list created in Stage 1 data analysis. Table 4.1 shows how codes were entered into this list and how columns were adjusted to show the respondent number as well as which question the coded responses refer to:

Table 4.1: Example of Coded Data from Stage 2 Questionnaire (Open-ended Questions)

\begin{tabular}{|l|l|l|l|}
\hline Code for Q26: Value Most? & Code Description & Respondent \# & Frequency \\
\hline [Obs.HT.value] & $\begin{array}{l}\text { Student values observing his/her host } \\
\text { teacher (HT) }\end{array}$ & $\begin{array}{l}1,3,4,6,7,9,10, \\
11,12,13,14\end{array}$ & 11 \\
\hline [Obs.HT.value.why] & Why student values observing his/her & & \\
\hline & $\mathrm{HT}$ & $6,7(\times 2), 12,14$ & 4 (why) \\
\hline [PT.value] & Student values practice teaching (PT) & $\begin{array}{l}3,4,5,8,10,11, \\
12,13,14\end{array}$ & \\
\hline [PT.why.value] & Why student values PT & $3,5,11,14$ & $4($ why) \\
\hline
\end{tabular}




\section{Chapter 5: Results from Stage 1}

In the previous chapter, I described the analytical tools used and steps taken to perform in-depth analysis of data collected from all four stages. In this chapter I share the results obtained from analyzing the practicum course outline and the transcribed interview with the course instructor in Stage 1.

\section{Stage 1 Practicum Course Syllabus: Findings}

As indicated in the previous chapter, I analyzed the practicum course syllabus in order to understand the course instructor's objectives and to understand the types of reflective assignments asked of the CTESL students. I compared the reflective activities on the syllabus with activities described in LTE literature. Table 5.1 illustrates this comparative process:

Table 5.1 Comparison of Practicum Course Syllabus with Scholarly Sources

\begin{tabular}{|l|l|c|}
\hline Reflective Assigniment & Description of Assignment & Mentioned in Kiterature? \\
\hline L2 Learner Interview and Paper & $\begin{array}{l}\text { Interview L2 learner and then } \\
\text { prepare report re: key issues }\end{array}$ & \multicolumn{1}{|c|}{ Yes } \\
\hline Lesson Planning \& Group Blog & $\begin{array}{l}\text { Design lesson plan; work with } \\
\text { other students and post online }\end{array}$ & Yes but without blog component \\
\hline $\begin{array}{l}\text { Discussion Group: In-person } \\
\text { (Fall) and Online (Winter) }\end{array}$ & $\begin{array}{l}\text { Present a "situation" based on } \\
\text { practicum experience; involve } \\
\text { peers in the discussion. }\end{array}$ & $\begin{array}{l}\text { Yes but online component was } \\
\text { related to an existing list-serve of a } \\
\text { large group of practicing teachers }\end{array}$ \\
\hline Poster Session & $\begin{array}{l}\text { Present professional ESL } \\
\text { teaching poster to peers }\end{array}$ & \multicolumn{1}{|c|}{ No } \\
\hline Conference with Instructor & $\begin{array}{l}\text { Meet with course instructor to } \\
\text { discuss practicum site visit }\end{array}$ & \multicolumn{1}{|c|}{ Yes } \\
\hline
\end{tabular}

As can be seen in Table 5.1, four out of the five activities are linked to LTE related literature with two variations on the online component. For example, Carter (2008) describes an

\footnotetext{
${ }^{16}$ Sources consulted are as follows: Bailey, Curtis and Nunan (2001); Carter (2008); Farrell (2007); Crookes (2003); Freeman and Cornwell (1993); Johnson (1994); Numrich (1996); Richards (1998); and Richards and Lockhart (1994).
} 
online reflective activity where student teachers were required to reflect on the usefulness of an already existing ES/FL teaching list-serve as a tool to further develop their understanding of the field. In contrast, the CTESL students in this study were not asked to participate in an external website/list-serve, but rather were asked to use the university's online discussion tool, Web-CT, as a medium to share their lesson plan ideas and practicum experiences. As well, Table 5.1 illustrates how the idea of a poster session was not mentioned by any of the consulted sources. Despite the apparent novelty of the poster session, however, it is clear that this activity is very much in line with other reflective assignments that require both individual and group reflection.

Illustrating the types of reflection asked of CTESL students, Table 5.2 also shows the frequency of the four types of reflection: individual, collaborative/group, online and in-person.

Table 5.2: Overview of Reflective Assignments Required of CTESL students

\begin{tabular}{|c|c|c|c|c|}
\hline Reflective Assignnent: & $\begin{array}{l}\text { Individual } \\
\text { Reflection? }\end{array}$ & $\begin{array}{l}\text { Collaborative } / \\
\text { Group Reflection? }\end{array}$ & $\begin{array}{l}\text { In-person } \\
\text { Reflection? }\end{array}$ & $\begin{array}{l}\text { Online } \\
\text { Reflection? }\end{array}$ \\
\hline L2 Learner Interview and Paper & Yes & No & No & No \\
\hline $\begin{array}{l}\text { Lesson Planning \& Group } \\
\text { Blog }\end{array}$ & Yes & Yes & Yes & Yes \\
\hline $\begin{array}{l}\text { Discussion Group: In-person } \\
\text { (Fall) and Online (Winter) }\end{array}$ & Yes & Yes & Yes (1/2 time) & Yes (1/2 time) \\
\hline Poster Session & Yes & Yes & Yes & No \\
\hline Conference with Instructor & Yes & Yes & Yes & No \\
\hline Frequency TOTAL: & 5 & 4 & 3.5 & 1.5 \\
\hline
\end{tabular}

Both Table 5.1 and 5.2 are important as they directly relate to my first research question: face, online, individual, and collective? 
These tables are relevant to above research question in the sense that, prior to data collection, I needed to understand the reflective course requirements asked of CTESL students.

The frequency total in Table 5.2 shows how often CTESL students were required to participate in a particular form of reflection. Note that individual reflection, as it is experienced in the practicum course, appears to be a prerequisite to collaborative reflection involving peers. This is not to say that two or more CTESL students are not capable of reflecting spontaneously with their peers when listening to other students talk about their practicum experiences, but it is to say that individual reflection in the CTESL practicum course is the most frequent form of reflection and always occurs prior to group reflection. This is significant because it suggests that the course instructor highly values individual reflection. Similarly, the frequency of collaborative reflection, evident in Table 5.2, suggests that the practicum course instructor sees value in having individual teacher learners share their reflections with peers.

\section{Stage 1 Interview with Practicum Course Instructor: Findings}

In this section I report on findings from Stage 1 data that relate to my four research questions as well as significant themes that emerged from the data. First, I describe: 1) the practicum course objectives from the instructor's perspective. I then report on the following significant themes: 2) lack of time issues; 3) benefits and challenges of different reflective assignments; 4) the instructor's view of reflective teaching; 5) the instructor's own reflections; and 6) the instructor's perception of CTESL student teachers' experiences.

\section{1) Practicum Course Objectives:}

In order to better understand the reflective assignments that were asked of the CTESL students, I needed to first understand the course objectives from the perspective of the practicum course instructor. Specifically, I wanted to compare her stated course objectives during the one- 
on-one interview in January 2009 with the information provided to student teachers in the course outline in September 2008. The following table provides a summary of this comparison:

Table 5.3: Practicum Course Objectives: Interview vs. Syllabus

\begin{tabular}{|c|c|c|}
\hline 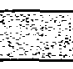 & Course Objectives Mentioned During Interview & Stated on Syllabus? \\
\hline 1) & $\begin{array}{l}\text { To have student teachers make links between educational theory } \\
\text { and teaching practice via a) observation and b) practicum teaching }\end{array}$ & Yes \\
\hline 2) & $\begin{array}{l}\text { To understand not just the practice of teaching ESL, "but to } \\
\text { understand multiple practices" (Interview with course instructor, } \\
\text { January } 9,2009 \text { ) }\end{array}$ & No* \\
\hline 3) & $\begin{array}{l}\text { To have student teachers learn from "not only from their own } \\
\text { practicum but other students' practicum experiences as well" (ibid) }\end{array}$ & No* \\
\hline 4) & $\begin{array}{l}\text { To provide student teachers with opportunities to reflect upon their } \\
\text { practicum experiences }\end{array}$ & No \\
\hline 5) & $\begin{array}{l}\text { To encourage TLs to see value in reflective teaching during their } \\
\text { practicum and as part of ongoing professional development }\end{array}$ & No \\
\hline
\end{tabular}

As can be seen from Table 5.3, four of the five course objectives that the instructor identified during the January 9, 2009 interview are not explicitly stated in the course syllabus. However, it is important to note that the instructor said she explicitly shared objectives 2) and 3) with CTESL students during regular class time. For the purposes of this study, Table 5.3 is important because it illustrates how a comprehensive understanding of the practicum course cannot be gleaned from analyzing the course syllabus alone. It shows how a one-on-one interview with the instructor was essential to understanding her course objectives. In turn, these stated objectives provided insight into the expectations the course instructor had for her own teaching as well as what she hoped CTESL students would take away from the practicum course. 
More importantly, the third objective stated during the interview, that of having TLs learn from "not only from their own practicum" but other students' practicum experiences as well, is directly relevant to my fourth research question, in terms of the focus on collaborative reflection:

What are the teacher learners' appraisal of the four different types of reflection: face-to-face, online, individual, and collective?

On the topic of collaborative learning and the need for TLs to learn from one another, Sarah $^{17}$, the course instructor, comments:

Each student will attend one practicum each term, which means they get two opportunities [in total throughout the school year]; but, in addition to that, the objective of the course is to provide sufficient opportunity for dialogue and discussion around what it means to be in the ESL classroom ... So learning not only from their own practicum but other peoples' practicum experiences as well. It sort of creates that multiple vision, multiple view of what the classroom could be like for their own experiences upon graduation (Interview with Sarah, page 1, January 9, 2009).

Later in the interview, Sarah reiterates this point, explaining that:

To go back to what I mentioned earlier. . .multiple practicum practices: how do we learn from each other and not simply silo the practicum experience - for one teacher for one location? ... We can only go to two practicum sites over the course of the year but in fact we can learn from 24 if we all dialogue and communicate with each other (Interview with Sarah, page 4 and 12, January 9, 2009).

Sarah revisits the concept of a silo later on in the interview. She considers the need for CTESL students to invest in connections with other TLs during their practicum placements as an essential part of their development. She draws a parallel between how individuals construct meaning in their everyday lives and how TLs construct their understanding of what it means to teach ESL. Going back to the idea of a constructivist model of teacher learning outlined in Chapter 2, we can see how Sarah's concept of teacher education involves active student learning; she views student knowledge as situated and mutually constructed. In her words:

\footnotetext{
${ }^{17}$ This is a pseudonym.
} 
Being [a] teacher without any connection to others - is an isolating position to be in. And one that I think limits the development of knowledge on the part of the individual ... I believe that the CTESL students benefit from having connections with others. When you're looking at the practicum experience, the student teachers are assigned to one practicum for 10 or 12 weeks. If it's their first and they're new at teaching English as a second language and [they] only went in and did only that, that would be what would inform [their] teaching. . .we don't grow up as individuals without multiple sources of information and knowledge coming in ... from that we make choices and we select and we look at things that make sense to us ... I think the same thing goes on with a CTESL student - physically it's not possibly for them to get into more than two practicum settings . . But hearing and learning about other practicum experiences really adds to that knowledge and then teachers can, ideally, begin to develop their own teacher sensibility from those multiple locations, some of them more intensely than others. Some of them more engaged than others. But you're learning from others. . .there's that dynamic going on, be it in the classroom or in their own networks that they form throughout the year (Interview with Sarah, page 10, January 9, 2009).

It is worth noting that Sarah recognizes that a range of student engagement can be expected regarding how committed individual TLs will be to the collaborative learning process. It is also worth noting that the dialogue and discussion that Sarah mentions involves both online (via Web-CT) and in-person forms of discussion. This is note-worthy because, as will be seen later in this thesis, CTESL students' appraisals of the online discussions were markedly different from their appraisal of in-person discussions.

\section{2) Lack of Time Issues}

A central theme that emerged while analyzing the transcribed data from my interview with the course instructor is that of a lack of time. Sarah identified the lack of time issue in three distinct areas: 1) in the practicum course that she teaches and the CTESL program as a whole; 2) on the part of the student teachers as they manage a full course load and practicum placement; and 3) on the part of the host teachers at various practicum sites.

Commenting on the amount of time that she and the Methodology instructor have to cover course material and create room for reflection and dialogue among TLs, Sarah notes: 
... there is just not enough time in the course to do all that you would like to do for reflection, for dialogue about the experiences. There is so much in a practicum or methodology course to share with student teachers, and so discussion times are limited and it's hard to manage a healthy discussion with limited time (Interview with Sarah, p.14, January 23, 2009).

Sarah's experience of not having enough time to foster long-term teacher development in her role as teacher educator is not unique. Crookes (2003) indicates that "there is not enough time in a practicum, or for that matter in an MA or certificate course, to do all the teacher development that might be desirable" (p.4, italics added). Note the similarity between Sarah's words and those of Crookes on the lack of time issue - they are almost identical. Elaborating on this issue, Crookes indicates that he has often reflected on how to best structure practicum courses "to compensate for their brevity" while meeting the challenge of supporting teachers' learning-to-teach processes "in connection with a practicum that would facilitate long-term teacher development" (p.20, italics added).

Although time is tight in the CTESL program, Sarah emphasizes that it is her goal to make time for students to reflect on their practicum experiences. She explains that "there's an objective of the course to provide opportunities for students to reflect upon their practicum experience. The challenge is trying to find the room within the course to be able to do that. But it is important to make room for that" (Interview with Sarah, p.15, January 23, 2009).

The lack of time issue is important as it directly impacts how the practicum course is organized. CTESL students are not required to go to their practicum course each week, but rather meet an average of nine times per semester. In the fall 2008 term, for example, three groups of eight students met on three separate occasions in November to discuss their practicum placements. Each group was assembled according to similar practicum placements: lower level community ESL, such as LINC literacy students; higher level community ESL, such as LINC 4, 
5, and 6; and advanced levels of English, such as English for Academic Purposes (EAP) and Enhanced Language Training (ELT) ${ }^{18}$.

The rationale for having three groups of eight students meet at separate times was threefold: 1) Each group would have similar practicum experiences to draw from and thus be able to follow and contribute to each other's chosen discussion points more easily; 2) Each group would be able to do so in a more intimate and less intimidating group environment than the whole class of 24 students; and 3) The remaining two groups that were not meeting that week, those not placed at a similar ESL setting, would be given a small break in their schedule for that particular week. As Sarah explains:

... the practicum is really demanding [for CTESL students], because somewhere in the balance of your week you have to find three hours to go to your practicum. And so we don't necessarily meet every week; it gives them [the student teachers] a little time to go away and do the practicum and then come back and either have a workshop or a discussion group. . .they're not coming every week; that's part of the curriculum (Interview with Sarah, p.14, January 23, 2009).

Sarah also identified lack of time as being an issue for the host teachers at participating practicum sites as well. Nevertheless, despite their busy schedules, Sarah said that host teachers routinely make time for CTESL students and many take on a mentoring role, sometimes emailing the TLs or talking with them on the phone outside of class. In her words:

It's important for the student teachers to make a connection with their mentors to be able to have to an opportunity to learn from them. It's sometimes a bit of a balancing act because many of the adult ESL teachers do have a lot of demands on them. They may be leaving right after the class, or they may be doing some prep for their afternoon class ... So time is often a big issue. . That being said, I do encourage the student teachers to meet with their teachers to organize a way in which

\footnotetext{
${ }^{18}$ First launched in 2004, ELT is fully funded by Citizenship and Immigration Canada (CIC). ELT is specifically geared toward Internationally Trained Professionals (ITP) who already possess strong English language skills but who need practical, work-related language study in order to break down the socialcultural barriers to finding work in their chosen or related field of expertise. Visit http://www.cic.gc.ca/english/resources/evaluation/elt/exe summary.asp for more information.
} 
they can ask questions and a lot of them have lots of opportunity during the week. Teachers are wonderful; you know, they'll have email conversations back and forth with them; some of them have phone conversation, particularly if they're going to be doing any short teaching activities. It's an opportunity for the CTESL student to get more insight into what is going on than simply through observation. (Interview with Sarah, p.7, January 9, 2009)

In addition to the issue of time, the above transcribed excerpt shows how many host teachers do form an integral part of the knowledge base that student teachers draw from while completing their CTESL program.

Sarah indicated that she wished there were more time in the CTESL program to allow for at least one meeting to take place among three major players in the practicum experience: between herself as the course instructor, the host teacher, and the student teacher. She considers it "really important to think of the practicum experience from the various participants involved" (ibid), suggesting that she, the host teacher, and the student teacher all have different roles to play but that these three roles are very much interconnected. She sees value in having the three players meet, but references a lack of time to date: "there hasn't been a formal dialogue or sitdown time with the three of us. I think that's something I would love to do. . but it goes back to that issue of time" (Interview with Sarah, p.8, January 9, 2009).

\section{3) Benefits and Challenges of Different Reflective Assignments}

Sarah has been teaching the practicum course for the past five years. In that time, there have been a range of reflective activities that she has implemented and experimented with. Some have been successful and deemed worthy of repeating in subsequent years; others have been less successful and therefore have not been repeated or have been adjusted accordingly. In this section, I report on how the course requirements for the 2008 to 2009 academic year (the time period during which the interviewed comments were made) differed from the previous year. Two major differences are worth noting. First, for the 2008 to 2009 academic year, the practicum 
course instructor decided that she would no longer require student teachers to complete journal reflections. Second, Sarah decided to re-implement an earlier group structure of having smaller groups assemble for pre-planned group discussions, rather than having whole class discussions. In this section, I also report on Sarah's experience with other reflective assignments, namely the practicum class visit and the end-of-year poster session.

\section{Journal Reflections: No Longer Part of Curriculum}

Sarah cited three problems that she experienced with having TLs complete journal reflections in the past. First, she felt the somewhat abstract nature of journal writing was too distant from the more familiar genres of academic writing typically asked of undergraduate and post-graduate students, such as writing a research paper or developing a lesson plan unit. According to Sarah, this led to some confusion as to what it was she was asking students to submit. Secondly, Sarah noticed a disconnect between her objective of wanting students to reflect on long-term teacher development issues with that of students who simply viewed a journal writing entry as a course requirement related to that particular semester of study. Thirdly, and related to the second issue, was the tendency for some CTESL students to view the assignment as simply a course requirement within the structure of a pass/fail grading system.

To expand on the first point, that of the somewhat abstract genre of journal writing, Sarah describes the confusion some of the TLs experienced when faced with the task of writing a reflective journal piece. Because journal writing is distinct from other assignments, such as a research paper that lends itself to "a clear rubric" to help answer many of students' questions, many of the questions that CTESL students had could not be answered. Sarah explains:

Often when I would present the journal, I was asked the question "What do you want to see in the journal?" So the student teachers were asking me what my expectations were for the journal. And often I found that it was difficult for the students to being to see that this was a paper really for them, rather than for me. The normal academic processes where a faculty member or an 
instructor might assign something and students fit into what is expected ... with a journal, it's very different: you're really looking at a paper that demonstrates your experience and what it is that you want to reflect upon - so there's a lot of choice. That was more difficult for some students to go through. I began to look at: are there other alternatives available that might still reach the same goal at the end but not go through that challenging 'what do you want - essay, paper, journal - kind of thing'? (Interview with Sarah, p.2, January 9, 2009)

Sarah describes how she found modeling the journal to be problematic in the sense that she felt it took away from the authentic aspect of journaling for oneself. She did not want students to view journaling as a genre that fit within a pre-determined format or modeled voice. In her words:

One of the difficulties with journaling was to try to model the journal without going back to what I started with - what they kept saying to me was 'Well, what do you want? What does it look like? How many pages? How many words?' - the very common questions that you would ask of an academic assignment. What I could model for them was reflective thinking and ways in which you might pose questions and ways in which you might look at alternative options and outcomes and things like that. But I couldn't model the journal or the model was just going to then allow somebody to then fit right into that model (Interview with Sarah, p.2, January 9, 2009).

The second problem that Sarah encountered with journal writing was getting students to view journaling as part of long-term teacher development, rather than simply an assignment to be completed for that particular semester. Commenting on this experience, Sarah noted that:

A journal was often seen as an assignment, and it was seen as something they just had to do at the end of December and at the end of April. Done that, completed 8 or 10 pages or whatever was required - again required - and [I had been] wanting to [have the student teachers] move beyond just submitting the paper and finishing it ... the possibility of longer-term change on the understanding of the student teacher. Is there another way that student teachers could begin to look at what it is that they're understanding in the classroom that might have a longer-term outcome in terms of how to reflect and how to implement reflection in their ongoing teaching? (Interview with Sarah, p.2, January 9, 2009)

Sarah builds upon this last point by adding that a reflective journal assignment is something she views as a part of a developmental "process" that warrants "a dialogue around the 
reflection" between student teacher and instructor (Interview with Sarah, p.2, January 9, 2009). Hence she views journal writing as having developmental value but remains unconvinced that all of her former CTESL students shared her perspective. Recall from Chapter 2 in this thesis that while many scholars maintain that journal writing for both pre-service and in-service teachers is highly beneficial (Brinton \& Holten, 1995; Brock, Wong, \& Wu, 1993; Carter, 2008; Johnson, 1994; Richards \& Lockhart, 1994; Ur, 1996), still others have acknowledged that this form of reflection, while having many benefits, also has a number of limitations, namely that not all teachers enjoy the process of reflective writing (Bailey, 1990; Farrell 2007; Richards, 1998).

However, while journals were not part of the practicum course requirements detailed in this study, the practicum course outline states the following: "you are encouraged to keep a daily $\log$ of your observations/experiences in your placements," and advises TLs that "your log notes will need to be detailed enough to help your remember the particular class/behaviour/event" to then "use this information later" to help with "presentations or group work" (Sarah's practicum course outline, pages 1-2). Thus CTESL students are explicitly encouraged, but not required, to write reflective notes about their practicum placements.

The third problem that Sarah experienced with journal writing, that of working within the confines of a pass/fail grading system, also relates to the second problem described above, that of students not always seeing the assignment as part of their long-term development as English language teachers. On the one hand, Sarah considers journals difficult to mark: "it is somewhat difficult to evaluate and to look at whether this is an A paper or a B paper in terms of when a student is doing reflection" and thus she sees merit in a pass/fail grading system (Interview with Sarah, p.3, January 9, 2009). On the other hand, she says that motivation for TLs to move beyond simply passing was not always there, particularly when faced with a busy schedule of four other courses and practicum site visits to plan for. As she describes it: 
... one of the challenges with pass fail is how do you allow students to see when they have done an exceptional piece of work and when they meet what is the minimum requirement in a pass/fail course? And given the pressures of the students and their own demands and everything else going on, often pass/fail simply becomes 'I've just done it' to do it. I can still pass. I don't have to reach and achieve. There isn't that motivation to achieve beyond simply doing it. And under multiple pressures and all kinds of things that are going on, sometimes students do come down to the wire and they just do it for the sake of doing it. And then I question, where's the reflection in that? I see conflict in it. I see the merits of both sides (Interview with Sarah, p.3, January 9, 2009).

For the three reasons outlined above, Sarah chose not to include journal writing as part of the 2008 to 2009 practicum course curriculum. I will now describe a second curriculum change that Sarah made to her course syllabus for the 2008-2009 academic year.

\section{Re-Introducing Smaller Discussion Groups}

As mentioned earlier, at the time of the interview in January 2009, Sarah had been teaching the practicum course for five years. During that period, she had experimented with both small and large group discussions. After reflecting on the effectiveness of having large group discussions in the 2007 to 2008 academic year, Sarah chose to re-introduce small group discussions as part of the practicum course requirements for the 2008 to 2009 academic year. In the fall 2008 term, students met once in small groups to present a practicum-related issue to members of their group. In the winter 2009 term, students met online to discuss practicumrelated issues, organized again in small groups.

To reiterate, in the fall term there were three groups total, separated according to: 1) TLs placed in an EAP or ELT classrooms; 2) TLs placed in a higher benchmarked community ESL classrooms such as LINC 4, 5, and 6; and 3) TLs placed at a lower benchmarked community ESL classrooms such as LINC 1 and Literacy. Again, for the fall term, only one group was required to meet at a time, allowing students from the two other groups to have a small break in their busy schedules. The goal was to ensure that CTESL students had a common 
point of reference for their discussions as well as a "more intimate setting for discussion and dialogue as opposed to the more standard large class" (Interview with Sarah, p.2, January 9, 2009). In other words, if TLs placed in a Literacy community ESL environment were listening to the practicum experiences of a TL placed in an EAP course at university, they would no doubt have a difficult time relating. And if CTESL students were encouraged to share their practicum experiences in a class with 23 other TLs, they might be less inclined to share than if they were in a group of only six other TLs. This last point is important because of Sarah's intent to foster collaborative reflection in the practicum course, to create opportunities for TLs to reflect individually and collectively, and thereby learn from one another.

Sarah identified a number of benefits associated with having CTESL students meet in person as well as online in small discussion groups. She also identified challenges that accompany these group discussions. In order to understand the benefits and challenges, it is necessary to first understand the exact nature of each discussion and what each student teacher was expected to contribute. For the in-person discussion groups, CTESL students were expected to take five minutes each to present a situation, recurring theme, or issue that they had experienced in their first practicum placement. They were instructed to ask a question to the other group members or create some type of activity to engage the group in reflection and discussion. In this way, each student was expected to act as both presenter and facilitator of discussion and collaborative reflection. For the online discussion groups, the course instructor led the initial group discussion. From there, students were expected to post and respond to discussion questions within their assigned group. Additionally students were required to work in their groups to create a number of lesson activities related to the English proficiency level of their practicum site ESL students (CTESL practicum course syllabus, September 2008). 
Sarah clearly views the smaller in-person discussion groups as beneficial for all TLs, including those who are shier to speak than their peers. She feels that all group members have an opportunity to learn from their peers in an informal, low-stress environment, commenting that:

If you have five or six or eight [students] sitting down talking about something, there's eye contact, there's an opportunity to ask questions ... it's a little less formal, a little less structured . . . everybody has a role to play in a group discussion; everybody has an opportunity to talk. No-one is forced to participate or ask questions ... I think the informal, small group environment allows for that. I also think people are really interested in hearing what other people are doing in their practicum and even to the quiet person, others will often say 'Well, what are you doing?' and they'll ask the person on their right or their left who may not have spoken up as much. . .everyone wants to pull their pieces in. And again, there's no structure to a group discussion per se and so some may speak for 15 minutes and some may speak for eight. But it's all meaningful (Interview with Sarah, p.13, January 23, 2009).

Sarah emphasized that smaller groups who share a homogeneous practicum context really do make for more successful discussions. She also emphasized that preparation time on the part of participating group members is key, commenting that they need to have "had some time to plan and think about what it is that [they] want to talk about" so that they can say: "OK, this is what I want to focus on. This is what I want to tell the others" (Interview with Sarah, p.13, January 23, 2009). Thus, in this context, individual reflection is a prerequisite to group reflection.

Sarah identified several challenges to fostering successful in-person discussions. First, is the recurring issue of having TLs see the discussion as part of their ongoing development as novice or more experienced English language teachers. Second is the issue of modeling the group discussion without limiting the nature and content of future discussions. In her words:

One of the challenges is: how do you flip it so that students don't see it as simply being a presentation? And they come prepared and they sort of ' $\mathrm{OK}$, I've made my little presentation. Phew. Done that - and I don't have to worry about it anymore' But rather to see it as a discussion and . . . not wanting to tell them exactly how to do it and exactly how to participate in a group discussion because you want it to have its own feeling, its own direction... I would like to encourage them to think about some things to come in with and 
how to encourage dialogue, but you have to just let it flow (Interview with Sarah, p.14, January 23, 2009).

The second point, that of not wanting to model the group discussion to students for fear of limiting the scope and nature of future discussions, takes on larger significance as Sarah shares that some of her CTESL students appeared to have misunderstood the goal of the activity. She explains that, prior to the group discussion, each group was provided with clear guidelines:

There was a handout and there was a flowchart and a checklist of what they needed to think about before coming into to the group discussion. Part of that checklist was to think about what activity or what questions do you have that will get the others engaged. I couldn't model that because if I did, again, I would be doing it for them, in advance. I would say that really limited understanding of what the expectations were around that as demonstrated in the absence of questions or an activity that students did after their discussion. It was a very interesting learning observation for me: probably a third of the class got it; a third of the class kind of knew what they were doing; and a third didn't get it at all. And so they presented their situation, and there was silence ... The outcome was that the discussions were great and the time spent was very valuable. But that part of the course requirement - I couldn't model it - but did they pick up on it? (Interview with Sarah, p.7, January 9, 2009)

The above comment is significant for two reasons: first, it appears that despite clear guidelines, approximately one third of CTESL students did not understand the collaborative nature of the planned discussions: they simply stuck with the somewhat standard presentation format of presenter shares and audience listens. Hence individual reflection may have taken place but the ensuing silence after the presentation meant that active group discussion and collaborative reflection did not take place. The above transcribed comment is significant for a second reason: even though one third of the group did not succeed in facilitating group discussion and reflection, the course instructor indicated that the group discussion that took place for the remaining two thirds of the time was very valuable. In other words, for those students who did understand (or who mostly understood) the collaborative intent of the activity, each was able to create an opportunity for both individual and group reflection to take place. 
With regard to the winter 2009 term, Sarah identified two benefits she anticipated TLs would take away from their online-based discussions. At the time of the interview, she had included an online learning component in her curriculum for two consecutive academic years. Sarah explained that CTESL students would be posting and responding to discussion questions:

By simulating group discussions around teaching and their practicum experiences, there would be two direct benefits: one, they'll get the experience of what it's like to be in an online group - the pluses and the minuses, absolutely - and, at the same time, they would have a forum for teacher reflection ... So the online learning allows ... does allow us to set up discussion groups and you can set it up in ways that you can have closed or open discussion groups, you can have everybody together or small groups... Within that forum, they can do what you could be doing in the classroom and they get the exposure to how that works (Interview with Sarah, p.4, January 9,2009 ).

The above comment suggests that online learning component of the course offers the benefits of in-person discussions with the added benefit of learning online.

But why is exposure to online learning so important for these TLs? Sarah describes a clear link to future employment opportunities, particularly in EFL, where CTESL graduates may be offered work online as part of a hybrid model of in-class language learning that is supplemented with online learning. Pre-service teachers therefore need to know how online learning works. And, from a pedagogical standpoint, Sarah notes a considerable amount of literature that "speaks to technology in the ESL classroom", and that "not to include it [a focus on ESL and technology] would be a gap in the program" (Interview with Sarah, p.4, January 9, 2009).

Although benefits of online learning were mentioned during my interview with Sarah, the topic of challenges associated with online learning did not come up. This is important, because, as will be discussed in Chapter 6, many CTESL students in Stage 2 of data collection indicated 
that they found online reflection to be the least useful form of reflection and expressed a strong preference for in-person reflection. The significance of this will be discussed in the next chapter.

\section{The Poster Session}

Sarah spoke very enthusiastically about the end-of-year poster session, which, at the time of interviewing, she had incorporated into the practicum course curriculum for four consecutive years. Her description makes it clear that a central goal of this assignment is to provide CTESL students with a forum for both individual and collaborative reflection. Equally important is the link that Sarah sees to long-term professional development, evident in the conference-like feel of the poster session. Rather than an isolated academic assignment, Sarah sees the poster session as an event where TLs share their reflections and knowledge in particular areas of ESL curriculum development. Sarah's enthusiasm for the poster session and her rationale for including it in the practicum course are easily identified:

The poster session is great. I love it. I'm a little biased toward it, but I do think it's great, for several reasons. The main purpose of it is to provide, again, an opportunity for the students to share a learning experience that they've had in their practicum setting with others. And I think that's the thread that runs through all the course requirements. The poster session allows a student to practice what might become a real possibility for them in their future as they participate in conferences. It's an excellent entrance into a more formal format for presenting at a conference, so for someone who's new to the field, it may be a little less intimidating to submit a proposal for a poster session than it is to submit a proposal for a formal workshop or a paper. But ultimately it also allows for 24 students to each create a poster; we split it up into 12 students for the first hour and 12 students for the second hour and each one takes a turn standing by their table. Informally, others just go around. So it's very much simulating that conference feel where the doors open at 11 $o$ 'clock and people come in and different people will gravitate to different posters and then sort of say 'Well, that's pretty cool. Why did you create that poster?' (Interview with Sarah, p.5, January 9, 2009)

Note how Sarah indicates that the common denominator in all the required course assignments is the sharing of "a learning experience" between TLs. This is significant because it supports the 
idea noted earlier (in my document analysis of the practicum course syllabus), that Sarah sees value in collaborative learning and reflection.

Another significant aspect of the poster session assignment is that Sarah believes it can be successfully modeled without compromising the TL's vision of how their poster will look and be presented. In this way, the poster session, from Sarah's perspective, stands out in contrast to journal writing, which she feels cannot be successfully modeled. She explains that:

On Web-CT, I put up a couple of links to poster sessions that are used in conferences. If you haven't ever been through a poster session, sometimes it can be a little bit confusing as to what is the expectation, 'what kind of poster do you want me to do?' So I put up several images from conferences up on the website ... they can see people mingling around in the room - I try to use pictures from TESOL ... I think in this case, because it can be quite distant for some individuals to make that connection between 'what do you want me to do' and the outcome. I think in some cases that modeling is important - I've found that by demonstrating it, it's much more successful than just trying to talk about it and hope that they understand it (Interview with Sarah, p.6, January 9,2009 ).

The above commentary is important simply because it reveals an underlying teaching philosophy of Sarah's: that some reflective activities can be successfully modeled and some cannot. Further, it reflects her position that, in some cases, modeling is necessary as it ensures greater comprehension on the part of her student teachers.

Even more importantly, the fact that Sarah sees value in modeling leads us to a recurring theme in the data set: that of loop input (Woodward, 1991). Recall from Chapter 2 that loop input is a used to describe parallel processes between ESL students and student teachers and/or TESL educators. In the case of modeling reflective activities, the parallel process or loop input is clear: Sarah sees value in modeling aspects of certain assignments to her student teachers much like many ES/FL teachers see value in modeling aspects of an assignment to their students. 


\section{The Practicum Site Visit}

Sarah also spoke enthusiastically about the practicum site visit, a new addition to the 2008-2009 practicum course syllabus. As stated earlier, the site visit involved either Sarah or the Methodology course instructor visiting one TL at their practicum site once during the academic year. This visit was followed by a one-one-consultation between the TL and instructor, designed to encourage more dialogue about ESL classroom practices. Noteworthy about Sarah's comments on the practicum site visit is the direct benefit that she, as the practicum course instructor, draws from the experience, as well as the potential benefits she outlines for the TL:

It's a way for the CTESL student and the instructor, as in, me, to make a stronger connection so that we [the Methodology course instructor and I] can have an opportunity to be a participant, for albeit a short period of time, in the classroom that the students are doing their practicum, so that I understand that environment. I get a feel for the physical environment, for the students, for perhaps some of the complex dynamics going on that they may be dealing with. And that could be things like physical space - a number of students attend multi-level classrooms. So that when the student teacher and I meet there's a really good opportunity for us to then talk about it. We can go through what happened during that hour that I was there - what happened during the 20 minutes that you may have been teaching within that hour. And it's so much richer if I've been there than if we just have office hours and they come and talk to me about a problem that they may have been having and I'm really not connected to their particular practicum . . . it's so valuable. I can't emphasize enough how important it is for me as the instructor of this course - being out there, being in their classroom, watching them for 20 minutes or an hour in some cases, interact with their students and then being able to talk to them about it. It's not an evaluation - it's simply an observation and a sharing of an hour with them. Then we've got something to talk about that we both share. I personally find it very rewarding (Interview with Sarah, p.8, January 9,2009 ).

Sarah's point about the practicum class visit not being an evaluation but simply an observation is an important one. Recent LTE literature (Farrell, 2007; Crookes, 2003) has emphasized the need for classroom observations to be a starting point for developmental dialogue with pre-service teachers, rather than evaluative and prescriptive in the sense of: how well have you met the predetermined teaching objectives? 
There is a connection between Sarah's intent to have TLs see value in reflecting on their long-term teacher development and her vision of the practicum site visit as a starting point for dialogue with CTESL students. When Sarah comments that she finds the visits to be personally rewarding, an important parallel can also be drawn: an apparent investment in her own long-term professional development. This parallel link is strengthened by the following comments:

As the CTESL instructor and depending upon how many years you've been doing it, you can become quite distant from the actual reality of the classroom. I think it's wonderful for us to be back there and to see the reality. I can then think about what it is that might be important to include in the curriculum, issues that I might want to reference either through additional readings or discussions in the classroom or thinking about, 'Right, maybe we should bring that person in as a guest speaker.' You have to be grounded. The only way to be grounded in this particular field is to be in the adult ESL classroom (Interview with Sarah, p.8, January 9, 2009).

This last point is important because it illustrates the value that Sarah draws from reflecting on the practicum site visits; it shows how this reflection informs (and will continue to inform) her own teaching practice (hence, reflection-for-practice). Worth remembering is that the practicum site visit was a new addition to the 2008-2009 curriculum. Sarah indicated that she plans to continue to organize site visits in future practicum courses. The value that she sees in reflecting on her own practice and staying 'grounded' can be summed up as a general theme of instructor reflection. This theme is connected to the next section in this chapter, that of Sarah's view of reflective teaching and snapshots of her own reflective thought processes as a TESL educator. Much like the instance of modeling noted on page 96, the occurrence of instructor reflection can be seen as another example of parallel processing or loop input.

\section{4) The Instructor's View of Reflective Teaching}

The following section describes Sarah's view of reflective teaching, her underlying philosophy of teaching, and her reasons for including reflective activities and assignments in her practicum course. 
When asked why she required TLs to do reflective activities and assignments in her practicum course, Sarah indicated the main pedagogical goal was to raise her students' awareness about their developing teaching practice. She elaborated on this point by sharing a series of reflective questions that she felt are important, questions she hoped her student teachers had begun to ask themselves during their practicum placements. In her words:

The main value of reflective teaching is to ensure that you are always cognizant of what you are doing in the classroom. Are you meeting both your objectives and the students' objectives? Are you always seeking out best practices for any given situation? Are you remaining open and curious? Are you mindful of all that is going on so that you can ensure that students are getting the best opportunity for acquiring the language? (Interview with Sarah, p.9, January 9 , 2009)

After sharing these reflective questions, Sarah went on to share key words that, for her, form an integral part of reflective teaching:

I think words that are really important [to reflective teaching] are being mindful, being curious, being open and being flexible ... I'm not sure that those are very formal terms - you know there are formal definitions of what reflective teaching is - but I think you have to integrate that [your own terms] into your philosophy of teaching. And my philosophy of teacher education is informed by that (Interview with Sarah, p.9, January 9, 2009)

In this way, we can see that Sarah's own teaching practice is informed by a series of reflective questions and key words, such as being mindful, curious, open, and flexible. Notice the emphasis on mindfulness, of always being cognizant of what you are doing in the classroom. Here again is clear evidence of loop input, in the sense that Sarah hopes her student teachers will adopt a similar reflective stance toward their teaching that she herself identifies as having. 
Sarah employs a metaphor ${ }^{19}$ for her role as teacher educator in encouraging CTESL students to become more reflective about their new or ongoing teaching practice. She presents the image of planting a seed:

If we can plant an initial seed within the student teachers that it's important to reflect on your own teaching and to continually seek out alternatives and options and questions - to take that mirror and look at what you're doing on occasion - then we've accomplished our goals in the practicum course and the program (Interview with Sarah, p.17, January 23, 2009).

The above comment reveals just how important Sarah considers reflective teaching: if she and the Methodology instructor (referred to as 'we') are able to convey the importance of reflective practice to CTESL students, and if these same TLs complete their CTESL program with the intent to be reflective teachers in the future, then Sarah believes she has succeeded in her role as teacher educator. Sarah is cautious, however, about the degree to which reflective seeds can take root during the course of two practicum placements. The issue of time resurfaces again:

\section{Because it's a new process, and like anything, when you're learning a new process, it isn't something that you immediately adopt . . . as you begin to gain more awareness about it, then it becomes a little more familiar and something that you can do. So, when I look at the student teachers, I think, 'If we've just started to get them to see that this is an important thing and to start using the vocabulary of reflection and thinking about it - 'and perhaps I could have' - then we're accomplishing our goals with the practicum (Interview with Sarah, p.17, January 23, 2009).}

From the above comment, it is clear that Sarah sees reflective practice as an ongoing process one she believes her student teachers will become increasingly familiar with through continued teaching experience, over time. Returning to the planting of seeds metaphor, one can suggest that reflective seeds require time, focused attention, and action to take root.

\footnotetext{
${ }^{19}$ Note that metaphors are understood to provide a gateway of understanding into TLs' views and beliefs about the process of teaching and learning (Farrell, 2007; Larrivee, 2008).
} 
Sarah's reflective comment of 'perhaps I could have' (that she hopes CTESL students will adopt), relates to reflection-on-action (Farrell, 2007; Ghaye \& Ghaye, 1998), as previously outlined in Chapter 2 of this thesis. Sarah hopes her students will recall particular moments of their teaching practice - such as lesson content, how they interacted with their students, or how they facilitated a particular activity - and then reflect on what they could have done differently. Note that this is distinct from reflection-for-action (Farrell, 2007), where teachers reflect upon aspects of their existing knowledge-base to plan for future, upcoming teaching moments. And yet the two are very much interconnected: novice and experienced teachers alike reflect on their teaching in order to improve and deepen their current and future practice.

\section{5) The Instructor's Own Reflections}

During my one-on-one interview with the practicum course instructor, Sarah shared a number of reflective thoughts about her teaching practice.

When asked about the pros and cons of a pass / fail grading system that she had to adopt as it was "already in process" when she first starting teaching in the CTESL program, Sarah indicated that had already spent some time reflecting on this very topic. She says: "I've found myself reflecting upon how is it that I can set up the course so that the students see the value of that [a pass / fail system that is non-evaluative]" (Interview with Sarah, p.3, January 9, 2009). This reflection, in turn, led to her decision to discontinue the practice of journal writing in the course, as she felt this type of assignment did not encourage the type of long-term reflective development she had previously hoped it would. Instead, working within the non-evaluative framework, she decided to re-introduce smaller discussion groups as well as introduce practicum site visits which then lead to CTESL student-instructor consultations. These two decisions clearly support her pedagogical goal of fostering dialogue between TLs and herself as part of long-term teacher development, rather than a one-time graded assignment. 
On the topic of online Web-CT-based discussion groups, first introduced in the 20072008 academic year, Sarah indicated that this is an area of the curriculum she often reflects on: "Two years ago, I began to look at: how could I expose them to online teaching? . . I've been reviewing and monitoring and thinking about the ways in which CTESL students can be made aware of technology through the Practicum and the Methodology course" (Interview with Sarah, p.4, January 9, 2009). When asked about the topic of in-person group discussions, Sarah indicated that she had reflected on aspects of a discussion group activity in the Fall 2008 term that did not go as well as she had anticipated. Although this issue was touched upon earlier in this chapter, it is worth revisiting because of the reflective tone in Sarah's account of what happened. Her reflective process takes the shape of having an internal dialogue or debate:

Here's a good debate I'm having with myself: the students in the past term were asked to do this group discussion... I would say that [there was a] really limited understanding of what the expectations were around that, as demonstrated in the absence of questions or an activity that students did after their discussion. It was a very interesting learning observation for me. . . that part of the course requirement - I couldn't model it - but did they pick up on it? Could modeling have benefited those who needed it? Great question. How do you play around with that one? (Interview with Sarah, p.7, January $9,2009)$

Note that the above excerpt is a clear example of reflection-on-practice: Sarah recalls a particular teaching moment in order to gain greater insight into her practice, with the related intent to benefit future CTESL students.

It is equally important to note that Sarah's reflective questions about modeling are not necessarily intended to be answered, as evident in her last question, how do you play around with that one? Rather, these questions suggest an overall inquisitive disposition toward her teaching practice and are in line with her previously cited teaching philosophy, one based on principles of being mindful, curious, open and flexible. In support of this inquisitive model of life-long teacher learning is the assertion by Crookes (2003) that "teachers working on their practice are similarly 
engaged in a process both of exploration and experimentation" (25-26, italics added). Neither exploration nor experimentation suggests the need to arrive at concrete, fixed answers; however, both terms suggest the need to ask questions.

Related to the issue of meeting the needs of her CTESL students is Sarah's goal of being aware of how individual and group dynamics play out in practice. She identifies the presence of loop input or parallel process: "Just as I teach about when to use groups and how to use groups and the effectiveness of groups, I think the same thing applies to CTESL. There's a time and a place for it ... you [as a teacher educator] have to be cognizant of that" (Interview with Sarah, p.13, January 23, 2009). Sarah indicates that she is also reflective about the range of learning styles that different student teachers have:

Some students like to plan out their learning. They like to have done their reading, they like to be able to sit back and take time. And if you throw them into a group discussion where they're being asked to speak spontaneously or they're being asked to throw out ideas and brainstorm and things like that well, for some people, that's not a preferred learning pattern; they're more confident if they're given some time. Some students are very tactile and really like working with material. So, for example, if you give three or four materials and you say 'come up with a lesson plan that you could do for LINC 1 using these four items' some students will get right into it because they can use the tools at hand - the manipulatives. Others would like to work first on a lesson plan just by themselves and work quietly through that and then begin to play with the materials. So I think all of those things come into play when you're working with CTESL students (Interview with Sarah, p.13, January 23, 2009).

Sarah's awareness that her students have a range of preferred learning styles is important, because, as Crookes (citing the work of Yee, 1990) notes: "becoming familiar with students, their backgrounds, their perspectives on learning ... is arguably a major aspect of teacher development" (2007, p. 42). The above interview excerpt is also significant as it reveals more loop input at play: Sarah is cognizant of different learning styles in the same way that she hopes 
her student teachers will become increasingly mindful of their adult ESL students' learning preferences and needs.

Sarah routinely engages in reflection between the fall and winter term each academic year. Her description of this reflective period indicates a pattern of reflecting-on-practice, with the intent to better reflect-for-practice. In Sarah's words:

What I tend to do is go through the fall term and I tend to reflect, quite a bit, usually over the holidays. I go back and look at the syllabus and I think "OK, did I do all of that?' There are always some unknown circumstances that come up. And then I usually look at what was scheduled for the winter, and 'Am I going to be able to do all of that?'- knowing the group, etc. So, you do a lot of that [reflecting]. What usually happens then in the first couple of weeks of January is you then implement a little bit of a revised schedule. . . I still continue to think about how I can encourage students to really reflect on their practicum experience. I sort of sway between thinking about what I could be doing more in the classroom to encourage that, to the understanding that - again, I go back to the idea of planting a seed (Interview with Sarah, p.13, January 23,2009 ).

What is interesting about the above comment is that Sarah is reflective about how she can best encourage her students to become increasingly reflective teachers. As such the loop input effect is obvious. Another interesting point is that Sarah's reflection-on-action, her ongoing reflections on knowing the group of CTESL students, has a direct impact on the shape of curriculum development from one term to the next. And, once again, there is a sense of internal dialogue or debate that Sarah is engaged in - referred to as tendency to sway between one line of action or pedagogical reasoning (doing more in the classroom to encourage reflective practice) and another (focusing on planting reflective seeds of thinking).

\section{6) The instructor's Perceptions of CTESL Students' Experiences}

Sarah indicated that she believes novice teachers are often chiefly concerned with issues that relate directly to them - such as lesson plan content and execution - and that they tend to be less aware of external issues, such as who their ESL students are as people. This is interesting 
because it supports Fuller's initial model of teacher development from the 1970s, as cited by Conway and Clark (2003), a model that suggested novice teachers, over time, tend to move from an inward focus of concern (such as designing an effective lesson plan) to outward concerns involving the needs of their students. Sarah comments that:

There is a sense of worrying about self and . . they are obviously, as new teachers, really wanting to do a good job and the focus is very much is on 'I really want to do a good job. I want my lesson to be successful. I've spent the last six hours planning this activity. I've poured my heart and soul into it (Interview with Sarah, p.17, January 23, 2009).

Sarah indicates that, for novice teachers, an inward focus on self is to be expected as they are likely somewhat "disconnected with who the students [they're working with] are" at this early stage in their development as teachers (Interview with Sarah, p.18, January 23, 2009). She explains that getting to know ESL students and thinking about their individual and group needs takes both time and experience:

Until you begin to develop a knowledge of who students are and understand from a practical perspective -- not just from a theoretical perspective about different learning styles and about different learners, you're not able yet to think from the perspective of the learner. That comes with time as you get to know what learners need. You're not able to think about the whole environment - the classroom, and the community, and the resources - you don't know them yet. . . As a new teacher, they often say 'Well, what do I do if?' What do I do if?' They don't know where to go if they have a challenge or a crisis on so many different levels. And again, the training that we provide for them is quite extensive, but ... there's only so much within a year that they can develop.... as they continue to practice then they'll gain more knowledge of those other areas (Interview with Sarah, p.17, January 23, 2009).

Due to their lack of previous language teaching experience, Sarah suggests that novice teachers benefit that much more from collaborating with their peers and from pooling their knowledge, ideas and insights. And given that some of the CTESL postgraduate students do have previous teaching experience to draw from, it makes sense that these same students will form an important part of the novice teachers' developing knowledge-base. As Sarah explains: 
As you begin to make networks with others and begin to see what other people are doing, you can have those conversations. They you [as a novice teacher] begin to also start thinking along other lines of what's possible (Interview with Sarah, p.17, January 23, 2009).

Again, the importance of collaborative reflection is emphasized. From Sarah's perspective, if a novice teacher is to develop a knowledge-base that incorporates both theory and practice, this process will require time, more teaching experience, deliberate reflection, and will be greatly enhanced through ongoing collaboration with peers, both during and after the CTESL program. 


\section{Chapter 6: Results from Questionnaire Data in Stage 2}

This chapter reports on findings from Stage 2, involving responses to both closed and open-ended questions on the questionnaire, completed by 14 CTESL students on February 9, 2009. First, findings from section one that relate to bio-data information will be reported on. Next, findings based on analysis to responses from 15 likert-scale questions in section two of the questionnaire will be shared. Box-plot graphs and other visuals will be provided to further explain my findings. Following this, findings from the third and final section of the questionnaire involving four open-ended questions will be shared.

\section{Bio-Data Information from Section 1 of Questionnaire}

The following findings relate to bio-data information collected from 14 undergraduate and postgraduate CTESL students. In section one of the questionnaire, respondents were asked to provide information on their gender, age group, undergraduate or post-graduate status, first language spoken, additional languages spoken, previous teaching experience and the nature of that teaching experience. Collecting this bio-data information was crucial for several reasons:

1. This bio-data helped me to "see" my research participants more clearly, both as individual teacher learners and holistically, as a group. This "picture" provided me with a context to better situate their answers to the four open-ended questions located in the final section of the questionnaire.

2. This "picture" allowed me to determine how the four TLs who agreed to be interviewed in Stage 3 and 4 of my study were similar and different to their peers who had not volunteered.

3. The bio-data information collected directly relates to my final research question: Do features such as age, gender, and previous language teaching experience (PLTE) appear to influence how receptive individual TLs are to the four types of practicum course reflection: face-to-face, online, individual, and collective?

4. Within the context of a constructivist model of teacher learning where student teachers are understood to be central players in their construction of personal 
theories of teaching and their overall teacher development, it makes sense that information on who these teacher learners are should be collected. In other words, if TLs are actively involved in constructing their knowledge-base of what it means to teach ES/FL, it is crucial that researchers have some insight into who it is that is constructing this knowledge, both individually and collectively.

Table 6.1, below, provides a summary of bio-data collected with regard to respondents' gender, age range, previous language teaching experience (PLTE), L1, and other languages spoken:

Table 6.1: Bio-Data collected from 14 CTESL students

\begin{tabular}{|c|c|c|c|c|}
\hline Gender, & Age range, & $\mathbf{L}$ & Other languages, & PLTE, \\
\hline Female $=11$ & $\begin{array}{l}\text { In } 20 \mathrm{~s}=7 \text { total } \\
\text { In } 30 \mathrm{~s}=3 \text { total } \\
40 \mathrm{~s} \& \text { older }=4 \text { total }\end{array}$ & $\begin{array}{l}\text { English = } 11 \\
\text { Serbian = } 1 \\
\text { Arabic = } 1 \\
\text { Polish = } 1\end{array}$ & $\begin{array}{l}\text { At least } 2 \text { languages at } \\
\text { intermediate level or } 1 \text { at } \\
\text { advanced level }=9 \text { total } \\
\text { At least one other language } \\
\text { at the intermediate level } \\
=4 \text { total } \\
\text { Only } 1 \text { other language at the } \\
\text { beginner level = } 1 \text { total }\end{array}$ & No $=10$ \\
\hline
\end{tabular}

Collectively, the group of 14 CTESL students who completed the questionnaire make up a diverse group of different ages, range of languages spoken, and previous language teaching experience. As can be seen from Table 6.1, there is a significant age range consisting of respondents in their 20s, 30s, 40s and older. While English is the L1 of 11 of the respondents, 3 respondents have a different mother tongue. This is important because first-hand experience with learning English as a second or foreign language could arguably be seen to contribute to the knowledge-base of this group in terms of what it means to learn English from both a linguistic and socio-cultural perspective. Also significant about the above table is the breadth of experience this group of CTESL students has regarding their reported ability of spoken proficiency in 
languages other than English. It is essential to stop and reflect on the fact that all of the 14 student teachers reported having an ability to speak a second language, and of the 14 CTESL students, 9 spoke at least two languages at the intermediate level or at least one other language at the advanced level. This is significant within the context of a constructivist model of LTE programs in the sense that this group of students may have drawn from their collective language learning experiences as they worked toward meeting the practicum course objective of bridging educational theory with practice while engaged in both individual and collective reflection.

Two other areas worth noting from Table 6.1 are the gender ratio of male and female CTESL students as well as the number of TLs with previous language teaching experience (PLTE). It is no secret that teaching is a female-dominated profession (Carter, 2008), and the data from my questionnaire clearly supports this demographic tendency. The second issue, that of PLTE, is also worth noting as almost one third of the respondents (4 out of 14) came into the CTESL program with at least three years' previous EFL, ESL or FSL teaching experience.

Collectively, these four TLs brought with them a total of approximately sixteen years of previous language teaching experience in Canada and abroad. Again, when we stop to consider how a constructivist model of teacher education operates, the significance of the breadth of experience that the four TLs bring into the program is obvious. It is worth noting that of these four TLs, three volunteered to participate in Stages 3 and 4 of my study.

One area of bio-data information collected from the questionnaire that is not covered in Table 6.1 (due to space limitations) is the undergraduate and post-graduate ratio of CTESL students. The ratio is split evenly, with 7 individuals enrolled as undergraduate students and 7 enrolled as post-graduate students. It is worth noting that out of the 7 undergraduate students, all of whom were in their fourth and final year of study, 6 of them were between the ages of 20-24. This means that the remaining 8 CTESL students out of the total 14 surveyed all experienced a 
break between their years of formal education and their decision to return to school. This fact is significant when we consider the role that increased life experience (encompassing things like work experience, knowledge of self, shifting career aspirations, travel, exposure to different cultures, etc.) may well play in a constructivist model of teacher education.

\section{Section 2: Findings from Likert Scale Responses}

In the following section, I report on findings from responses to the 15 likert-scale questions that appeared in the second part of the questionnaire. I also focus on findings that are significant according to Statistical Package for the Social Sciences (SPSS) data analysis in the area of correlation coefficients. While doing so I focus on findings relevant to the following research question:

Do features such as age, gender, and previous language teaching experience appear to influence how receptive individual students are to the four types of reflection: online, in-person, individual and collective?

Due to the range of answers that students provided regarding their motivation to obtain their CTESL, I was not able to assign a numerical value to this particular variable and was not able to run statistical analysis for this variable. However I was able to assign a number for the following variables: 1) age; 2) gender: 3) PLTE; 4) L1; 5) other languages spoken; and 6) type of student (undergrad or post-grad). In this section, I present 4 box-plot graphs to show significant relationships found between responses to likert-scale questions and two of the six variables just outlined. These graphs help illustrate the degree to which certain independent variables that do not change - such as CTESL students' age range - influence the value they place on particular forms of reflection or other practicum-related experiences.

Before I used SPSS to undergo additional analysis on data generated from section one and two of my questionnaire (bio-date information and responses to likert-scale questions), I first 
recorded all responses from the likert-scale questions into a Word document. I listed all 15 questions and then, consulting each completed questionnaire, tallied up the total number of responses, ranging from 1 (strongly agree) to 6 (strongly disagree). This allowed me to assess how the 14 CTESL students responded as a group. Though this form of analysis is admittedly quite simple, it was nevertheless very helpful in determining what type of reflection the CTESL group valued the most as a group, and conversely, what type of reflection they valued the least.

Again, this form of analysis served as a starting point, generating more questions that I then sought to answer using SPSS. For example, I noticed that all 14 respondents indicated that talking about their practicum with other students was useful, but that the same homogenous agreement did not occur when asked about how useful they found the online Web-CT discussion group. Here is a condensed version of the likert-scale responses from that original Word document, including responses that caused me to ask follow-up questions in Stages 3 and 4.

Table 6.2: Likert-Scale Responses that Generated Follow-Up Questions 1-strongly agree; 2 -agree; 3 -somewhat agree; 4 -somewhat disagree; 5 disagree; 6 -strongly disagree

\begin{tabular}{|c|c|c|c|c|c|c|c|}
\hline Q. & & 1 & 2 & 3 & 4 & 5 & 6 \\
\hline 11 & $\begin{array}{l}\text { In this course, I have had adequate opportunities to } \\
\text { engage in personal reflection. }\end{array}$ & 4 & 9 & 1 & & & \\
\hline 12 & $\begin{array}{l}\text { In this course, I have had adequate opportunities to } \\
\text { reflect with my peers. }\end{array}$ & 5 & 8 & 1 & & & \\
\hline 13 & $\begin{array}{l}\text { In this course, I have had difficulty linking educational } \\
\text { theory with my practicum teaching. }\end{array}$ & 1 & 3 & 4 & 4 & 1 & 1 \\
\hline 16 & $\begin{array}{l}\text { The practicum placement is an essential part of the } \\
\text { CTESL program. }\end{array}$ & 12 & 1 & 1 & & & \\
\hline 18 & $\begin{array}{l}\text { I value the opportunity to observe my host teacher(s) } \\
\text { teach in their classroom. }\end{array}$ & 10 & 4 & & & & \\
\hline 22 & $\begin{array}{l}\text { In this class, I feel comfortable sharing my practicum } \\
\text { experiences with other students. }\end{array}$ & 6 & 6 & 2 & & & \\
\hline 23 & $\begin{array}{l}\text { Talking about my practicum experiences with other } \\
\text { students is useful. }\end{array}$ & 6 & 5 & 3 & & & \\
\hline 24 & The online Web-CT discussion group is useful. & 1 & 2 & 6 & 3 & & 2 \\
\hline
\end{tabular}

Some of the questions that this early stage of analysis raised for me are as follows: 
1. Responses to questions 11 and 12 indicate respondents feel they were given adequate opportunity to reflect individually and collectively and question 23 shows a group consensus that collective in-person reflection (through sharing with peers) is beneficial. However this homogenous agreement is not found in the TLs' responses to question 24 that relates to online reflection. Question 24 shows that only 6 TLs somewhat agree that online discussions are useful; 3 somewhat disagree and 2 strongly disagree. Only 3 out of 14 TLs see a clear benefit to online discussions with their peers about their practicum placements. Why might this be?

2. Responses to question 16 shows that 12 out of 14 TLs strongly agree that the practicum placement is an essential part of the CTESL program, meaning that $86 \%$ of the group strongly agreed. What are some reasons given for this agreement?

3. Question 18 generated a lot of agreement among the 14 respondents, with 10 TLs indicating strong agreement and 4 students indicating regular agreement. Would the four TLs who agreed to be interviewed in Stage 3 and 4 be able to provide insight on why they and their peers found observing their host teacher(s) so valuable?

\section{Stage 2 Results Continued: Findings from SPSS Data Analysis}

Though SPSS is often used in quantitative studies involving a representative sample with the intent to generalize findings, this was clearly not my objective. The statistical analysis undertaken in Stage 2 of this study functioned as a preliminary step, allowing me to identify patterns within this particular group and to refine my focus of data collection in Stages 3 and 4. Results obtained via SPSS data analysis were part of an overall qualitative analysis. In this section, I report on the following findings:

1. There is evidence of internal reliability for questionnaire responses to likert-scale questions, i.e., evidence to suggest individual respondents responded consistently;

2. Previous language teaching experience (PLTE) has the most significant impact, affecting respondents' answers to question 13,18 , and 19 ;

3. Age has a significant impact on respondents' answers to question 21;

4. Although gender appears to affect respondents' answers to question 18, on closer examination, the responses are more likely attributed to PLTE. 


\section{1) Evidence of Internal Reliability: Responses to Likert-Scale Questions}

As indicated in Chapter 3, I decided to mix the directionality of two questions that measured the same construct but employed different directionality of wording:

\begin{tabular}{|c|c|c|c|c|c|}
\hline $\begin{array}{c}1 \\
\text { Strongly Agree }\end{array}$ & $\begin{array}{c}2 \\
\text { Agree }\end{array}$ & $\begin{array}{c}3 \\
\text { Somewhat Agree }\end{array}$ & $\begin{array}{c}4 \\
\text { Somewhat Disagree }\end{array}$ & $\begin{array}{c}5 \\
\text { Disagree }\end{array}$ & $\begin{array}{c}6 \\
\text { Strongly Disagree }\end{array}$ \\
\hline \multicolumn{6}{|c|}{ 17. During my practice teaching, I sometimes feel pressure to teach a particular way } \\
\hline 2 & & 2 & 4 & 5 & 6 \\
\hline \multicolumn{6}{|c|}{ 20. Ifeel free to experiment and try out new ideas in my practice teaching } \\
\hline 1 & & 2 & 4 & 5 & 6 \\
\hline
\end{tabular}

Again, one of the goals of including these two questions on the questionnaire was to help me assess internal respondent validity once the questionnaires were completed. Using SPSS software, I was able to run an analysis to determine evidence of reliability. The results indicate that responses from the questionnaire are in fact reliable:

Table 6.3: Correlations $^{20}$ for Questions 17 and 20

\begin{tabular}{|c|c|c|c|c|}
\hline & \multirow{2}{*}{$\frac{\text { Q17pressure }}{1.000}$} & \multirow{2}{*}{$\begin{array}{r}\text { Q20freedom } \\
.793^{2}\end{array}$} \\
\hline \multirow[t]{6}{*}{. } & & \multirow{3}{*}{$\begin{array}{l}\text { Spearman's rho } \\
\qquad \begin{array}{ll}\text { Q17pressure } & \text { Correlation Coefficient } \\
\text { Sig. (2-tailed) } \\
\mathrm{N}\end{array} \\
\end{array}$} & & \\
\hline & & & \multirow[b]{2}{*}{14} & \\
\hline & Q17pressure & & & \\
\hline & \multirow{3}{*}{ Q20freedom } & $\mathrm{C}$ & $.793^{\circ}$ & \multirow[t]{3}{*}{1.000} \\
\hline & & Sig. (2-tailed) & 001 & \\
\hline & & & 14 & \\
\hline
\end{tabular}

20 Correlation is significant at the 0.01 level 
Also, when I ran Spearman correlation coefficient analysis for all other likert-scale questions, I discovered a significant correlation for questions 21 and 23 . Although questions 21 and 23 do not measure the exact same construct, they measure two very similar constructs that both relate to the theme of collaborative learning. The following table shows that correlation coefficient:

Table 6.4: Correlations for Questions 21 and 23

\begin{tabular}{|c|c|c|c|}
\hline \multicolumn{2}{|l|}{ Spearman's rho } & Q21learn_peers_poor & Q23talk_useful \\
\hline \multicolumn{2}{|c|}{ Q21learn_peers_poo Correlation } & 1.000 & $687^{-1}$ \\
\hline$r$ & Coefficient & & \\
\hline & Sig. (2-tailed) & & 007 \\
\hline & $\mathrm{N}$ & 14 & 14 \\
\hline Q23talk_useful & Correlation & 687 & 1.000 \\
\hline & Coefficient & & \\
\hline & Sig. (2-tailed) & 007 & \\
\hline & $\mathrm{N}$ & 14 & 14 \\
\hline
\end{tabular}

Thus the correlation significance for questions 21 and 23 as well as 17 and 20 help establish the internal reliability of my questionnaire with respect to CTESL students' responses to the likertscale questions.

\section{Box plot Graphs: How to decipher them}

In the following section, I share four box-plot graphs that visually demonstrate how PLTE is the most significant feature in this study, affecting CTESL students' experience of their practicum placements. Before doing this, I refer to the work of Drew, Hardman, and Hosp (2008) who give an excellent summary of how to read box-plot graphs.

Box plots are used "to compare performance among groups on a continuous variable. Each group gets its own box that describes its performance (or responses to likert-scale questions) using the median and inter-quartile range" (Drew, Hardman, \& Hosp, 2008, p.278, 
italics and words in parenthesis added). In the case of my data, I looked at the responses of gender-, age- and previous language teaching experience (PLTE)-based groups. With gender, this resulted in two distinct groups; with age-range; this resulted in three groups; and with PLTE, two. The continuous variable is the likert-scale question which CTESL students answered; their answers can be conceptualized as performance.

The two boxes on the Box plot 1 graph show how two different groups of CTESL students have answered the same likert-scale question. On the horizontal side of the graph we see the two groups labelled vertically as group yes and no (those who do have PLTE and those who do not). Horizontally we see the likert-scale question that the two groups have responded to: In this course, I have had difficulty linking educational theory with my practicum teaching, coded simply as Q13 diffi_link. Horizontally we also see the full range of answers (from a total possible likert-scale range of 1-6) attributed to responses of both groups. A full range of answers can be seen in Box plot 1. Other likert-scale questions generated a much smaller response range. This can be seen in Box plot 2 where there the range of answers was very small - only 1 to 2 .

In this way, each box shows the full range of answers attributed to each group when they answered the specific likert-scale question. In Box plot 1 the yes group (those who do have PLTE) have a range of answers from 3 to 6 on the likert-scale. The no group have answers ranging from 1 to 4 . The bolded line in the middle of each box represents the median, or the middle range of answers from all members of that particular group. The line in the middle of each box can be understood as the 50th percentile; the bottom of the box can be understood as the 25 th percentile and the top of the box the $75^{\text {th }}$ percentile. The "whiskers" or stems that resemble the shape "T" at the top and an inverted "T" at the bottom of each box are understood to encompass the $10^{\text {th }}$ and $90^{\text {th }}$ percentiles (ibid). 
In Box plot 1 we can see that the median answer for those with PLTE (the yes group) is 4.5 and the median answer for those with no PLTE is 3.5 when responding to the statement: $I n$ this course, I have had difficulty linking educational theory with my practicum teaching. Thus

Box plot 1: Impact PLTE has on difficulty experienced linking theory with practice $e^{21}$

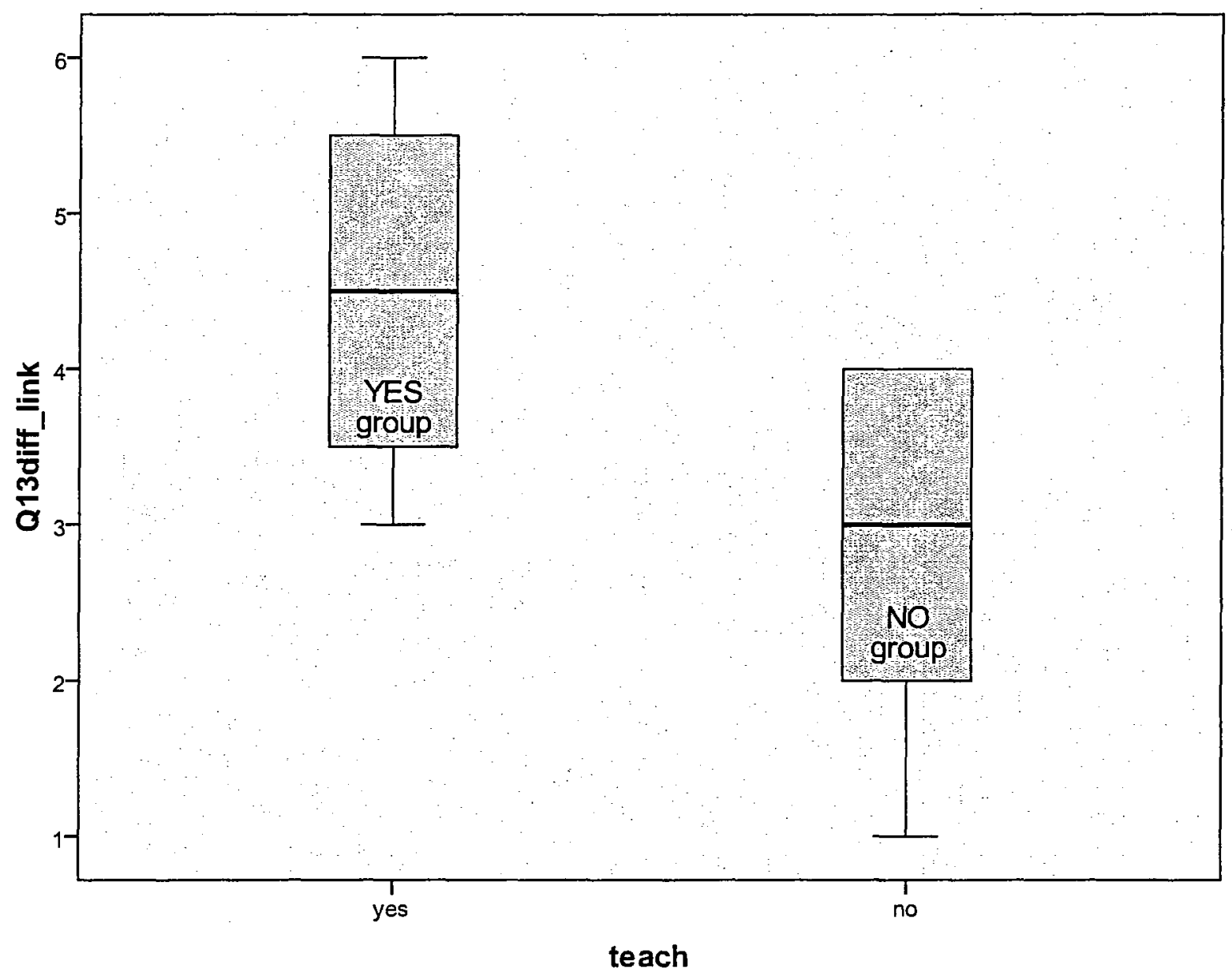

there is a full 1.5 scale difference in their answers. Also significant is that the end range for the no group is 4 , whereas for the yes group it is 6 . Clearly these two groups feel differently about this same likert-scale question. Thus box plots help demonstrate if features such as age, gender and PLTE made a difference in how 14 TLs responded to likert scale questions.

${ }^{21}$ Again, the statement students were asked to respond to was: In this course, I have had difficulty linking educational theory with my practicum teaching. 


\section{2) PLTE: Most Significant Feature}

Box plot 1 illustrates the significance that previous language teaching experience (PLTE) has on the degree of difficulty students experience when linking educational theory and practice.

This box plot ${ }^{22}$ clearly demonstrates the importance that PLTE plays in the degree of difficulty that student teachers (in this study) experienced or did not experience in their attempts to link educational theory with practice. Bearing in mind from Table 5.3, that one of the stated objectives on the practicum course outline was to have TLs make links between educational theory and teaching practice, the data shown in Box plot 1 takes on additional significance.

It is important to note that PLTE is the most significant feature in three different areas of the CTESL practicum. Box plots 1, 2 and 3 illustrate the following findings:

1. PLTE decreases the amount of difficulty TLs experienced linking educational theory with practice (link between PLTE and question 13 on the questionnaire). See Box plot 1.

2. PLTE influences how emphatically the 14 CTESL students valued observing their host teachers; those who had no PLTE saw greater value than those who had PLTE (link between PLTE and question 18). See Box plot 2.

3. PLTE influences the amount of feedback the TLs indicated they would have liked to have received from their host teachers; those who had no PLTE generally desired more feedback compared to those who had PLTE (link between PLTE and question 19). See Box plot 3.

The statement on question 18 of the questionnaire read: I value the opportunity to observe my host teacher(s) teach in their classroom and generated a very high agreement rate among all respondents, producing a very small range of response from 1 (strongly agree) to 2 (agree). Box plot 2, immediately below, illustrates how 9 out of 10 CTESL student respondents with no PLTE strongly agreed (responding with a 1) with the statement, whereas 3 out of 4 respondents who

\footnotetext{
${ }^{22}$ Recall that $1=$ strongly agree; 2 =agree; $3=$ somewhat agree; $4=$ somewhat disagree; $5=$ disagree; $6=$ strongly disagree
} 
had PLTE only agreed with this statement (responding with a 2). This distinction, although small, is nevertheless important. It is important for the simple reason that observation of more experienced teachers as well as one's peers is linked to critical reflection for both pre-service and in-service teachers (Richards, 1998).

Box plot 2: Impact PLTE has on intensity of value felt re: observing host teachers

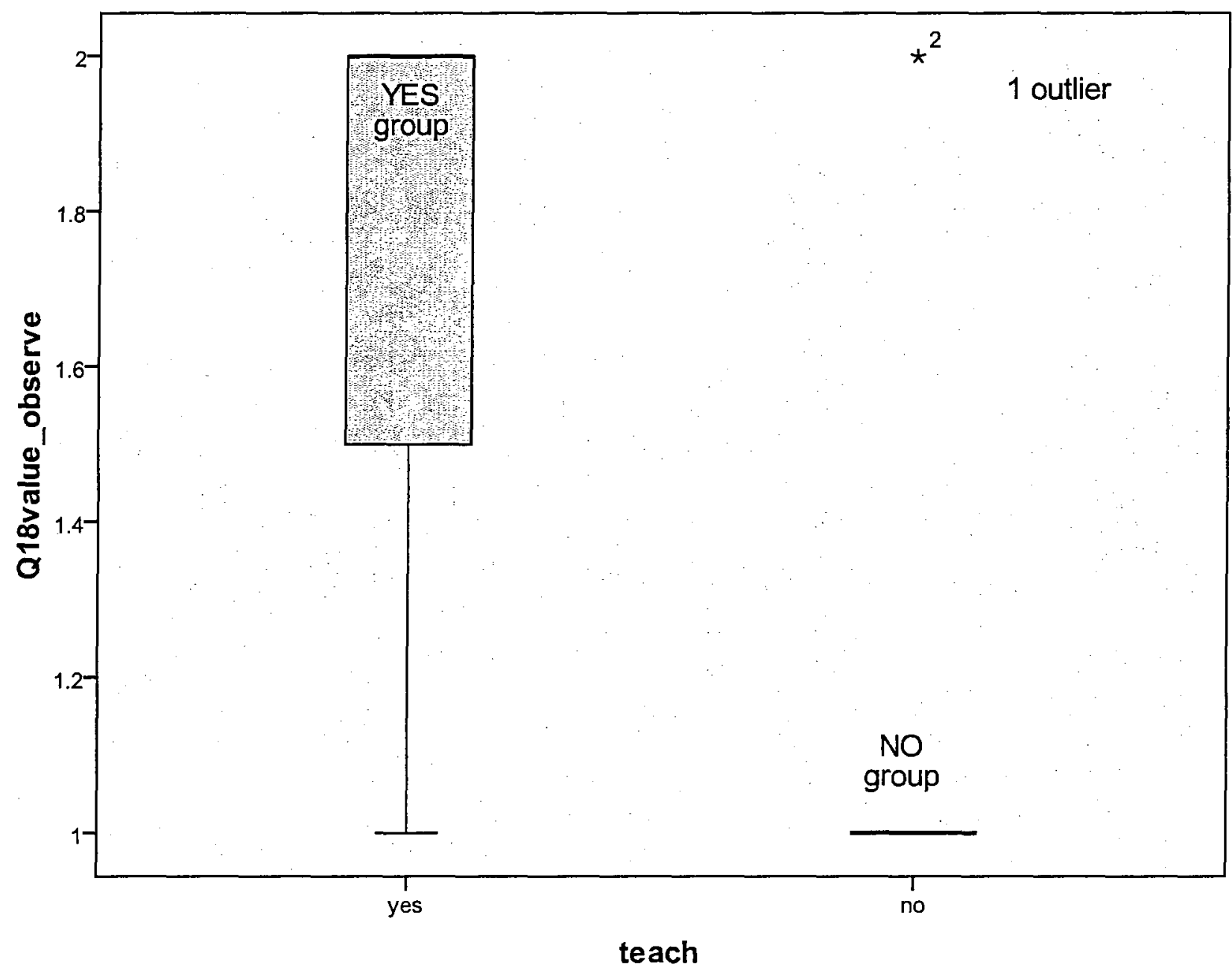

Notice the absence of "strings" or whiskers for those with no PLTE in Box plot 2. Note also the bolded middle line for both groups, representing the $50^{\text {th }}$ percentile. We can clearly see that the there is a full 1 scale difference in the answers between the yes group (those with PLTE) and the 
no group (those with no PLTE) with the median response for the yes group at 2 (agree) and the median for the no group is at 1 (strongly agree).

Although observation of one's host teacher(s) does not fit into the four types of reflection previously outlined in my research question, it nevertheless constitutes an important basis for critical reflection. It has been considered an essential part of LTE programs for over a decade now (Richards, 1998). CTESL students' appraisal of this form of reflection is therefore an important consideration in this study. A clear demarcation seen in Box plot 2 between those who have PLTE and those who do not with regard to how strongly they value observation of host teachers is worth reflecting on. The response of the outlier, respondent number 2 , identified by the ${ }^{*}$ symbol at the top right, will be discussed in Chapter 8.

Box plot 3 on the following page shows how PLTE influenced the degree to which CTESL students wanted to receive feedback from their host teachers; those who had no PLTE generally desired more feedback compared to those who had PLTE. The statement on question 19 of the questionnaire read: I would like to have more feedback from my host teacher regarding my teaching and generated a range of answers, from 1 (strongly agree) to 6 (strongly disagree). Despite this large spread of answers, we can see that the yes group's range is actually quite small: from 3 to 5 . And we can see the no group range is also quite small: from 1 to 3 for eight out of the ten students who had no PLTE. The two outliers ${ }^{23}$ in the no PLTE group, respondents 8 and 9 , had circled 5 and 6, responding with strongly disagree and disagree.

Fortunately, additional information was provided by one of the two outliers. Respondent 8 , who indicated strong disagreement by circling 6 , included the following comment next her circled response: received sufficient feedback. This comment is fortunate because it tells me that

\footnotetext{
${ }^{23}$ Though used most frequently in quantitative studies, I have used the term here simply because SPSS data analysis, even when used for qualitative studies, automatically shows "outliers" in Box plot graphs.
} 
her host teacher had met her needs in this particular area of her teaching development. Interestingly, respondent 8 is the only CTESL student out of 14 surveyed who wrote additional comments (a total of two) next to her circled responses.

Similar to Box plot 1 and 2, the bolded $50^{\text {th }}$ percentile line for each group in Box plot 3 shows a clear demarcation between those who have PLTE and those who do not.

Box plot 3: Impact PLTE has on amount of feedback desired by student teachers

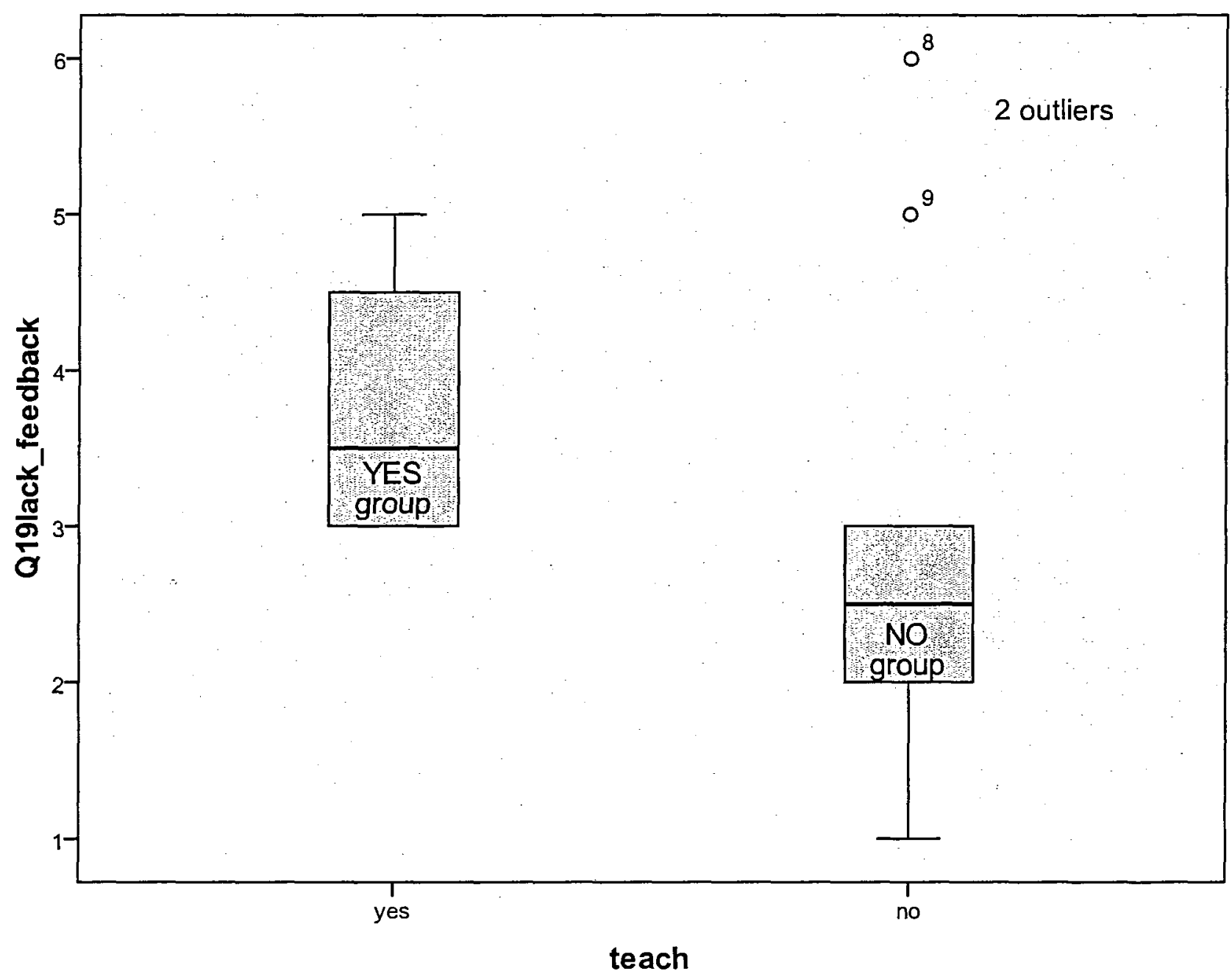

And, similar to responses to question 18 shown in Box plot 2, responses to question 19, illustrated in Box plot 3, show a full 1 scale difference in the answers between the yes and no 
group. Worth remembering from Box plot 1 is that answers to question 13 generated a full 1.5 scale difference in the answers between the yes and no group.

When looking at the data shown in Box plots 1, 2 and 3, it is clear that PLTE made a difference in how 14 CTESL students experienced three distinct aspects of their practicum placements. Thus PLTE is a significant feature in my study.

\section{3) Age Factor Significant re: Value placed on Learning from Peers}

Although age is not as significant a feature as PLTE is in this study, it nevertheless does appear to make a difference in one particular aspect of the practicum experience: the value that TLs placed on learning from their peers. Question 21 included the following statement: I seldom learn anything new when listening to my classmates talk about their practicum. Notice how the emphasis is on listening, rather than talking. Hence the focus of this question is: what value do TLs place on listening to the practicum experiences of their peers? Going back to the results from Stage 1, we know that the practicum course instructor considers collaborative learning and dialogue among student teachers an essential part of the CTESL program. Recall Sarah's view that "hearing and learning about other practicum experiences really adds to that knowledge [base]" and that, through listening to each other's experiences, "teachers can, ideally, begin to develop their own teacher sensibility from those multiple locations" (Interview with Sarah, page 10, January 9, 2009). Thus it is important to ask CTESL students for their opinion on this topic.

Box plot 4 on the following page suggests that age influences the degree to which students find listening to their peers to be an important source for learning. There is a wide spread of answers from 1 to 6 among all 14 respondents. Still, we can see a clear step-ladder effect from left to right: the median for group in their 20 s is 4 ; the median for the group in their $30 \mathrm{~s}$ is 5 and the median for the group in their $40 \mathrm{~s}$ is $\mathbf{6}$. However, despite the apparent 
significance of the age factor, we need to be mindful that the group in their 20s consists of 7 members and their answers only range from 4 to 6 , whereas for the group in their 30 s consists of only 3 members and their range is from 1 to 5 .

Box plot 4: Age factor and the value students placed on learning from peers



Interestingly, the group in their 40s has 4 members (more than the group in their 30s) and has the smallest range of answers from 5 to 6 . This means that students aged 40 and above all disagreed or strongly disagreed that they seldom learned anything from listening to their peers. In this way, we can make the argument that the "mature students" in my study do value learning more than their younger classmates. While making this argument we need to remember that the 
group in their $20 \mathrm{~s}$ all disagreed with the statement but did so with less intensity than their older classmates.

\section{4) Gender Significance re: Value Observing HT is likely misleading}

At first glance, it appears that gender, like PLTE, has a significant impact on the value that students place on observing their host teachers. Question 18, which included the statement $I$ value the opportunity to observe my host teacher(s) teach in their classroom, generated two different responses from female and male students. All 3 male respondents indicated agreement with this statement, whereas 9 out of 10 female respondents indicated strong agreement.

However, it is important to note that even though the data shows all 3 male students found observing their host teachers slightly less valuable than their female peers, this pattern is not conclisive. It is not conclusive because 2 of the 3 males each had at least three years' previous ES/FL teaching experience when they entered the CTESL program, meaning that the value they placed on observing their host teacher is just as likely attributed to their PLTE as it is to their gender. Again, consider Box plot 2, which shows the differences among those with PLTE and those with no PLTE: TLs with no previous language teaching experience value observing their host teachers more than the experienced teaching group.

\section{Stage 2: Findings from Responses to Open-Ended Questions}

In this section, I report on findings generated from responses to the four open-ended questions in the final part of my questionnaire. Before doing so, I share responses that students gave when asked about their primary reason for obtaining the CTESL (as indicated earlier, these responses varied considerably and could not be coded numerically). In the process of reporting on findings from the students' responses to the four open-ended questions, I quote a number of respondents directly. My rationale for doing so is to allow the reader to listen in to the voices of 
student teachers, rather than focusing exclusively on a paraphrased version of their thoughts. As Ralph, Wimmer, and Walker (2008) have noted, scholars need to listen carefully to what student teachers have to say about their practicum experiences as this remains an under-researched area.

\section{TLs' Primary Reasons for Obtaining the CTESL}

Table 6.5 provides a summary of the responses that the 14 TLs gave when asked: What is your primary reason for obtaining the CTESL? Although asked to identify a primary reason, a number of students gave two answers instead of one. For example, two students indicated they were motivated to gain both TESL Ontario certification and practical teaching experience. Here is a summary of their responses, ranked according to frequency:

Table 6.5: TLs' Primary Reason for Obtaining the CTESL

\begin{tabular}{|c|c|}
\hline Reason for Obtaining the CTESL & Frequency Total \\
\hline TESL Ontario Certification & 5 \\
\hline To gain practical teaching experience & 2 \\
\hline To teach ESL in the future & 2 \\
\hline To teach EFL in the future & 2 \\
\hline Qualifying year for M.A. in ALS & 2 \\
\hline Overseas travel opportunities & 1 \\
\hline Self-development, part of sabbatical & 1 \\
\hline Professional development & 1 \\
\hline
\end{tabular}

From Table 6.5 we can see that certification from TESL Ontario is the most frequent reason given for wanting to obtain the CTESL.

What is interesting about Table 6.5 is the diversity of responses that extend beyond the practical dimensions associated with certification processes. For example, overseas travel opportunities suggests an interest in exploring other cultures and is less linked to teaching aspirations when compared to the answer of professional development. Note that the student who indicated an interest in professional development already had 3.5 years' PLTE coming into the 
program and the individual who identified self-development as a central motivator had 5 years' PLTE. The respondent who indicated an interest in overseas travel - clearly not linked to professional teacher development - had no PLTE.

\section{CTESL Students' Future ELT-Related Aspirations}

In Chapter 2, I provided an overview of how Fuller's 1975 model of teacher development was adopted by Conway and Clark (2003). I also indicated how their study looked at both novice teachers' concerns and aspirations. Following this research pattern, I chose to ask the 14 CTESL students surveyed about their past and present teaching-related concerns as well as their teaching-related aspirations. In the following section I report on a range of future aspirations identified by the group of 14 CTESL students in response to the open-ended question: What aspirations do you have for your future as an English language teacher?

Recall the importance, as described in Chapter 1 and Chapter 2, of the need to identify how invested this particular group of student teachers appears to be in their long-term development as ES/FL teachers. Again, if reflective teaching is based on the premise that critical reflection is essential to ongoing professional development, and if reflective practice has indeed become an integral part of both LTE and GTE programs due to this established connection, we need to assess how invested CTESL students are in teaching ES/FL as a career. If students are only partially invested, the reflective model of teacher education may lose some of its relevance.

As can be seen from Table 6.6 on the following page, the majority (10 out of 14) of CTESL students indicated that they hoped to continue to teach English upon completion of the program. For the remaining four students who did not express an interest in teaching ESL or EFL, three of them expressed an interest in curriculum design and one of them indicated she was undecided. Respondent 4, who was undecided, commented that: "This may become a career 
shift, or it may remain an experience I learned from. I haven't decided yet" (underlined emphasis part of the original comment).

Table 6.6: CTESL Students' Future ELT-Related Aspirations

\begin{tabular}{|c|c|c|c|}
\hline & Students Teachers' Aspirations & Respondent \# & Total Frequency \\
\hline 1. & To continue to teach & $2,6,7,8,9,10,11,12,13,14$ & 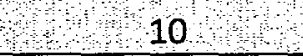 \\
\hline 2. & To teach overseas (EFL) & $3,6,7,8,11$ & प1 \\
\hline 3. & To teach ESL & $6,11,12,13$ & औय 4 \\
\hline 4. & Formal curriculum design & $1,5,6$ & 423 \\
\hline 5. & To be a "good" teacher & $2,8,10$ & 1213 \\
\hline 6. & To travel and teach & $3,7,9$ & मी. 3 \\
\hline 7. & To teach ES/FL at University/College & 6 & 1 \\
\hline 8. & Undecided & 4 & 1 \\
\hline 9. & To use acquired knowledge & 7 & 1 \\
\hline 10. & To build theoretical base further & 14 & 1 \\
\hline
\end{tabular}

Significantly, respondent 4 came into the program with five years' PLTE and her primary motivation for obtaining the CTESL was self-development. Interestingly, respondent 4 also volunteered to participate in Stage 3 and 4 of my study, and during the interview process, indicated that she had, at that later stage, become more invested in exploring ESL as a career.

Going back to the three student teachers who indicated an interest in the field of curriculum design, respondent 1 wrote: "I really want to get into the field of ESL curriculum development." And respondent 5 commented: "I am more interested in curriculum planning than in English teaching. I see teaching as being a useful skill if I choose to travel" (italics added). Note that respondent 5 sees English as a ticket to travel, not as a career path that she is purposefully headed toward.

\section{CTESL Students' ELT-Related Concerns in September 2008}

Table 6.7 below illustrates the range of responses generated from the question: Thinking back to September 2008, what concerns, if any, did you have at that time about your first 
practicum teaching experience? Note the mix of both inward-focused and outward-focused concerns. In Chapter 8 I will comment further on the significance of inward-looking concerns, associated with both the self and with professional development, as well as those that are outward-looking, such as concerns about meeting ESL students' needs.

Table 6.7: CTESL Students' ELT-Related Concerns in September 2008

\begin{tabular}{|l|c|c|}
\hline Past Concerns in September 2008 & Respondent \# & Total Frequency \\
\hline Relationship with host teacher & $3,5,10,12$ & $1,7,9$ \\
\hline Nervous about performance aspect of teaching & 1,7 & 8,11 \\
\hline Teaching in front of a large class & 11,13 & 2 \\
\hline Being able to answer ESL students' questions & 6,14 & 1 \\
\hline Meeting students' needs & 4 & 1 \\
\hline No previous concerns & 12,2 & 1 \\
\hline Access to adequate teaching resources & 13 & 1 \\
\hline Fear of the unknown / general apprehension & 13 & 2 \\
\hline Transition from teaching children to adults & & \\
\hline Being faced with so many different student needs & & \\
\hline
\end{tabular}

As can be seen from Table 6.7, the two most frequent answers were 1) the relationship TLs were going to have with their host teacher; and 2) being nervous about the performance aspect of teaching. For respondents 1 and 7, this second concern specifically included the idea of teaching in front of a large group of students.

In terms of the first concern, that of having a positive relationship with the host teacher, respondent 10 indicated that although she was initially concerned in September, her concern did not manifest into reality. She writes: "I have been lucky with both host teachers so far." In terms of the second issue, that of teacher performance, respondents 8 and 11's concern of not being able to answer ESL students' questions also relates to a performance aspect of teaching. Also 
important to note is that respondents $\mathbf{7 , 1 0}$, and $\mathbf{1 1}$, three student teachers who indicated they had felt nervous about the performance aspect of teaching, were all novice teachers.

Significantly, respondents 6 and 14 - both male and both with 3.5 years' PLTE coming into the program - indicated that they had no concerns in September 2008 about their practicum placements. Respondent 6 commented that he had "no real concerns because I had teaching experience." Also interesting is respondent $\mathbf{1 3}$ and $\mathbf{4}$, two female student teachers who came into the program with 4.5 and 5 years' PLTE. Both CTESL students had very specific concerns compared to those students who had no PLTE. For example, respondent 4 indicated that she was concerned about "what materials/resources, if any, I could find that would work." Respondent 13 indicated she was concerned about "making the transition to teaching adults" as she had previously taught children; she was also concerned about "going into a class with so many different first languages and needs." Conversely, respondents 2 and 12, both novice teachers, had concerns that were far more general. Respondent 2 indicated that he felt "somewhat apprehensive" and respondent 12 indicated a simple "fear of the unknown."

\section{CTESL Students' ELT-Related Concerns in February 2009}

Table 6.8, on the following page, shows CTESL students' responses to the following open-ended question, asked in the final section of the questionnaire: Looking ahead to the future, what concerns, if any, do you have about teaching English? Table 6.8 shows that the top two concerns that CTESL students had about their future teaching practice were 1) being able to meet the needs of their students; and 2) developing their own teaching materials. 
Table 6.8: CTESL Students' ELT-Related Concerns in February 2009

\begin{tabular}{|l|c|c|}
\hline Future Concerns in February 2009 & Respondent \# & Total Frequency \\
\hline Meeting the needs of ES/FL students & $8,9,11$ & 3 \\
\hline Developing own teaching materials & $5,6,10$ & 3 \\
\hline No concerns & $2,4,13$ & 3 \\
\hline Finding work & 1,14 & 2 \\
\hline Managing workload & 3,10 & 2 \\
\hline Being ready to teach own ESL class & 7,12 & 1 \\
\hline Size of ESL classrooms & 7 & 1 \\
\hline Able to make use of SLA theory and research in class & 8 & 1 \\
\hline Being an effective teacher & 11 & \\
\hline
\end{tabular}

On the topic of the first concern, respondent 9 indicated that she was concerned about being "a resource for the students. I hope that the information I share with them will be helpful in their language learning." Similarly, respondent 11 indicated an interest in meeting students' needs, expressing a concern about "coming up with effective and consistent lesson plans and activities that keep students engaged and interested" (italics added).

On the topic of the second concern, that of curriculum design, respondent 5 , a novice teacher, indicated that she was "a bit worried about coming up with teaching materials during my first year or two." Similarly, respondent 10, also a novice teacher, indicated she was concerned about "not having a course outline to follow" when running her own class. This appears to be related to her second concern, that of "the number of hours which will be required for lesson preparation." Interestingly, respondent 6 had PLTE coming into the program but nevertheless expressed a concern about "curriculum design for courses that don't have textbooks." Hence both respondent 10 and 6 expressed concerns related to the idea of a lack of direction or resources provided by their future places of work. 
Note that respondents 4 and 13, two female students who came into the program with over 4 years' PLTE, indicated that they had no future concerns. Respondent 2, on the other hand, came into the program with no PLTE, yet indicated that he had no future concerns about teaching English.

Practical concerns such as finding employment and managing future workloads were also reported. Respondent 1, an undergraduate degree between the age of 20 and 24, indicated that she was "worried about where I will find a job, mostly," but added that "I think I worry about this less than I would if I hadn't participated in CTESL". This is no doubt a concern shared by many undergraduate students in their final year of study. However respondent 14, a postgraduate student with 3.5 years' PLTE, is also concerned about employment: "The market in Canada doesn't look too promising ... I'll probably be forced to go back overseas to make a living." Given that the questionnaire was administered in February 2009, during a period of economic recession in Canada, the concern of finding future employment is understandable.

Finally, the perspective of two novice teachers with regard to their future teaching concerns is worth mentioning. Both respondents 7 and 12 were concerned about their readiness to run their own ESL or EFL classroom. Respondent 7 wrote that "I believe that I need much more exposure to teaching in general" (italics added) and respondent 12 expressed concern "about whether I will be adequately prepared for each new teaching task, level, or environment."

\section{What 14 CTESL Students Valued the Most}

In this section I report on answers that students provided to the open-ended question: Which 2 or 3 aspects of this practicum course/placement do you find most valuable? Again, I quote a number of students directly in the process. 
Table 6.9: What Did 14 CTESL Students Value the Most?

\begin{tabular}{|l|c|c|}
\hline What They Valued Most & Respondent \# & Total Frequency \\
\hline Observing host teachers & $1,3,4,6,7,9,10,11,12,13,14$ & 11 \\
\hline Practice Teaching & $3,4,5,8,10,11,12,13,14$ & 9 \\
\hline Being in a "real" ESL classroom & $1,9,11$ & 3 \\
\hline Discussions with CTESL peers & $5,8,13$ & 1 \\
\hline Online discussion / Web-CT & 6,13 & 1 \\
\hline Observing an ESL classroom & 1,8 & 1 \\
\hline Interacting with ESL students & 9 & 1 \\
\hline Practice teaching with feedback & 12 & 1 \\
\hline Collecting HT's teaching materials & 3 & 1 \\
\hline Developing own teaching materials & 4 & 13 \\
\hline Learning from the course instructor & 14 & 13 \\
\hline Interview with ESL learner & & 13 \\
\hline
\end{tabular}

From Table 6.9, we can observe the following:

1. The majority of the group, 11 out of 14 CTESL students, reported that observing their host teachers was of great value to them;

2. The majority of the group, 9 out of 14 CTESL students, reported that practice teaching was of great value to them;

3. 7 out of the 11 students who reported significant value in observing their host teacher also reported value in practice teaching; hence for 7 students, observation and practice teaching were of equal value;

4. Being in a "real" classroom and interacting with and observing ESL students was of significant value to more than one quarter (4 students total) of those surveyed.

\section{The Value of Observing Host Teachers: CTESL Students Comment}

The following comments provide insight into why observation formed such an important part of the CTESL students' practicum experiences. To begin with, consider the perspective of respondent 1, a novice teacher, who wrote: "I absolutely love the opportunity to observe a host teacher and classroom and think that this is the most valuable part of the CTESL program" 
(italics added). Similarly, consider the perspective of respondent 12, who also came into the program with no previous teaching experience. She writes that observing her host teacher "gives me a starting point and a model of how teaching can be done."

Interestingly, respondent 14, who came into the program with 3.5 years' PLTE, has a different perspective on the value of observing his host teachers, noting that "it builds on a body of experiences and understanding of different teachers' approaches" (italics added). Notice how this respondent, who has PLTE, references the concept of building upon an existing knowledgebase. Contrast this with the perspective of respondent 12 , who, as a novice, feels that observation has given her a starting point. Respondent 6, who, like respondent 14 , came into the program with 3.5 years' PLTE, emphasized the practical aspect to observing other teachers but did not reference an existing knowledge-base. He comments that observation "is perhaps the best way to learn teaching as it offers practical examples of classroom teaching" (underlined emphasis is part of the original comment). Fortunately respondent 6 was one of the four CTESL students who volunteered to participate in Stage 3 and 4 of my study. I was thus able to ask him follow-up questions about his perceived value of observing teachers. His answers, which I will share when reporting on findings from Stage 3, shed further insight into the importance of observation for both pre-service and in-service teachers.

\section{The Value of Practice Teaching: CTESL Students Comment}

On the topic of student teachers' experience of practice teaching, it is worth noting that respondent 5 indicated that observing host teachers was of value only in conjunction with practice teaching. She writes that: "Practice teaching is, by far, the most valuable because I am given the opportunity to prepare and execute my own lesson plans. Observing is somewhat useful but only in conjunction with the teaching" (italics added). This student teacher sees observation 
as having value only when positioned against a backdrop of practice teaching. This perspective on observation is important to consider, especially given the central role that observation plays in both LTE and GTE (Richards, 1998) and given TESL Ontario's certification requirement that practice teaching must not occur until observation of the ESL classroom has taken place.

Respondent 3 indicates that, for her, practice teaching is slightly more important than observation. She emphasizes the practical, hands-on aspect to taking on the role of an ESL teacher: "Practice Teaching is most valuable. There's a difference between talking about teaching and actually doing it" (italics added). Respondent 11, who places equal value on practice teaching and observation, provides additional insight into why teaching is such an important part of the practicum experience, commenting that it "helps [me] to differentiate between what looks good on paper versus what actually works and allows me to reflect on my own skills and strategies" (italics added). Note that she makes an implicit reference to the difference between theoretical knowledge (what looks good on paper) with practical experience (what works in the classroom). Note also that she finds practice teaching to be a source for reflection-on-action, allowing her to reflect on her developing skills and strategies.

\section{The Value of Being in a "Real" Classroom: Student Teachers Comment}

Interestingly, the three students who referenced the importance of being in a "real" ESL classroom were all novice teachers between 20 and 24 years old and spoke English as their L1. It is therefore not too great a stretch to suggest that all three female undergraduate students came into the program with a very limited practical understanding of what teaching ESL entails. As such, for respondent 1, a novice teacher, "having access to real-life situations that I could then reflect on was interesting and practical" (italics added). Similarly, respondent 9 notes that "actually interacting with and meeting ESL students" was "very valuable" as it helped her 
visualize "what it would be like to be in a real ESL class" (italics added). And respondent 11 noted that observing her host teacher provided her with "real experience of how an ESL class really works" (italics added). Again, note the significance of the fact that all 3 student teachers came into the program with no PLTE and that all 3 referenced the value of having exposure to a "real" ESL classroom.

\section{Individual Cases: What Individual Students Valued Most}

There are two more cases worth noting. One is the difference in responses between respondent 3 and respondent 4. Respondent 3, who came into the program with no PLTE, emphasized the value she drew from collecting teaching materials from her host teacher. She comments that collecting materials from her host teachers for her "own future use" is useful and of value. Respondent 4, on the other hand, who came into the program with 5 years' PLTE, commented on the value of developing her own teaching materials.

Another area worth noting is the response of two student teachers, respondents 6 and 13 who indicated that Web-CT based online discussions were of significant value to them in their practicum course. This is important because online reflection, as discussed earlier, was the least preferred form of reflection among the group as a whole. Worth remembering is that 5 out of the 14 students indicated that they did not find online reflection via Web-CT useful and an additional 6 students found it only slightly useful. Fortunately both respondents 6 and 13 volunteered in Stage 3 and 4 of my study; I was thus able to gather more data to better understand their reasons for findings Web-CT useful when the majority of their peers did not.

\section{Individual Cases: Outlier from Stage 2 SPSS Data Analysis}

Worth revisiting is the fact that respondent 8, the "outlier" noted in Box plot 3 on page 118, was the only TL to include two comments in the closed-question section of the 
questionnaire. As I was unable to assign her comments a numerical value, I will now briefly address the significance of her second comment here. Question 20 provided the following statement: I feel free to experiment and try out new ideas in my practice teaching. Next to her circled response of 1, strongly agree, respondent 8 indicated that her response related to her first practicum placement only. She wrote: Only in my first practicum. No teaching opportunity in $E A P$. This finding is significant because it reveals how the question of what TLs value the most about their practicum placements may have produced deceptively simple answers. Space limitations prevented me from asking students what (if anything) was problematic about their practicum experiences. However respondent 8 has opened up a dialogue about how complex the practicum experience is while highlighting the importance of a LTE program that offers preservice teachers two practicum placements, not just one. 


\section{Chapter 7: Results from Stage 3 and 4}

In this chapter I report on findings from Stage 3 and 4 . As noted previously, one of the central goals of this thesis is to directly quote CTESL students involved in this study whenever possible. Again, my rationale for doing so is to allow the reader to listen in to the voices of student teachers as they discuss issues related to their practicum experiences.

I begin with a demographic profile of the four TLs who participated in both Stage 3 and 4 of this study. I also provide information on their first and second practicum placements. I then share the perspectives of these four CTESL students in the following areas: 1) Why the practicum placement is an essential part of CTESL; 2) Why they feel observation is essential part of teacher development; 3) The value of learning with and from peers; 4) The pros and cons of online reflection; 5) Issues linking educational theory with practice; 6) Lack of time issues; 7) Their experiences of reflective teaching.

\section{Demographic Profile of the Four TLs Interviewed in Stage 3 and 4}

Table 7.1, provided on the following page, illustrates several important features of the group of four CTESL students interviewed in Stage 3 and 4. First, this is a diverse group. We can see that each TL belongs to a different age range and that two of the four CTESL students' L1 is not English. Second, this group brings a considerable amount of previous language teaching experience - 13 years total - to the CTESL program. While Elaine does not have any PLTE, her previous work experience encompasses two different careers: one, as a civil servant and two, as an engineer. Also, this is a highly educated group: coming into the program, all had at least an undergraduate degree; Alima also had a Masters and Karen also had a B. Ed. 
Table 7.1 Demographic Profile of Four TLs Interviewed in Stage 3 and 4

\begin{tabular}{|c|c|c|c|c|}
\hline Pseudonym: & Karen & Marek & Alima & Elaine \\
\hline Gender. & Female & Male & Female & Female \\
\hline Age range: & $25-29$ & $30-34$ & $35-39$ & 50 plus \\
\hline 1: & English & Not English & Not English & English \\
\hline Education: & $\begin{array}{l}\text { B.Ed. } \\
\text { B.A. History }\end{array}$ & B.A. Comp. Lit & $\begin{array}{l}\text { B.A. } \\
\text { in Eng. Lit } \\
\text { \& Art His. } \\
\text { M.A. }\end{array}$ & $\begin{array}{l}\text { B. Engineering } \\
\text { B.A. } \\
\text { (in progress) }\end{array}$ \\
\hline pHAT/work & $\begin{array}{l}4.5 \text { years } \\
\text { teaching FSL in } \\
\text { Ontario \& } 2 \text { ESL } \\
\text { camps and work } \\
\text { at immigrant } \\
\text { centre }\end{array}$ & $\begin{array}{l}3.5 \text { years teaching } \\
\text { EFL in Asia }\end{array}$ & $\begin{array}{l}5 \text { years teaching } \\
\text { English Literature } \\
\text { in the Middle } \\
\text { East; some ESL } \\
\text { volunteer work in } \\
\text { Ontario }\end{array}$ & $\begin{array}{l}\text { No PLTE but: } \\
\text { Former civil } \\
\text { servant; } \\
\text { engineer in high } \\
\text { tech field }\end{array}$ \\
\hline Placement 1. & LINC 1 Literacy & ELT Oral Skills & LINC 3 & LINC 3-4 \\
\hline Placement 2 & ELT Writing & LINC 6-7 Writing & LINC 1 Literacy & LINC 1 Literacy \\
\hline
\end{tabular}

Note from the above table that for Alima, Karen, and Elaine, their first practicum placement was noticeably different to that of their second. However, for Marek, this was not the case. The significance of placement similarity for Marek is addressed later on in this chapter.

In terms of speaking a different L1, both Alima and Marek indicated that it did not directly impact their experience of working with ESL students as they are both highly proficient in English. However, both indicated that they were able to relate to their ESL learners here in Canada on a personal level because of the immigration process that they themselves had gone through. Alima explains that:

I do relate to their immigrant experience, though, because even though I came to Canada at the age of 28 and I spoke like this, it wasn't so much the language and the vocabulary that people used me that I couldn't always follow. It was the cultural nuances that were difficult for me to follow - it took me a while 
to learn to navigate, you know, the way people respond to you or don't respond to you, and the interactions - that's closely related to language but it's a different kind of language. I mean, one example I always give is of telemarketing: I would be in the apartment and people would call and I wouldn't know whether this was something that I was supposed to buy or not and I didn't understand the context or the connotations of agreeing to something or not. I didn't understand the full implications. So, things like that. I felt like an alien. And so I relate to that part of their experience. Although I forget to relate to the part where I need to be aware of what the limitations are for them linguistically. But I can switch to what I would do if I was trying to do something in French, and that's what I compare it to (Interview with Alima, p.6. February 24, 2009).

Note that, at times, Alima indicated that she forgets to relate to the linguistic limitations her practicum students encounter, but that she is able to identify with their experience by thinking about her own experiences communicating in French.

As Marek attended both high school and university here in Canada, he feels he is not really able to relate to ESL students' language learning experiences first-hand. However he indicated that he is able to relate their immigrant experiences when he thinks back to the adjustments his parents had to make shortly after immigrating to Canada. He explains that:

With adults, I can see them going through - I think of my parents when I look at them. Not so much myself, because I integrated a long time ago. As a child you can fit in better than your parents can, you know? So, yeah ... it's more personal for me to see these adults struggling to find jobs in their careers or just having to do things that are not related to what they were doing back in their countries - you know, doctors driving cabs. Also, just struggling with the language. My parents, my mom, her English is pretty good, but there's an accent, and it'll always be there (Interview with Marek, p.5, February 25, 2009).

Thus, we can see from the above interview excerpts that Marek and Alima are able to relate to their ESL students on a personal level because they have gone through the immigration process or have seen their parents' making an effort to acculturate. 


\section{But Why is this Demographic Information Important?}

Documenting demographic CTESL student information such as L1 spoken, age range, PLTE, and educational background is important for two reasons. First, recall the focus on collaborative learning that Sarah emphasized when describing the goals of her course. Recall also that a constructivist model of teacher education sees students constructing their own meaning, drawing from the knowledge-base of their peers in the process. Second, as Table 7.1, illustrates, Karen, Marek, Alima, and Elaine are all "mature" students in the sense that they have made the decision to return to university to pursue their CTESL or a degree in Linguistics after already having completed an undergraduate degree. They all have a minimum of three years' teaching or other work experiences to draw from. This makes them distinct from some of their younger peers (those between the age of 20 and 24) who participated in Stage 2 of this study and had not yet completed their undergraduate degree. These younger participants did not have the previous language teaching experience or breadth of other work experience coming into the program. Thus when reading the comments of Karen, Marek, Alima, and Elaine, it is essential to remember that they are distinct from their younger peers who did not choose to volunteer in Stage 3 and 4. Their comments cannot and should not be attributed to other CTESL students.

\section{1) Why the Practicum Placement is an Essential Part of CTESL}

Alima, a student teacher who came into the program with 5 years' PLTE, indicated that for her, the practicum placement was the main reason she entered the CTESL program. She emphasized the practical value of being in an ESL classroom, of observing and interacting with ESL students and host teachers. Interestingly, she used the words "real experience" to describe the value of the practicum placement, which is strikingly similar to respondent 11 from Stage 2 
who noted the value of having a "real experience of how an ESL class really works." During the one-one-one interview, Alima elaborated on why being in a "real" classroom was so important: ...the practicum is an essential part of the course. It's the main reason I took this [practicum] course. I didn't want pure academic study; I wanted a practical experience. ... it's all about the real experience - the value of it is that you get a real-life shot of what goes in a real classroom: what it's like, how many people are there, what the students' problems are, what the teachers are like, what they go through, and the circumstances you're working in. So it gives you a reality check - that's really important. For me, personally, it's a reality check of remembering that I can't speak a hundred miles a minute and not to use complicated words - that I have to be mindful of how to express myself. That was a good reality check because it took me a while to adjust to that. [Pause] I think it's [the practicum] just so key - it's the most important part of the course (Interview with Alima, p. 14, February 24, 2009).

Note how Alima references the importance of a reality check: when teaching English Literature in the Middle East, she had been covering passages from Chaucer and Shakespeare to students who were very proficient in English. Thus at the outset of her LINC 3-4 first placement, Alima was not yet aware of the need to avoid unnecessarily complicated words that were beyond the comprehension of ESL students at that particular level.

Elaine, who came into the program with no PLTE but with many years' work experience in two different careers, indicated that her second practicum placement had taken on additional value when she started going on an everyday basis. Due to a bus strike situation that affected the city for the month of January 2009 , Elaine did not have an opportunity to visit her practicum class until February 2009. To make up for the lost hours, Elaine decided to visit her practicum class every day during reading week. Comparing this "immersion" experience to that of her first practicum placement where she only went in once a week, Elaine comments:

I went in during break week - every day, which was - I really liked that - the everyday aspect, because you can get a sense of what's really happening. In my other practicum, where I was only there one morning a week, there was really no continuity. You feel like a visitor every time. It's hard to get yourself into the flow of things (Interview with Elaine, p.4, February 25, 2009). 
Note that the CTESL program featured in this study secures practicum placements for TLs on a part-time basis; student teachers attend regular university classes and complete course work while attending one practicum placement each semester. Note also that there is one other CTESL program offered in the same city (compared to the one featured in this study) that secures practicum placements for its student teachers on a full-time basis, offering an immersion experience but over a shorter period of time. Which practicum model benefits the TL most? As Elaine explains, there is also a disadvantage to the everyday, immersion-like experience:

At some point I would like to see if they [the ESL students] actually make some progress. I haven't been able to witness that yet. Being there every day for one week is a nice way to see how class works, but it's not a way to see their progress over time (Interview with Elaine, p.5, February 25, 2009).

Hence, from Elaine's perspective, there are benefits and disadvantages to both part-time and fulltime practicum placements.

For Karen, who came into the program with a B. Ed. and 4.5 years' PLTE, an essential part of the practicum experience was the interaction with her host teachers as well as the ESL students. In her words: "I've had two really positive experiences so far. Last term, the teacher I was with, we would often take 20 minutes or more after class talking about the morning" (Interview with Karen, p. 4, February 27, 2009). Her enthusiasm for working with both groups of students and her host teachers is worth noting: "It was fantastic. I'm really enjoying this term, too" (Interview with Karen, p.2, February 27, 2009).

Karen also indicated she had noticed a significant difference between the Literacy class in her first placement and the ELT writing class in her second placement. Describing the ELT class, Karen commented that the students were "very advanced" and indicated that for the Literacy level students, "it was the opposite extreme" (Interview with Karen, p.2, February 27, 2009). Both Alima and Elaine echo Karen's perspective. Alima noted that with Literacy 
students, "they don't formulate full sentences and you can't take anything for granted" (Interview with Alima, p.3, February 24, 2009). She indicated that, compared to LINC 3, it took her much more time to plan lessons for Literacy students where she was "building blocks one at a time" (Interview with Alima, p.3, February 24, 2009). Elaine indicated that although she enjoyed working with Literacy students, she missed the ability to have a "real conversation" with LINC 3-4 students. In her words:

Going from a 3-4, where you can actually have a real conversation, to a literacy level, where some of them barely understand individual words; they're still working on the alphabet and they don't really get the connection between the alphabet and the sounds or the words that they represent. It's different - it's really, really different. . . What I liked about the LINC 3-4 was the conversation that would come out of things. For instance, if we started talking about police, or something, somebody in the class would ask a question, and the next thing you know it's a whole full conversation; the whole class in involved. . . But that can't happen in the literacy class (Interview with Elaine, p. 4, February 25, 2009).

Note the practical knowledge that Elaine has gained from her two very different practica.

Marek, who came into the program with 3.5 years' PLTE, indicated that his two placements were actually very similar. Interestingly, he expressed a desire to have exposure to more than just two practicum sites, whereas none of the three other student teachers (who all had two very different placements) did. Marek indicated that the similarity of his two placements was one of the reasons he valued listening to the experiences of his peers placed at different settings so much. He commented that a discussion with his peers:

... gives you an idea of different levels, because we only get a chance to teach at two different levels, and for me, actually, I've been teaching at sort of the same level for the whole year - LINC 6-7 and the ELT. But you can listen to stories of Literacy or EAP and it's interesting. Unfortunately we don't get a chance to actually see all these different classes (Interview with Marek, p.6, February 25, 2009). 
Note the similarity between Marek's perspective on the value of listening to his peers and Sarah's explanation for why she feels group discussion is such an important part of the CTESL program. Recall Sarah' aim to have student teachers "learn from each other and not simply silo the practicum experience - for one teacher for one location" and her recognition that while CTESL students "can only go to two practicum sites over the course of the year," they can potentially "learn from 24 " if they "all dialogue and communicate with each other" (Interview with Sarah, page 4 and 12, January 9, 2009).

\section{2) Why Observation is an Essential Part of Teacher Development}

Recall that in Stage 2, all 14 CTESL students indicated that they found observing their host teacher to be of value or of great value to them. For this reason, I followed-up on this area and asked all four TLs to explain why they found observing their host teachers beneficial.

All four TLs interviewed in Stage 3 emphasized the importance not only of observing their host teachers, but also their practicum ESL students. Karen, commenting what she had learned from observing her first host teacher, had the following to say:

... last term I learned a lot about seeing what the needs are in your group, and being adaptable to that. She [the host teacher] had good strategies for bringing in authentic materials. And I remember that she felt that at the beginner type level, the most important thing was to encourage them in whatever English they were producing. She had a really good team environment going on, so it never felt like there was a lot of distance (Interview with Karen, p.4. February 27, 2009).

Notice how the value Karen draws from observing her first host teacher encompasses numerous aspects. of teaching: 1) accommodating the needs of different students; 2) authenticity of materials used; 3) the issue of encouragement and motivation; and 4) classroom dynamics and collaborative work environment. 
Alima felt she was learning more in her second placement because she was observing more than she had in her first placement. She also indicated that in her first term of the program, she had experienced somewhat of a cognitive overload and this interfered with her ability to learn as much as she otherwise might have from her practicum experience. In her words:

I've learned more from this term than I did last term, partly because I was pushing to teach as many hours as possible last term - and that meant less observation. My teacher last term was extremely open to me teaching ... But I had more opportunity to observe this term, and that's why I feel like I learnt more. And also, I was at the beginning of my course last term, and maybe I was trying to take in a lot of things at the same time (Interview with Alima, p.3-4, February 24, 2009).

Similar to Karen, Alima noticed numerous aspects of her host teacher's practice while observing her class, from the very first day of observation:

From just the first lesson of observing my teacher at the Literacy level, I noticed how methodical she was. She still had to speak naturally, but much more slowly, to try to choose her words more carefully, and rely heavily on visual aids. She was also communicating with me as she was teaching to let me know that, for example, at the beginning of the lesson they do four sentences which they call the story, and she does the day and the weather, and she gets them to say what the day is, what the date is, and what the weather is like. And she doesn't necessarily write grammatically; she said that some research tells you that it's more effective to write what they say, rather than what they should be saying, because that's the language that they're producing. And so she's communicating with me back and forth as she's doing this. So I noticed her pace, her approach, and her style - you know, the style is very repetitive (Interview with Alima, p.4, February 24, 2009).

There are several things worth noting about the above interview excerpt. First, is the intriguing blend between role of observer and participant that occurred in Alima's second practicum placement: Her host teacher was communicating key points about her teaching practice to Alima while engaged in the act of teaching. Thus she was reflecting-in-action out loud in order to make her in-the-moment teaching decisions more transparent to Alima. It is important to note that this is termed "transparency of practice", occurring in instances where a host teacher will "model her 
thinking process" or walk the student teacher "through a decision-making process" (Goethals, Howard, \& Sanders, 2004, p.182).

Though this transparency of practice is expected to occur between a host teacher and student teacher prior to or after a lesson (Goethals, Howard, \& Sanders, 2004), it is likely that it occurred during Alima's practicum visits because the pace of the Literacy class was much slower than other LINC levels, allowing for these brief exchanges to occur between host teacher and student teacher without interrupting the flow of the lesson. A second point worth mentioning about the above excerpt are the different aspects to the observation process that Alima refers to: 1) how methodical and repetitive her host teacher was with the Literacy students; 2) her host teacher's reliance on visual aids; 3 ) the fact that her host teacher does not write grammatically and why this is so; and 4) her host teacher's pace and overall approach to teaching.

Interestingly, Elaine also comments on the repetitive style of her Literacy host teacher but does not provide the same amount of details as Alima when describing what she has learned through observation. In her words:

... she [the host teacher] does the same thing every day. At the beginning, she does the weather. So the students come in and they are given a newspaper and they look on the front page to find where the weather section is, so they can read, you know, D8 if that's where the weather is. If they know what to look for, they can read the temperature. Sometimes they remember to say minus - the high is minus 6 today - but a lot of times they will forget even that, very basic stuff (Interview with Elaine, p.4, February 25, 2009).

Marek, who came into the program with 3.5 years' PLTE, suggested that his previous teaching experience has increased the value he derives from observing other teachers. He suggests that PLTE allows him to observe teachers more critically than those student teachers who have no previous teaching experience. Marek explains that:

... as an observer, as someone who has taught a bit and had some experience, you can observe the teachers more critically than if you hadn't taught at 
all. You can observe the connection the teacher has with the students and what they're doing in your opinion is effective or not. I think it's important to think about these things (Interview with Marek, p.6, February 25, 2009).

Note that Marek indicates that observation has provided a source of reflection for him; he has spent time reflecting on what his host teachers are doing and whether it is effective or not; and indicated that for him, thinking about these things is important. Marek also indicated that observing his CTESL peers doing an assigned microteaching activity (in the Methodology course) was of value to him: "It was the only time we had an opportunity to see our peers and see their styles" (Interview with Marek, p.11, February 25, 2009). He indicated that watching his peers teach is one aspect of the CTESL program he will remember the most in future years.

Significantly, both Alima and Marek had observed other teachers prior to starting the CTESL program, as part of their former workplace orientation and training initiatives. For Alima, this period of observation took place before she started teaching her own English Literature classes. She indicates that she "had observed a few teachers" and that this observation period then gave her the idea to reformulate her class into a U-shape, rather than sticking with the standard theatre style. She found that a U-shape class gave her access to all of her students and "made their English class different ... like they were coming to somewhere that I hoped was a bit more creative and friendly than other classes" (Interview with Alima, p.6, February 24, 2009). From observing other teachers, she got the "idea for pair work and group work" as she "hadn't been exposed to group and pair work at all" before that time (Interview with Alima, p.6, February 24, 2009).

For Marek, this period of observation was part of his school's initial training program as well as part of an ongoing mandatory teacher discussion group. He indicates that for him, "in [Asia], the best thing was to watch other teachers. . I always found it beneficial, you know, to get new teaching ideas" (Interview with Marek, p.3, February 25, 2009). Marek finds 
observation gives him additional perspective on "different teaching styles and different ways of dealing with students, whether it's just dealing with students' questions, or approaching certain topics" (Interview with Marek, p.3, February 25, 2009). Describing the mandatory monthly meetings, Marek commented that "all the teachers had to share demos" and that he found this sharing process helpful (Interview with Marek, p.3, February 25, 2009)..

Alima provides a great example of how TLs, particularly those with PLTE, can learn from both positive and negative observation moments. She describes her experience of observing a substitute teacher filling in for the regular host teacher. The teacher arrived late and seemed frantic when he walked in; she observed that the energy in the room "was the opposite of the kind of energy that [the host teacher] puts in, because you need to be very calm and clear and make sure they're with you" (Interview with Alima, p.5, February 24, 2009). She observed that:

... he [the substitute teacher] just couldn't get to the point where he was doing things in a way that they [the students] could grasp, and it was going too fast. It was hard, and I feel there was also a lack of preparation. So that was learning as well, because that provided such a bold contrast [to the host teacher]. It's helping me when I'm thinking of the lesson that I will eventually test in class and that I hope to turn into my project for Methodology (Interview with Alima, p.5, February 24, 2009).

Note how observation of a substitute teacher who was not able to connect with the ESL students in the same way Alima's host teacher did was a source of learning for Alima. Note how she describes this observation as providing a reference point for how not to interact with these ESL learners. In short, this observation, because it was negative, has helped Alima reflect-for-action, as she thought about how to meet the needs of her students during a future lesson.

\section{3) The Value of Learning with and from Peers}

As has been noted, Marek found value in attending monthly meeting with other English Immersion teachers in Taiwan where they gave teaching demos and discussed teaching-related 
issues. What about the value that he and three other TLs drew from working with their peers during the CTESL program?

Alima indicated that for her, she learns best by listening to and talking with other TLs. She identified two benefits to discussing practicum-related issues with her CTESL classmates. First, Alima liked hearing other student teachers' opinions, ideas, and experiences. Second, she found talking about her teaching experiences to be therapeutic. In her words:

\begin{abstract}
... the only way I learn is by hearing other peoples' opinions, hearing what happened to them and telling them what happened with me. And part of it is also a therapeutic thing, where I get to spout out everything that happened to me, and in a way it kind of gets it out of my system. And at the same time, that's when I'm able to start thinking about it, 'OK, well, why did that happen?' - Once I get it out, you know, my emotional reaction to it (Interview with Alima, p. 9, February 24, 2009).
\end{abstract}

What is most striking about the above excerpt is that, within the context of a reflective model of teacher education, Alima finds that talking about her practicum-related experiences helps her to process the teaching event that occurred and then reflect on it more objectively. In terms of what she learns from listening to her peers talk about their practicum-related experiences, Alima indicated that "each person in my CTESL class has different strengths. It's not about who gets the best ideas and who goes on with the bright ideas - it's about getting them and making them work" (Interview with Alima, p. 9, February 24, 2009). Alima shares a similar philosophy to the course instructor regarding the collaborative nature of teaching, stating that "in teaching, or in learning anything really, even in fundraising, there's got to be collaboration" (Interview with Alima, p. 9, February 24, 2009).

Elaine was very clear about the value of learning from her peers:

Many of my [classmates] have teaching experience - they blow me away, actually. Some of them are just so amazing, and it's incredible to watch them. Some of them are just so natural at it. But what I do like about sharing experiences is that they also share back, and I find I learn from what they come up with (Interview with Elaine, p. 9, February 25, 2009). 
Worth remembering is that Elaine is the only student teacher in stage 3 and 4 who has no PLTE. This is significant because it helps explain the following comment about her learning-to-teach developmental stage:

I think I'm still at the stage where I'm learning quite a bit from my peers. So, when I'm listening to them talking, I'm thinking, wow, I wish I could do that. That's the stage I'm at (Interview with Elaine, p. 9, February 25, 2009).

Describing a collaborative project that she had been working on with her classmates, Elaine recalled that some of her peers were "able to zero right in on what's essential, what's important, what works - and I'm going, 'Yeah, this is great! This is really good. Why can't I think of things like that?' (Interview with Elaine, p. 9, February 25, 2009)

Similar to Alima, Elaine describes a therapeutic aspect of sharing with peers. She indicates that in addition to learning from her peers because they have "such good ideas about things," another important part of the process is:

... coming to terms with the fact that sometimes classes themselves aren't what you expect they are going to be. So, if I'm in a classroom where I feel like I don't really know what I'm doing and then I hear from somebody else that they're as uncomfortable as I am - due to whatever: things that might have happened, the students themselves or whatever - then it just puts you a little bit at ease, reminds you that that's just the way life is sometimes (Interview with Elaine, p. 10, February 25, 2009).

Karen indicated that she found value in learning from her peers both inside and outside CTESL university classrooms. In terms of class projects, she found that "planning in groups together" was "helpful" because "as teachers you work on your own a lot," thus referencing the potentially isolating aspect of teaching (Interview with Karen, p. 7, February 27, 2009). Karen indicated that at the beginning of her second practicum, she had sought out student teachers who 
had been teaching at the same level in their first placement. On the topic of sharing her practicum experiences with other TLs, she says:

I think it's helpful because, for example, there are two or three other people that are working at the same level that I am. It's nice to hear what they're doing in their classrooms, to hear different lesson ideas, that sort of thing. People that have been at that organization last term - I talked to them before I started, so I appreciated that, because I knew the students would be a different type of clientele from my LINC-literacy class in the first semester (Interview with Karen, p. 7, February 27, 2009).

Note the self-directed learning aspect of Karen's decision to seek out TLs who had taught at the same organization the term previously. It can be argued that the dialogue she had with the abovementioned TL acted as grounds for reflection-for-action before Karen had even met her practicum students. At the very least, from the above excerpts in this section, we can establish that discussing with and learning from peers is an integral part of the CTESL program.

\section{4) The Pros and Cons of Online Reflection}

Recall that from Stage 2 that online reflection via Web-CT was the least preferred form of reflection among the group of CTESL students surveyed. Fortunately, of the four TLs who agreed to be interviewed in Stage 3, one of them, Marek, was decidedly in favour of online reflection and one of them, Elaine, was decidedly not in favour. After referring to their completed questionnaires I decided to ask all four TLs a follow-up question, with the intent to better understand this aspect of their practicum course experience from more than one perspective. In this section, I report on the views of Elaine and Marek. I then present the more neutral perspectives of Karen and Alima.

Elaine was decidedly not in favour of online reflection via Web-CT. She much preferred discussing with her peers in person and thought this was a much better use of time. Marek, on the 
other hand, was decidedly supportive of Web-CT and found it much easier to discuss with his peers online than in person. Table 7.2 presents Marek and Elaine's differing point of views:

Table 7.2: The Experience of Web-CT Online Reflection: Two Perspectives

\begin{tabular}{|c|c|}
\hline Marek's perspective & Elaine's perspectiye, \\
\hline $\begin{array}{l}\text { For me, it was easier to say things - you } \\
\text { know, I don't like big discussions [in person]. I } \\
\text { found it easier to write things, and I like the } \\
\text { aspect of being able to go over what you've } \\
\text { said ... I was more active during that [online] } \\
\text { discussion than I was during the class } \\
\text { discussion... I found a lot of people didn't like } \\
\text { the discussion because they felt like we could } \\
\text { have it in class, but I thought that a lot of } \\
\text { these topics would never be discussed during } \\
\text { class because there wouldn't be time to } \\
\text { really think about them ... the [online] } \\
\text { discussion would start with a particular thread } \\
\text { and then it would evolve into something longer } \\
\text { - maybe this wouldn't happen during a lecture. } \\
\text { I don't know; I felt it worked quite well, at least } \\
\text { for me. And just having more time to think } \\
\text { about it - you don't have to reply right away. } \\
\text { You have an hour or two; you can read it and } \\
\text { think about it and then go back to it. So you } \\
\text { have more time to reflect in a way. If you } \\
\text { don't have an opinion that's already formulated } \\
\text { you can think about it and come back to it. }\end{array}$ & $\begin{array}{l}\text { "This term we've been doing a lot of online } \\
\text { stuff and nobody seems to be really into that. } \\
\text { And so some people aren't participating at all, } \\
\text { and for those of us who are participating - we } \\
\text { don't really know what our role is supposed } \\
\text { to be. And the fact that it's taking up way } \\
\text { more time than it would if we were talking } \\
\text { in a classroom. We would rather do the } \\
\text { roundtable discussion where all } 24 \text { of us are in } \\
\text { the same room, and just throw out bits of } \\
\text { information as we come up with it, rather than } \\
\text { trying to force it online. You know, trying to } \\
\text { type up stories, and then you go away. Then } \\
\text { you have to come back the next morning and } \\
\text { see if someone has responded to you. It was a } \\
\text { really frustrating, long, painful experience." }\end{array}$ \\
\hline $\begin{array}{l}\text { I think some students didn't like it because...it's } \\
\text { just not their thing. }\end{array}$ & \\
\hline
\end{tabular}

Note from Table 7.2 the recurring issue of time, from two differing perspectives. First, Elaine indicates that the online forum for discussion takes up more time than it would do if CTESL students were to have had the discussion during class time. Second, Marek's point relates to the same issue. His perspective is that it is exactly because of the delay in reading and responding to other students' online contributions that he is able to step back and have more time to reflect before replying. Would it have made a difference if the course instructor had explicitly stated, 
before introducing the online component of the course, that part of the value of online learning is the fact that the delay in response allows for more in-depth reflection? Possibly, but, as Marek noted, "I think some students didn't like it because...it's just not their thing." This observation that online reflection is just not their thing suggests that personality or learning preferences might be part of the equation.

Despite finding fault with the online forum for group discussion and reflection, Elaine was able to identify a pedagogical reason for including it in the practicum course when asked. Placing herself in Sarah (the practicum course instructor)'s shoes, Elaine commented that:

I'm assuming that she's trying to show us that this is a possibility when we are teachers, to have our students go on the web and use a blog or use a website, or whatever. I think that is her goal - but it doesn't work for everybody. It doesn't have as much value as what it seems that she's trying to get across to us (Interview with Elaine, p.11, February 25, 2009).

Hence the intended loop input that Sarah described in Stage 1 has been successfully identified by Elaine in Stage 3, at least in theory. However, in practice, Elaine remains unconvinced.

Alima and Karen offer additional insight into the pros and cons of online-based reflection. Both indicated that they prefer to discuss with their peers in person, but Alima was more emphatic on this point. In her words:

I put it down to learning style, personality and also, you know, I'm in that generation that just missed computer studies as I was graduating from high school. Going online - I obviously do go online - I use email and use the internet for occasional research. But it's not how I grew up. I don't feel comfortable. I'm very much an in-person, face-to-face communicator. I do not like doing things online. And the kind of synergy and creativity that can be generated through blogging and things like that - I am aware that it can happen, but not for me. Because I just don't want to do it; I don't want to keep clicking and have to be on the internet just to share ideas - I can do that in person. So, it's just a personality thing (Interview with Alima, p.10, February 24, 2009). 
Interestingly, in my analysis of Stage 2 data, when I ran a correlation coefficient between responses to likert-scale question 24 (that asked students to rate the usefulness of online Web-CT discussions) and age, age did not show up as a significant feature. Other features such as gender, PLTE, L1, and type of student also did not show up as significant. Thus the "older generation" theory does not apply, at least not in this study. Could personality and learning style have been the deciding features? Possibly, but I had no way to measure for this (as this would have been far beyond the scope of my research focus).

Also interesting is the fact that, similar to Elaine, Alima was able to identify a pedagogical reason for having online Web-CT based discussions:

... from [the practicum course instructor's] perspective, for example, we need to know - as teachers being trained to be teachers - that technology is there and is growing at the speed of light, it's going to be a part of teaching - especially for long-distance teaching. It's a skill that you need to be aware of, even if you don't have it or plan to pursue it. I think it's something that you need to be aware of. . . I don't think you can get around it any other way. I think it [the online discussion] was the way to go. Unless you have someone experience things as they are, it's hard to explain it to them (Interview with Alima, p.10, February 24, 2009).

Karen's perspective on the online Web-CT discussions is also note-worthy. She prefers to communicate in-person but does see some benefit to the online forum:

I prefer to talk in person, but sometimes someone will post a challenge they're having at a placement, and other people write back to that classmate about it, so that's helpful ... I don't mind it being a component of the course, because sometimes you hear from classmates that don't seem to be keen to share a lot in class, but they seem to really like to write. So, I still find it useful, yeah ... sometimes for me I find it more helpful to type something up first, and then post it. So you're reflecting more, maybe in a different way, when you write something up. At least for me, because in person maybe it's more like .. . talking something out. I think they do serve different purposes (Interview with Karen, p.8, February 27, 2009).

Note the similarity between Karen's perspective on online reflection and that of Marek. Karen indicated that she heard from classmates that don't seem to be keen to share a lot in class, but 
who seem to really like to write. Recall that Marek said he was more active during online discussions than he was during the class discussions. Note also the point Karen raised about online reflection serving a different purpose to in-person reflection and the idea that you're reflecting more, maybe in a different way, when you write something up. Compare this to Marek's perspective: he feels that with online discussions, students have more time to reflect.

Alima makes a very convincing argument about the merits of online discussion, even though she admits she much prefers to discuss with her peers in-person. Similar to both Marek and Karen, she suggests that some TLs prefer to share their reflections in writing, rather than spontaneously, in person. In her words:

There are other students who don't feel comfortable having discussions in class, and it [the online discussion] works for them. Again, it's about addressing a wide spectrum of learning styles in your classroom and being respectful of all of the differences (Interview with Alima, p.11, February 24, 2009).

Thus, while she may prefer to discuss with her peers in person, Alima is nevertheless able to make a convincing, pedagogically-sound argument for including online discussions in the practicum course curriculum.

\section{5) Issues Linking Educational Theory with Practice}

As indicated previously, PLTE was a significant feature that influenced the degree of difficulty that student teachers experienced in their attempts to link educational theory with practice. Box plot 1 on page 114 showed a full 1.5 scale difference in how the yes and no group answered question 13, with the median response for those with PLTE indicating that they had not experienced difficulty linking educational theory and practice and the median response for those with no PLTE indicating that they had. Recall also that linking educational theory with practice was one of the practicum course objectives that Sarah identified in Stage 1. For these reasons, I 
decided to follow-up in Stage 3 and asked all four TLs why they did or did not experience difficulty linking educational theory and practice.

Karen indicated on the questionnaire that she had not experienced any difficulty linking educational theory with practice. During the interview, Karen commented that she had learned from her CTESL courses about the importance of developing content that was cohesive, contextualized in a meaningful way, and relevant to students' lives. She had learned about "not just the communicative approach" but also about "making sure you're giving the overall picture of the language ... not breaking things up into pieces too much, and making sure that your activities are going to be meaningful" (Interview with Karen, p. 6, February 27, 2009). She indicated that she had seen evidence of meaningful activities in both of her practicum placements and thus hadn't experienced any difficulty making links to the theory from her CTESL courses.

Marek had not experienced any difficulty linking educational theory in his first practicum placement, but the same was not true for his second placement. In his words:

.. . definitely with the first semester practicum, it was as if what she was doing in the class was exactly what we were covering in Methodology: taskbased, needs analysis, communicative teaching, student-centered - it was all there. But it's a bit more difficult to this semester to link this stuff. . .I guess; because it's a writing course, it's a bit more teacher-centered. So there's a lot of going through grammar exercises - it's not as communicative as we've been talking about in CTESL - not as much as it perhaps should be (Interview with Marek, p.10 and 2, February 25, 2009).

Note how Marek, without being prompted, offers his own critical reflection on the fact that his second practicum class should be more communicative. What is equally interesting to note is that the first practicum class that he observed was communicative in a way that he had never observed before. Marek explains that:

The teacher would come in and she'd have a lot of the material prepared, the students would get into groups and start working. There was very little teacher talk in the class, which for me, was something new, because I was 
quite used to this sort of teacher-centered thing that we were trained to do in [Asia], with concrete results and lots of paper (Interview with Marek, p.10 and 2, February 25, 2009).

Thus Marek's critical appraisal of his second host teacher's teacher-centered approach in her ESL classroom stems from the links he was able to make between theory and practice in his first practicum placement, specifically, links made based on observing his host teacher. Hence we have yet another example of the value of observing host teachers and how observation forms an important part of critical reflection.

Alima indicated that the difficulty she experienced linking educational theory and practice was related to the fact that she was behind on her CTESL course readings. More importantly, the difficulty she had experienced was related to her need to have time to process the information presented in the readings. Alima also indicated that her main focus had been on acquiring practical, rather than theoretical knowledge; this has resulted in her not having as firm a "grasp" on her readings as she perhaps otherwise would have. In her words:

... an admission on my part: my ability to catch up with reading on theory and feeling like I have a grasp on it - you know, I came into the program looking for the practical. So that's what my focus has been; I've been picking and choosing what I really focus on. But I'm aware that to feel like a TESL professional, I need to have a strong grasp on theory, especially when it comes to issues around, for example, Second Language Acquisition. We're doing that course right now and it's full of theory and contradictory hypotheses. And feeling like I have a grasp on that - I don't. And so that's mostly my own issue - I have to get a grasp on it, I have to read it, I have to formulate it. But I think it comes with experience, too ... And I think the courses themselves, in terms of our Methodology class, a little bit in our practicum class, and especially in our SLA course, there are attempts to make us link the two. . . But for me, it's just a matter of feeling like catching up, or not catching up is more like it (Interview with Alima, p.14, February 24, 2009).

Of the four TLs who volunteered in Stage 3, Elaine experienced the greatest difficulty linking educational theory and practice. She attributes this to the fact that she is a novice teacher. 
Elaine indicated that because she came into the CTESL program with no PLTE, she did not have a reference point for linking theory with practice. She explained that:

. . . implementing the things you learn in class: you read about all of these theories, different methodologies to accomplish your teaching. But, when it comes right down to it, you have to actually stand in front of a classroom, talk to a bunch of students and get them to participate in this plan that you've got going and, a) you need to know what kind of a plan is right for this group of students; b) you've got a group of students who are so varied that you have to make a dozen plans to accommodate all of them and it's got to be an almost impossible task. You've got to find some way of making it all work together. And until I've done that, until I've actually been there, and seen it all - or seen enough to be able to say, 'OK, yeah, I can do this for this guy and can take this guy aside and have him do this.' But at this point I'm not there yet. I know it's out there and I have to get there - but I'm not there yet (Interview with Elaine, p.14-15, February 25, 2009).

Worth noting from the above excerpt is the fact that Elaine sees accommodating a range of student needs to be "an almost impossible task" and that the practical knowledge of how to accomplish this daunting task is "out there" but can only be acquired through hands-on experience. Elaine goes on to explain that her host teachers have reassured her on this point, telling her that "when they first started, it wasn't so easy" (Interview with Elaine, p.14-15, February 25,2009$)$. She concludes that her ability to link educational theory and practice will come with time and experience:

Time is a great teacher. Experience is a great teacher. Experience is really the only teacher. You can use the theory, but a lot of it kind of goes in and out, very quickly, because that's all you're doing is learning the theory. At some point, there has to be some sort of a transition whereby you actually get to try to implement some of the ideas and concepts (Interview with Elaine, $\mathrm{p}$ 15 , February 25, 2009).

Note the need Elaine identified for implementing the theory that she has learned about. Again, the significance of PLTE is at play here, given that those TLs who entered the CTESL program had some previous experiences with teaching to draw from when reading about educational theory in their CTESL classes. As Richards (1998) indicates, those with PLTE have a repertoire 
- no matter how small or intuitively-based - of previous teaching images and experiences to draw from.

\section{6) Lack of time Issues}

Lack of time issues came up in Stage 3 during my interview with Karen as they did in Stage 1 during my interview with Sarah, the course instructor. First, Karen indicated that in order to reflect on one's practice, time needs to be intentionally set aside. She indicated that in her previous teaching experience as an FSL teacher working full-time with students from grade 4 to 8 , she had found it difficult to make time to reflect on her practice. Although her schedule as a CTESL student was quite busy, she indicated that she found there was more time to reflect as a student teacher than an in-service teacher. Comparing the two experiences, she says:

... it can sometimes be challenging when you're juggling other courses [as a CTESL student] to take the time to do that [reflect]. But I think it's important because that's when you can look at how you need to change your teaching. I think it's valuable, and that's what I've appreciated about this year - because being a student and teaching as well, but being more in the student role, it gives you more time to reflect. When you're teaching full-time, you're on the go all the time (Interview with Karen, p 7, February 27, 2009).

Hence, from the above excerpt, we can see Karen thinks it's important for both pre-service and in-service teachers to make time for reflection.

Karen also commented that a lack of time issue influenced the amount of feedback she received from her second host teacher. Recall that in her first practicum placement, her host teacher would often take about 20 minutes to de-brief with Karen after the morning lesson. Karen indicated that because the second host teacher worked during the day and then taught ELT classes in the evening, there wasn't much free time for feedback or discussion. She comments that "because of the nature of the timing of the evening class [ELT, second placement] - the instructor works during the day - we chat a little bit after class but it's a little hard because she 
works all day" (Interview with Karen, p 4, February 27, 2009). Recall from Stage 1 that this is the same issue that Sarah identified: "many of the adult ESL teachers do have a lot of demands on them. They may be leaving right after the class ... So time is often a big issue" (Interview with Sarah, p.7, January 9, 2009).

\section{7) Experiences with Reflective Teaching}

Alima, Marek, and Karen all identified themselves as being naturally reflective individuals and Elaine indicated that she was definitely introspective, which she felt was similar to, but not synonymous with, being reflective. Alima strongly identified with the notion of being reflective and indicated that although she had once considered her tendency to be reflective a negative trait, this perspective changed when she first started teaching:

Every job I've had and everything that I do, I really think about it. It used to be a very bad trait, until I became a teacher, and then it became really useful ... I mean, I relive a lot of things over and over again, especially when they don't go very well. I really have the instinct to want to somehow fix them. So that's why I never quit when I was teaching in Jordon. The first year was rough and the second year was a little better, but I just couldn't quit, because I knew that it had to be better somehow - there was a way to make it work (Interview with Alima, p.12, February 24, 2009).

Note the underlying theme of reflecting on teaching moments that did not go as well as planned in order to improve upon one's future practice. This perspective is echoed by both Marek and Elaine and will be reported on the following page.

All four TLs emphasized the importance of reflection for both pre-service and in-service teachers. However, Alima was the most emphatic about this point. In her words:

I don't think you can be a teacher without doing it. I mean . . . if you don't reflect, that means you are going back and doing exactly the same thing that you did yesterday that may not have worked or may have worked, but you don't know that it did or didn't, because you didn't even think about it. You're not living consciously as a teacher. You're not actually teaching you're just going through the motions of something and really not being aware of it. So it's just impossible to be a teacher without it. I mean, anything you do 
in life, you should be reflecting on, because that's how you grow. So it helps you grow. You need to think about even the things that went right and how you can somehow make them happen again. Um, and also, those things are obvious; students will tell you, directly or indirectly, and adults will be shyer, in my experience because they don't like to openly criticise. Teenagers will tell you to your face. Yeah ... I think it [reflection] is the foundation of teaching (Interview with Alima, p.7, February 24, 2009).

Clearly Alima sees value in being reflective, not just about her teaching practice, but about anything you do in life because that's how you grow. Importantly, the above excerpt shows how positive teaching moments can also be a useful source of reflection in order to somehow make them happen again.

Alima also indicated that when teaching overseas, she was reflective about her teaching practice and "did it all the time" but not always consciously. She feels that individual reflection is the reason she was able to improve and develop as a teacher: "That's the way I developed as a teacher, and I really did develop as a teacher. I'm not saying I was perfect five years later, but I could sense a huge difference (Interview with Alima, p.7, February 24, 2009).

Marek had a similar perspective on the issue of reflective teaching. He indicated that for him, being reflective is one of the necessary criterions for effective teaching. In his words:

You know, if you're just coming into the classroom and doing your thing without at all considering what's working for the students or not, and if you're not learning from your lessons, how can you be a good teacher? ... I think if you're teaching, it's important to think about what you're doing and what worked and what didn't work in the classroom, and adjusting to then make lessons better (Interview with Marek, p.10 and 6, February 25, 2009).

Marek went on to say that part of being reflective involves "researching and testing different methods" (Interview with Marek, p.10 and 6, February 25, 2009). This suggests that he supports Richard's (1998) theory that reflective teaching necessarily involves active exploration and 
experimentation on the part of the teacher. Marek, similar to Alima, also feels that reflection is needed to improve one's teaching practice:

You know, sometimes you do something and it doesn't work. You have an idea that this activity will work and then you realize it's flawed in some way. So you can revise it and then make it better . . . better for the students (Interview with Marek, p.8, February 25, 2009).

Similar to Alima and Marek, Elaine sees reflection as very much associated with wanting

to improve one's practice. She comments that:

... if you think about things that you've done, and then you realize that you could have done them a better way, then the next time you do them, chances are you'll be able to incorporate some of that 'better way' that you came up and maybe even then come up with yet a better way. So, constant improvement is the key (Interview with Elaine, p. 9, February 25, 2009).

\section{Not all Teachers Reflect in the Same Way}

Karen makes a very interesting point about reflective teaching. While sharing the same point of view as Marek, Alima, and Elaine that being reflective is "just a component of good teaching" (Interview with Karen, p. 10, February 27, 2009), she also emphasizes that the process is personal, individualized, and unique to each practitioner. In her words:

I think everybody does it differently. We don't all teach in the same way and we don't all reflect in the same way. Somebody might - for them it might be just as valuable to write just a couple of quick notes on their lesson plan and maybe for someone else - to ask for the students to fill in an evaluation, and then you look that over, and that could be part of reflection (Interview with Karen, p. 10, February 27, 2009).

This point that Karen makes about reflection being unique to each teacher is an important one to consider, especially within the context of the CTESL program where students are engaged in four types of reflection: online, in-person, individual, and collaborative. The online medium involves reading and writing (typing) and includes a delayed response, whereas the in-person medium involves listening and speaking in a more spontaneous manner. 
Related to this point is the issue of teacher educators and ESL teachers alike (hence, loop input) needing to address "a wide spectrum of learning styles" in their classrooms and to be "respectful of all of the differences" (Interview with Alima, p.11, February 24, 2009). Conveniently, Alima indicated that one of her learning preferences was to reflect mentally, not through writing, whereas Karen indicated that she found writing down her reflections to be very helpful. Table 7.3 illustrates these two different reflective learning preferences:

Table 7.3: Two Different Reflective Styles

\begin{tabular}{|c|c|}
\hline Alima's preferred reflective style & Karen's preferred reflective style \\
\hline $\begin{array}{l}\text { In the context of this course, I wrote them } \\
\text { [reflective notes] occasionally, but I didn't } \\
\text { stick to that. Partly because I'm an inpatient } \\
\text { person and I can't write down everything I'm } \\
\text { thinking - I know it's not going to go away, } \\
\text { because it's in my head. So most of it stays } \\
\text { in my head and I'm the kind of person who } \\
\text { likes to keep moving on. I don't want to } \\
\text { take all this time to write everything } \\
\text { down; but it stays with me (Interview with } \\
\text { Alima, p.12) }\end{array}$ & $\begin{array}{l}\text { For me, I need to write some things down. } \\
\text { Whether that's going to be on Web-CT and } \\
\text { I'm going to print that off, or whether I need } \\
\text { to write some notes in a notebook, because } \\
\text { otherwise I'm not going to remember why } \\
\text { something was positive or not...for example, } \\
\text { last term, with my Literacy placement, we } \\
\text { talked after most of the lessons, and I would } \\
\text { try to take notes while we were talking or } \\
\text { shortly after. So I see value in doing it } \\
\text { (Interview with Karen, p.8-9). }\end{array}$ \\
\hline
\end{tabular}

When we recall that Bailey (1990) emphasizes that journal writing should always be voluntary and never be forced on student teachers, the significance of Alima and Karen's differing perspectives on writing down their reflections takes on greater meaning. Worth re-considering is that Karen found both online and in-person reflection to be beneficial, whereas for Alima, "the only way I learn is by hearing other peoples' opinions, hearing what happened to them and telling them what happened with me" (Interview with Alima, p. 9, February 24, 2009).

Elaine also supports the idea that reflective teaching is unique to each individual:

I don't think you can be forced to be reflective about something - that's difficult. You know, here's a topic - reflect on it. Some things just don't affect you the same way ... introspection is a very personal thing. So 
you're going to be introspective about things that affect you, things that you tune into (Interview with Elaine, p.13, February 25, 2009).

From the above excerpt, we can clearly see that Elaine shares Karen's sentiment that reflection is a very personal experience, a process unique to each practitioner. The idea that every teacher be given choice over what they want to reflect on as well as which medium they choose to reflect in takes on additional significance in light of the combined above excerpts.

\section{The Practicum Site Visit: A Collaborative Experience}

Recall from Chapter 5 how enthusiastically Sarah described the latest addition to her 2008-2009 course curriculum: the practicum site visit. Again, this site visit was followed by a one-on-one consultation between the TL who had been observed and the practicum course instructor or the methodology instructor who had been observing. The purpose of the follow-up consultation was to enable each TL to discuss their practicum experiences with their instructor.

As reported earlier, Sarah described this visit not as a type of formal evaluation, but rather "simply an observation and a sharing of an hour with them [the CTESL students]" (Interview with Sarah, p.8, January 9, 2009). This is significant because of the link to LTE literature where teacher educators have emphasized that observation of TLs, whether by peers or practicum supervisors, should involve descriptive, not evaluative feedback. Observation becomes a starting point for developmental dialogue that both the observer and observee can learn from.

I specifically asked Karen about her experience of the practicum site visit and the follow-up consultation because she was the only $\mathrm{TL}$ in this study who came into the program with a B.Ed. and thus had prior experience being a practicum setting. Here is that exchange:

INTERVIEWER: This is the last question that relates to your B.Ed. experience. Were you evaluated during your practicum? And if you were, do you think that the CTESL program should have that component of evaluating its student teachers? 
KAREN: Yes, we had to be. But I'm not sure if we should [be evaluated by an observer in the CTESL program]. I mean, I had somebody come in and observe me last term, so that was similar, but it felt a lot more like a partnership, which was nice, because it was more just comments and sitting down with one of my profs. It didn't feel as stressful, because you knew your grade wasn't dependent on this day (Interview with Karen, p.3, February 27, 2009).

Note how Karen describes the CTESL practicum site visit and subsequent consultation as being a lot more like a partnership than her experience of being observed five years' earlier during her B. Ed program. Note also how she found the process less "stressful" because she knew her grade wasn't dependent on this day. In this way, we can see that Sarah's intent to have the practicum site visit be a collaborative experience for each TL being observed was actualized.

Why are Karen's reflections on the "partnership" aspect of the practicum site visit so important to consider? There are two reasons. First, if LTE programs are indeed influenced by trends in GTE programs (Crandall, 2000), asking someone like Karen to compare her experience being observed as a B. Ed. student (GTE context) with being observed as a CTESL student (LTE context) is timely. Secondly, the practicum site visit is the latest addition to the CTESL program and Sarah enthusiastically indicated that she planned to include it in future years. Asking Karen to comment on her experience of the site visit and the follow-up consultation and compare it with her B.Ed. experience is important because it sheds light on how useful the process might be from a CTESL student's perspective.

\section{Hindsight Reflection: The Impact of PLTE}

Marek and Alima both touched upon an aspect of reflective practice that I have not encountered previously in my readings on reflective language teaching. Both indicated that they had reflected on previous language teaching experiences prior to the CTESL program. Specifically, they had thought about the ways they might have better met the needs of their 
former students in light of new theoretical knowledge gained in their CTESL courses. Hindsight reflection is a term that I am employing here to describe this occurrence. In this study, I apply this term exclusively to teacher learners who come into the CTESL program with previous language teaching experience (PLTE) and, while broadening their theoretical knowledge-base via course-work, develop new insights about their former practice.

The following excerpt, from Alima, provides a great example of hindsight reflection: ... looking back, I wish I knew then what I know now, in terms of dealing with these students who needed help - they needed a lot of help - they needed scaffolding, help with their writing ... especially for the weaker ones ... to help them really get over their struggles with certain structures and very typical mistakes, like subject verb agreement and the $3^{\text {rd }}$ person singular present tense verb ending and things like that.[But] I didn't have that training (Interview with Alima, p.1 and 3, February 24, 2009).

Notice how Alima indicated her lack of teacher training and theoretical SLA knowledge meant that, in the past, she didn't understand the importance of scaffolding the writing process for her weaker learners. Her comment of I wish I knew then what I know now is a key indicator that she has, during the course of the CTESL program, engaged in hindsight reflection.

Similarly, Marek indicated that the theoretical knowledge from his CTESL courses had provided him with new insights about his previous language teaching practice. He also indicated that observing his first host teacher was an important part of seeing the theory of communicative language teaching (CLT) being put into action. Marek said that he realized, from his CTESL courses, that he had "much to learn as a teacher" because much of what he did in Taiwan "was based on outdated methods" (Interview with Marek, p.12, February 25, 2009). Marek described his teaching approach in Asia and indicated that he would have done some things differently if he could have applied then what he knows today. In his words:

... the tasks [in Asia] weren't usually student-centered, there wasn't a lot of communicative teaching - which I'm just learning about now. I think I would 
have done some things differently if I could. I would have done a lot more group work, had information gaps, and have the students negotiate their own meaning. I don't know - perhaps less correction. So here, especially last semester, I was quite surprised to see it was all about the students. She just came in, she had some tasks, she assigned them, and that was it. She was there to help out and answer questions, but it was a lot of group work (Interview with Marek, p.5, February 25, 2009).

From the above excerpt we can see how Marek has applied both theory and theory in practice (via observation of his first host teacher) to then reflect upon his former teaching in Taiwan. From here he has thought about some of things he would do differently if he could. In Chapter 8 I will further discuss the significance of hindsight reflection - a form of reflection that Marek, Alima and Karen all engaged in.

\section{Stage 4: Findings from the Group Interview}

In the final section of this chapter I report on findings from Stage 4, which involved a group interview with Elaine, Marek, Alima, and Karen. As mentioned in Chapter 3, the decision to include a group interview as part of my research design was to create an opportunity for a synergistic exchange of ideas about reflective teaching, pooling together the ideas and experiences of 4 TLs in one setting. Recall that Kleiber (2004) asserts that this type of group environment allows researchers to gather data "not available through individual interviews or surveys" because of the unique social interaction that occurs between participants (p.97).

Questions asked during the group interview related to themes such as the role of reflection in the CTESL program, the value of observing host teachers, the value of discussing the practicum with peers as well as group work, and the participants' sense of development as English teachers. As indicated in Chapter 3, I also asked the group for their input on results from the questionnaire in Stage 2. In particular, I wanted their input on why they and eleven of their peers had all indicated that the practicum was an essential part of the CTESL program. 


\section{The Practicum: an Essential Part of CTESL}

When asked about why they had indicated on the questionnaire that the practicum was an essential part of the CTESL program, Alima and Elaine were the most vocal. For Elaine, she indicated that both observation and practice teaching were the two most important aspects of the practicum as they helped her develop a sense of what teaching ESL in the community entails:

... the only way you can really get out there is to get out there. I think having that kind of setting where you can go once a week to observe, take notes, try a few things out and get your feet wet, and, as you go along, you're learning things in class [CTESL classes] as well; so that way you are building your repertoire of things that you can do in the classroom (Group interview, p.1, March 11, 2009).

Note Elaine's reference again to the concept of building a repertoire of things she can bring to her future classrooms. Effectively, this repertoire can be understood to reflect her developing knowledge-base of what it means to teach ESL. It encompasses both theory (what she is learning in class) and practice (observations of her host teachers and students as well as practice teaching).

Elaine indicated that developing her own materials and adjusting existing materials to better meet the needs of her Literacy ESL students has also been an important part of her practicum experience:

... if you're just going by the little textbooks that are out there, well. . .I had an incident last time where I discovered that some of the materials I had encountered were really not suitable for the level they claimed to be suitable for and I had to completely revise the materials. I had found a picture story book in the resource centre . . I took a chapter out of that dealing with numbers. These picture stories are like a comic-book scenario where you have left to right and top to bottom. And students did not understand this. I gave them a copy of the page with two distinct stories on it, following a story-board format, and they were clueless. I couldn't get them to understand what was going on. So what I ended up doing was extracting the whole thing, to put it on individual pieces of paper, blow it up, colour it, make it nice and bright and add text. And then, when I went back last week to do this, they understood everything. They really enjoyed it. But the original material is just not suitable as is - it needed to be modified. And it was only because I had 
tried it and failed that $I$ was able to realize this. . . you really do need to have some experience (Group interview, p.1, March 11, 2009).

Similarly, Alima noted the importance of gaining hands-on experience of what it's like to be in the ESL classroom, both as teacher and observer:

It's one of those things where you say it so many times that it almost sounds like a cliché - that experience is the best teacher. But it's really true. In the case of teaching, it's such a dynamic process we're talking about. Everything shifts; every class is different and every time you have a group of human beings in the same room, you're dealing with different dynamics. You cannot know what that's like unless you've seen it for yourself and you've dabbled a bit in teaching. It's also about changing perspectives. When you're observing, at least for me, I feel like I'm the position of being a student. I'm looking at what the teaching is doing and I'm thinking about their presentation skills and the energy they project onto the room. I can view what they're doing critically. But once I got up there and was in her shoes the other day, well I probably did some of the things I thought she shouldn't be doing. And you get nervous, I mean, once you're up there, your whole perspective of the classroom changes. But you really need to experience that for yourself in order to get it (Group interview, p.2. March 11, 2009).

What is interesting about the above excerpt is the similarity between Alima words here in Stage 4: experience is the best teacher and those of Elaine, shared in Stage 3: Experience is a great teacher. Experience is really the only teacher (Interview with Elaine, p 15, February 25, 2009).

Also note-worthy is the point that Alima makes about observing her host teacher. She indicates that observation has allowed her to step back and consider what it is like in that teaching moment to be in the position of a student. Alima also indicates that when she is teaching, her whole perspective of the classroom changes and she can no longer maintain that critical perspective. Also interesting about the above excerpt is the fact that TLs in the CTESL program are not provided with an opportunity to view themselves teach on videotape or microcassette, which would effectively allow them to observe themselves in action and potentially consider their teaching from a student's perspective. 
Elaine also indicated that she found observing how her host teacher interacted with ESL

students to be beneficial. In her words:

... when you're observing, you're noticing the students and the teacher. You can see how the teacher can't always be aware of everything that's going on. She might be busy talking to one student and not recognizing right away that another student is lost. And when I'm in that position I find I'm having the same trouble ... and it makes you aware how difficult it is to keep track of everything as you're trying to keep your energy up, moving the lesson forward and trying to make sure that everyone gets their turn. But can you, really, be spot on all the time? It's not that easy (Group interview, p.2. March 11, 2009).

Note how Elaine recognizes that the challenges inherent in teaching a class of adult ESL learners because she has a) experienced them in her practice teaching and b) become increasingly aware of them while observing her host teacher in action. Note also the reflective tone of her question of can you really be spot on all the time and her equally reflective response of it's not that easy.

\section{Collaborating with Host Teachers}

Karen indicated that, for her, one of the most valuable aspects of her first practicum experience was the collaborative work relationship she developed with her host teacher:

... it was nice to have that other instructor there ... we would sit after class and go over things when it was possible. We could say, 'Oh, that person's getting this, that's great' or, 'that activity didn't go very well, we won't do that again' - It was just a nice way of sharing those things. It was helpful. Sometimes she would ask me what I thought of an activity she had done, so I felt like things were on the same level, that she would ask me about her teaching (Group interview, p. 3, March 9, 2009).

What is fascinating about the above excerpt is the fact that Karen's host teacher would sometimes ask Karen for feedback on her own teaching. Here we see strong evidence of reflective practice on the part of the host teacher. The host teacher does not place herself in the role of expert teacher or "master teacher" but, on the contrary, asks Karen for insights and feedback about her practice. Note also that Karen indicated she felt that things were on the same 
level, suggesting that that the concept of a master teacher was not part of the mutually beneficial and collaborative work relationship they had developed.

\section{Enthusiasm for the Poster Session}

When the group interview took place on March 11, 2009, the CTESL students had just completed their end-of-course poster session activity. Given the enthusiasm that Sarah, the practicum course instructor, expressed for this reflective activity in Stage 1, I thought it fitting to ask the four TLs about their experiences and opinions of the poster session.

All four CTESL students indicated that they had found the poster session beneficial.

Elaine was the first to respond, and did so enthusiastically:

Well, I was just so excited just to tell everyone what I did - you know, I was just so high on this one lesson that I finally got to work. I just didn't want to shut up about it! (Laughs) I would have sat there all day and talked about. And, going around the room, a lot of people had really good ideas. It was just a little sad for me that we were only able to hear from half of the class, so there were many people I didn't get to hear from - because we were presenting at the same time as each other (Group interview, p.5. March 11, 2009).

From the above excerpt we can see that Elaine experienced two benefits from the poster session:

1) the excitement she felt about sharing a lesson activity that she finally got to work and

2) listening to the ideas of her peers. Related to the second point, we can also see that Elaine felt disappointed that she wasn't able to listen to the ideas of all her peers. Hence we can see that for Elaine, the poster session was very valuable.

Alima, Marek, and Karen also indicated that they found this end-of-term activity to be beneficial. They focused mostly on what they had learned from their peers. In Alima's words:

... talking about it [your poster], you get to hone your message around what you did and why you did what you did. But for me, it was more interesting to go around and see other peoples' work because there's always an idea that's nicer than mine. I found a lot of them very creative . . but for me, it was just the pleasure of seeing other people's ideas that I can steal. And 
also, from an artistic perspective, because I'm a visual person and I learn visually, I tend to enjoy things that way. Some of the posters were quite artistic and seemed to have a good eye for design. So that was an added bonus in terms of taking it in (Group interview, p.6. March 9, 2009).

Note that Alima found seeing other peoples' work to be most beneficial because there's always an idea that's nicer than hers. Recall that Alima has the most amount of PLTE of the 14 students surveyed in Stage 2. Her comment therefore takes on larger significance; clearly she feels she can learn from all of her peers, including those who have less or no PLTE.

Like Alima, Marek and Karen both indicated that, for them, the main value of the poster session was the opportunity to learn from their peers. Karen notes that "It was nice to talk with people and share ideas - because they'll think of things that you haven't thought of" (Group interview, p.6. March 9, 2009). Referring back to what Alima said about stealing other people's ideas, Marek commented, "I agree with what's been said, especially the stealing part" (Group interview, p.6. March 9, 2009).

In this way, we can argue that Sarah's goal of creating a collaborative learning environment through the poster session activity has been met, at least from the perspective of four TLs, three of whom had several years' PLTE. Even more interesting is that one of the TLs felt the activity was so effective that it should not be restricted to an end-of-year experience:

if I was outside the course, looking at it objectively, not as a student having to do all this work, looking at it in terms of what I would expect, well, as a teacher training course, I wondered why there weren't several poster sessions spread out. I know - you're going to kill me! [Laughingly refers to Elaine, Marek, and Karen]. It is a lot of work, I confess, but this is a teacher training course. It's about being together condensed ideas and creating room for discussion and helping to generate ideas. So it feels like a natural activity to have (Group interview, p.7. March 11, 2009). 
From Alima's perspective, though the poster session activity required a lot of work, this was time well spent in terms of the final outcome where she and her peers could bring together condensed ideas and create room for discussion.

\section{Their Development as Teachers}

As reported previously, one of Sarah's objectives as the practicum course instructor was to encourage long-term professional development among the CTESL students. For this reason, I asked the four TLs in Stage 4 about their development as both novice and experienced teachers over the course of the CTESL program.

Alima was the first to respond to the question of teacher development. In her words:

I had a few years of experience in high school with first-language speakers. That had prepared me somewhat. It gave me an experience of what it's like to be in a classroom ... but second language teaching is different. You're paying attention to different things, including how you communicate with the class, how you explain, or amplify or clarify things. There are so many things that I took for granted in the past. I was teaching Shakespeare and Chaucer, so you're talking about students who are capable as first language speakers. With second language speakers, as soon as I walked in, I realized ... how much I take for granted when I communicate and how I need to be really explicit. The explanation that I gave for a word shouldn't be three times as hard as the word itself. That was one thing. Also the courses as a whole have really helped. You have to take Introduction to Linguistics, Second Language Acquisition, the Methodology, and some electives. All of those courses and the accumulation of the knowledge that I've been exposed to has created for me a fundamental shift in my perception of second language learning, and what is a realistic and what is an unrealistic goal for second language learners ... [these experiences have] really have shifted the way I look at things. Completely and that's a positive for me (Group interview, p.3, March 11, 2009).

Worth noting is the fact that Alima describes a fundamental shift in the way she views second language learning and acquisition. This shift is based not only on practical experience gained through her practicum placements but also the theoretical knowledge through her course work. Recall from Stage 3 that Alima indicated she had no teacher training prior to the CTESL 
program. Also worth noting from Stage 3 is that Alima had engaged in hindsight reflection about her previous teaching experiences in Jordon.

On the topic of teacher development, Elaine indicated that her recent experiences working with Literacy students had really enriched her developing teaching practice. Her former concerns about having to be "on" and in performance mode did not materialize in practice:

I didn't have any previous teaching experience [coming into CTESL]. So for me it was about taking me from square one and getting me to a point where I felt like I could. Because, prior to last year, I had thought, there's no way I could ever be a teacher ... [which was based on] just the general fear of just having to doing presentations, that you have to be 'on' and know all this stuff, and you have to sound fluid the whole time - that's what I pictured. But it's so different where I am right now ... it's fun - it's really fun. And like I said, last week, when I was doing the revamp of the story-board thing and I saw them going 'aha' all the time - it was just so - it just felt so good. There are no words for it. That was the moment that I had been waiting for. You know, I think you should do what gives you energy, and that really gave me energy. So there you go. I am a convert (Group interview, p.4, March 11, 2009).

Note how Elaine had been waiting for that crucial moment of really connecting with her ESL Literacy students, of feeling like she was able to anticipate and directly meet their needs. Note also the emotional and significant transformation that has occurred within a short period of time: from feeling like there's no way I could ever be a teacher to being a convert. Perhaps the emotional charge behind this transformation and the admission earlier that, during the poster session, she was just so high on this one lesson that she finally got to work is based in part on the fact that Elaine did not have any PLTE to draw from. It is not too great a stretch to suggest that Elaine was experiencing, for the first time, the emotive high that many ESL teachers experience when they begin to really connect with and meet the learning needs of their students.

Marek remained uncertain as to the extent to which he had developed as a teacher during the CTESL program. He felt he needed more time teaching ESL students in order to gauge his improvement. In his words: 
I feel like I've been given some new tools and introduced to different methods that I wasn't aware of before . . . But I'm not sure how I've developed because I haven't taught a lot of practicum hours so far. Once I get more into teaching I'll see how much CTESL has helped me (Group interview, p.4, March 11, 2009).

Similarly, Karen indicated that while she found observing her host teacher and students to be of great value, she couldn't really comment on her development over the course of the CTESL program because she hadn't had that many hours doing practice teaching. She explains that "I think I have developed in certain ways, but because we're doing more observing, you can only develop so much" (Group interview, p.5, March 11, 2009). It is important to note that both Marek and Karen came into the program with several years' PLTE and both indicated that, while observing their host teacher and students is of great value, their actual teacher development is limited due to the relatively few number of practice teaching hours.

\section{Lack of Time Issues}

While lack of time issues did not feature prominently in the group interview, it did still come up as a topic of conversation. Due to links with Stage 1 and Stage 3 interview data, I therefore feel it is worth mentioning here, however briefly.

Marek indicated an interest in having additional practicum hours as a way to increase his interactions with the ESL students he had met during his placements:

One of the most enjoyable things I think for me this semester was just going to class and hanging out with the students. I enjoyed it. I wish I could do it more often ... I enjoy the hands-on experience and I would like more of it, actually (Group interview, p. 12, March 11, 2009).

However, Alima was quick to point out that more practicum hours would be difficult, given the already demanding schedule that CTESL students has. She indicated that there is a lack of time issue at play. She commented that: 
. . . with more practicum hours, something would have to give, like our electives, for example. Because, to be honest, 5 courses a term, it doesn't sound like a lot, but actually it translates into a lot of deadlines. And when you're teaching in your practicum, you need time to prepare. I found I needed like seven times more time than the actual lesson to come up with something that I felt could be a lesson. I don't know, it takes me a long time (Group interview, p. 12, March 11, 2009).

From the above excerpt, we can see that the intense CTESL student schedule that Sarah referenced during her one-one-interview in Stage 1 is echoed by Alima here in Stage 4. Hence any addition to the CTESL program - whether it be in the form of increased practicum hours or additional assignments to be handed in - would place greater demands on the CTESL students. If we consider that reflective teaching is one of the goals of the CTESL program, the likelihood that reflection would take place amidst an increasingly busy schedule seems doubtful.

\section{Hindsight Reflection Revisited}

Recall earlier in this chapter that hindsight reflection was reported as a significant finding from Stage 3 interview data. In Stage 4, additional examples of hindsight reflection were observed. In Stage 3, both Marek and Alima reflected on how their recent insights, based on newly acquired theoretical knowledge, caused them to reflect on their previous teaching practice and think about what they might have done differently. In Stage 4, Karen follows suit. On the topic of how she has developed as a teacher during the CTESL program, Karen indicated that she had been reflected on her previous practice and asking herself a number of reflective questions:

I've been doing some reflecting and wondering, $\mathrm{OK}$, did I use too much Grammar Translation when I was working with children? What did I do? ... For example, in the first term of [the Methodology] class when we went through all the different methods, I thought back to my teaching and thought about stuff that I would change . . . I think just having that opportunity when you're back in university to stop and look at your beliefs about things and to try out some different methods in someone else's classroom where it's a pretty safe set-up, you're in somebody else's situation - just having that opportunity to think of some different tools that you would use (Group interview, p.5, March 11, 2009). 
Note the seamless quality where Karen first shares a form of hindsight reflection about her previous teaching practice of working with children and then transitions to talking about having an opportunity to reflect on her teaching beliefs and try out new methods in her current practicum placements. Note also how this period of reflection is tied to her future practice, to think of some different tools that [she] would use. Thus reflection-for-action has occurred.

\section{The Place of Reflection in the CTESL Program and Beyond}

Given that reflection has become an integral part of LTE programs for well over a decade now (Richards \& Ho, 1998) and plays a significant role the content and organization of the CTESL practicum course, I thought it timely to ask Alima, Marek, Karen, and Elaine about their experiences of reflective teaching and if they thought reflection was over-emphasized in the CTESL program. Here is their response to those questions, below. Note the snowball effect outlined previously in Chapter 3 (Krueger \& Casey, 2009):

ELAINE: ... I tend to reflect by myself all the time anyway. But when you make it a task it kind of changes the perspective of it. I don't know if I like being forced to reflect. I need to reflect when it's time to reflect. It just sort of happens, as necessary.

ALIMA: I can see where you're coming from. But ... from my past teaching at that high school, I was surprised at how many long-term teachers were jaded and somewhat skeptical and not very helpful as teachers anymore. And sometimes even experienced teachers don't bother to reflect. It sounds contradictory, but some people don't see the purpose or the value in reflecting and it may need to be said to them, explicitly, that this is ... I mean, when I taught in high school, I reflected every day. My whole life was about, how can I make this better, to make things work? But it's not always obvious to everybody and some people don't actually see the purpose of why they're there - they see it as a thing to do as opposed to I'm here help these people and actually make things work for them.

MAREK: I'm not sure that reflection is something that can be taught. I reflect on my teaching even though no-one ever told me to reflect on it. But I think it's quite necessary to do it if you want to be a good teacher. But as you were saying, at some point some people fossilize in their teaching style and they fall into a routine without considering that the classes are not all the same, that the students are different and that you have to adjust your teaching, sometimes. But I'm not sure if being told to reflect will actually make people reflect in the end (Group Interview, p.7-8, March 11, 2009). 
From the above excerpt, we can see how reflective teaching is a complex issue: according to Elaine, it should never be forced upon teachers. And yet, as Alima notes, sometimes even experienced teachers don't bother to reflect. Marek raises the question of whether or not being told to reflect will make a difference for teachers who aren't inclined to be reflective about their practice. Yet he indicates that reflection is quite necessary if you want to be a good teacher.

On the topic of being forced to reflect, both Alima and Karen indicated that this was never the case in the CTESL program. Notice again the snowball effect of their comments:

\begin{abstract}
ALIMA: I mean, [the practicum course instructor] didn't ask us to submit our reflections every week after the practicum. She suggested that this was a very useful practice that was a fundamental part of teaching and it would help you think about things that maybe you didn't have time to write about during class. I mean, it really helps you become a better observer, and I think as a teacher that's what you need to be. I think that's a reasonable approach. It was facilitated - from my perspective, it was never forced.
\end{abstract}

MAREK: Yeah, and I think that's enough. But I think that if you truly enjoy teaching and you want to be a good teacher, you will reflect. If you don't, perhaps you shouldn't be teaching.

ELAINE: Well, I think that's true in any walk of life. If you want to be good at what you do, you'll think about how you can be the best you can do.

KAREN: And I think in this program, it was encouraged. But I agree with [Alima] - we weren't told to submit 5 pages every second week with our reflections on how our practicum was going. They could have asked us to do that, but they didn't.

(Group interview, p.8, March 11, 2009)

What is particularly interesting about the above excerpt is the fact that Karen emphasizes that journal reflections could have been a required component of the practicum course but weren't. This point is significant because of Sarah's decision, identified earlier in this thesis, not to include journal writing as part of the course curriculum. 


\section{Group Response to 'Baby Bird' Metaphor Prompt}

At the end of the group interview in Stage 4, I presented Alima, Elaine, Marek and Karen with a written prompt. The prompt was based on a teacher educator who had adopted the metaphor of a baby bird when describing the learning-to-teach process that student teachers go through (Bold \& Chambers, 2009). Recall that metaphors are understood to help TLs begin to articulate their beliefs and views on teaching and learning (Farrell, 2007; Knowles, Cole, \& Presswood, 1994; Larrivee, 2008). I wondered if a discussion centered on a baby bird metaphor describing the role of teacher educators might in turn reveal how the four TLs saw themselves as student teachers in the learning-to-teach process. I deliberately waited until the end of the interview to provide this prompt and indicated that I felt the metaphor image was problematic without indicating why as I hoped to prompt disagreement or agreement and start a discussion within the group. Here is the prompt that each participant was given to reflect upon:

\section{What do you think about this image?}

At an educational conference, a teacher educator was talking about their role in helping student teachers prepare to become "critically reflective practitioners" - to help them step back and think critically about their teaching practice. The author referred to their instructor role as being like that of a mother bird preparing her baby birds for flight.

I feel this metaphor is problematic, but I would like to hear your perspective. Can you think of a more fitting metaphor or image to describe the process of helping student teachers to become more reflective teachers? Or do you think the mother bird analogy is fitting? If yes, how so?

After the group had taken a few minutes think about their response to the above prompt, I made sure to listen to what the least experienced teacher, Elaine, had to say before asking to hear from the most experienced teacher, Alima. Again, as noted in Chapter 3, I wanted to make sure that the one novice teacher in the group, Elaine, had a chance to speak before being potentially influenced by others. 
ELAINE: I'm curious to know what you think is wrong with the mother bird image?

INTERVIEWER: Ah, well, I'll tell you afterward. Not before, but I'll tell you after.

ELAINE: Well, it sort of fits. I don't know.

INTERVIEWER: Tell me how it fits for you and then we'll hear from Alima.

ELAINE: Well, first you picture the mother bird ramming the worm down the baby bird's throat and then eventually, they start nudging them out of the nest. So I can see parts where it sort of fits. But I can't think of a better metaphor.

MAREK: I guess some of us have already started flying, so maybe we're looking at how to fly better?

ALIMA: Well, there are a couple of issues. To me, it comes across as patronizing. There are two things here: the whole thing that's being put across in this program is that teaching is a life-long learning experience. So there's a bit of a contradiction here in having the teacher trainer having the upper hand or the superior knowledge and the teacher trainee being dependent on that knowledge. But also, in terms of what we've learned about second language acquisition, the theory, approach and methodology - it's centered around collaboration. The student is not a passive recipient of knowledge, but they are an active participant. This [analogy] to me suggests a hierarchical relationship because birds are reliant on their mother to survive, to do anything. I don't feel a student teacher relationship should be like that. There should be more collaboration involved. Does that make sense to you - what I'm trying to say?

INTERVIEWER: I'm going to hold off for now, but then I will tell you what I think later.

ELAINE: Well, when I first started, that's exactly the position I felt I was in. I really felt like I had absolutely no knowledge of anything and I really wanted a lot of input.

MAREK: So you felt like a baby bird. . .

ELAINE: Yeah, I really felt like a baby bird. I didn't want to go to the practicum too soon; I didn't want to start teaching too soon, because I didn't think I was ready. So I wanted a lot of time. And then when they told me they were coming to my practicum for the teacher visit, I felt like it was a bit too soon. It was my first time teaching and [the Methodology instructor] was there. I was sort of in and out of my comfort level. I didn't know what I was doing. I was kind of winging it and I figured, OK, here's my first experience - take it or leave it - what could I do? But at least Daddy bird was there! (Group laughs)

(Group interview, page 9-10, March 11, 2009)

I find the above interview excerpt fascinating, for several reasons. First, is the diversity of responses generated by the four TLs: Elaine found that as a novice teacher, she could relate to 
the baby bird image of not wanting to leave the nest too early - not teaching before she felt ready. Alima, who had the most amount of PLTE in the group, found the baby bird image to be patronizing and incongruent with the concept of a collaborative model of language teacher education. Finally, Marek did not appear to find the image to be particularly problematic, although he did not appear to find it particularly helpful, either. Karen was also fairly neutral. She provided her response to the baby bird image a little later on in the exchange:

I think it still somewhat fits. I don't see the bird as necessarily passive. Even though they are being shoved out of the nest, they still need to learn to fly. The way that they fly when they first leave the nest, well, they're going to have to learn to fly better as an adult bird. So yeah, I think it still somewhat fits (Group interview, p.11, March 11, 2009).

I was particularly intrigued by Elaine's comment about the mother bird (teacher educator) ramming the worm down the baby bird's throat. For this reason I asked her a follow-up question to determine what exactly she meant by worms. Here is that exchange:

INTERVIEWER: Now I have to ask you about this image of the mother bird and the baby bird. You mentioned the mother bird giving the baby bird a worm. What would the worm represent?

ELAINE: Well, this is all the knowledge that they have that you need. And they try to kind of stuff it into you, at first, until you're strong enough to go out get your own.

INTERVIEWER: So it's all the information that was given to you?

ELAINE: Yeah. Kind of like, they needed to direct me as to what was the valuable information that I needed to know. And I wanted that direction.

(Group Interview, p.10, March 11, 2009)

Note the difference between Alima and Elaine's response to the baby bird metaphor prompt. Consider again that Alima came into the program with 5 years' PLTE and Elaine had no previous teaching experience. Could this account for the significant difference in their response to the prompt? I would argue that, yes, it can. 
If metaphor construction is indeed helpful for both pre-service and in-service teachers, thought to provide TLs with a visual tool to begin to articulate their roles as current and future teachers (Farrell, 2007; Knowles, Cole, \& Presswood, 1994; Larrivee, 2008), then an equally important question might be: what do significant differences in metaphor construction suggest?

The idea that one metaphor could somehow "fit" for all teacher learners at all stages of their career would suggest a prescriptive view of teaching. On the other hand, the idea that the very metaphors and maxims that teachers employ may in fact be indicators of how critically reflective they are about their practice would seem to hold some weight (Farrell, 2007; Richards, 1990; Scrivener, 1994). More importantly, and of relevance to this thesis, is the idea that metaphors used by both novice and experienced teachers may reflect their developmental stage and perceptions of learning-to-teach. It is my position that metaphor construction will invariably evolve over time for reflective language teachers as they develop their teaching repertoire and reflect on their developing practice. In other words, a metaphor that a TL identifies with at the outset of their teaching practice may no longer "fit" two years later. Similarly, a metaphor that a TL identifies with in their second year of teaching may no longer "fit" when they have been teaching for 10 years, particularly if they have been engaged in a critically reflective practice. 


\section{CHAPTER 8: Triangulation of Data Sets and Discussion}

In this chapter, I provide triangulated data sets from Stages 1, 2, 3, and 4 in order to address significant themes that recur within each stage. I then explore the case of an outlier ${ }^{24}$ in Stage 2 in order to ensure comprehensive data treatment (Silverman \& Marvasti, 2008). Finally, I discuss the significance of findings from individual stages of my data, indicating their relevance to literary sources reviewed in Chapter 2 of this thesis.

\section{Triangulation of Data Sets}

Three different sources of data were collected in the undertaking of research in this case study: 1) Document analysis of the practicum course outline in Stage 1;2) Questionnaire in Stage 2; and 3) One-on-one interviews in Stage 1 and 3, as well as a group interview in Stage 4. These different sources of data allowed me to triangulate my research findings. In the interest of brevity, I provide a summary of the triangulated data sets in the form of numbered list, below.

\section{Summary of Triangulated Data Sets:}

1. Previous language teaching experience (PLTE) was determined to be the most significant independent variable in Stage 2 affecting:

(1) The degree of difficulty 14 TLs experienced in their efforts to link educational theory and practice;

(2) The degree of value TLs placed on observing their host teachers; and

(3) The amount of feedback TLs indicated that would like to have received from their host teachers.

Similarly, data from Stage 3 and 4 indicate the importance PLTE plays a significant role with regard to the type of learning experiences TLs have. In particular, hindsight reflection was linked to the three TLs interviewed who had PLTE: Alima, Karen, and

\footnotetext{
${ }^{24}$ Though typically associated with quantitative studies, I am using the term outlier in a far more general sense.
} 
Marek. Also in Stage 3, Marek indicated that, from his perspective, PLTE allows TLs to more critically observe other teachers.

2. Observing host teachers and being provided with the opportunity to teach were identified in Stage 2 by 14 TLs as being the two most valuable aspects of the practicum experience. These findings were supported in Stage 3 and 4 by Alima, Karen, Marek, and Elaine. However, while Marek and Karen (both of whom had PLTE) indicated that observation was highly beneficial, they also felt their actual development as teachers over the course of the CTESL program was limited due to the limited number of hours of practice teaching.

3. The real experience of a practicum placement is pivotal: Both respondent $\mathbf{1 1}$ in Stage 1 and Alima in Stage 3 indicated that they valued the "real experience" of teaching ESL that the practicum placement offered. Respondent 11 in Stage 2 valued having a "real experience of how an ESL class really works" and in Stage 3, Alima commented that "it's all about the real experience - the value of it is that you get a real-life shot of what goes in a real classroom: what it's like, how many people are there, what the students' problems are, what the teachers are like, what they go through, and the circumstances you're working in."

4. The benefits of discussing with and learning from CTESL peers was identified by Sarah in Stage 1 and confirmed by all four TLs in Stage 3. Specifically, Alima echoed Sarah's sentiment that collaborating with peers is an essential part of reflective teacher development.

5. The value of observing host teachers identified in Stage 2 was seen to encompasses numerous aspects of teaching by Karen, Elaine and Alima in Stage 3, such as:

(1) Accommodating the needs of different students;

(2) Host teachers' encouragement of ESL learners;

(3) The host teacher's pace and overall approach to teaching (e.g., methodical and repetitive when working with Literacy students);

(4) Use of visual aids and authentic materials in class; and

(5) Overall classroom dynamics and collaborative work environment.

6. Sarah in Stage 1 and Alima and Marek in Stage 3 indicated that positive and negative teaching experiences can be a source for critical reflection. Further, Alima indicated that observing a somewhat ineffective substitute host teacher provided her with insights on how not to teach ESL / interact with ESL learners. 
7. The practicum site visit, the latest addition to the 2008-2009 curriculum, was seen as a collaborative, "partnership" model for teacher development by both Sarah in Stage 1 and Karen, in Stage 3.

8. The poster session was considered a highly beneficial and collaborative reflective activity by Sarah in Stage 1 and all four TLs interviewed in Stage 4. Alima found it so beneficial and collaborative that she wondered why it was only featured as an endof-the-year activity.

9. While online reflection was highly valued by the course instructor in Stage 1, the majority of student teachers surveyed in Stage 2 (14 TLs total) indicated that this was their least preferred form of reflection. Stage 3 data provided further insight into why some TLs (such as Marek) find online discussion beneficial and other TLs (such as Elaine) do not. In Stage 3, Alima and Karen provided insight into the possible link between enjoyment of online learning and factors such as learning style preferences and personality type.

10. Lack of time issues was a central theme in Stage 1 findings from the interview with Sarah. This issue was also mentioned in Stage 3 by Karen with regard to lack of time from the TLs perspective as well as her host teacher's busy schedule (resulting in decreased feedback). Lack of time was also touched upon by Alima in Stage 4 regarding the intense schedule that CTESL students have.

11. Experience is the best teacher was a theme that emerged during the interview with Elaine (who had no PLTE) in Stage 3 and was echoed by Alima (who has 5 years' PLTE) in Stage 4.

12. Host teachers play as important role in the practicum experience, forming part of TLs' knowledge-base was a theme that emerged in Stage 1 with Sarah as well as in Stage 3 during the interview with Karen and Alima.

13. Reflecting-on-practice with the intent to improve future practice (reflection-forpractice) was seen as an essential part of reflective practice by Sarah in Stage 1 and as well as by Marek, Karen, Elaine and Alima in Stage 3 and 4.

14. A range of reflective activities is needed in LTE programs. This theme emerged in Stage 1 with Sarah and was echoed by all 4 TLs in Stage 3 and 4 . 


\section{Concerns of 14 TLs: Links to Conway \& Clark's (2003) Work}

Chapter 2 provided an overview Conway and Clark's (2003) model of teacher development. Chapter 6 reported on the concerns that 14 CTESL students indicated they experienced in September 2008 and their concerns in February 2009 as they looked ahead to the future. I provide Table 6.7 and 6.8 for comparative purposes and to answer the question: how did TLs' concerns change over a 6-month period?

Table 6.7: CTESL Students' ELT-Related Concerns in September 2008

\begin{tabular}{|l|c|c|}
\hline Past Concerns in September 2008 & Respondent \# & Total Frequency \\
\hline Relationship with host teacher & $3,5,10,12$ & $\mathbf{4}$ \\
\hline Nervous about performance aspect of teaching & $1,7,9$ & 3 \\
\hline Teaching in front of a large class & 1,7 & 2 \\
\hline Being able to answer ESL students' questions & 8,11 & 2 \\
\hline Meeting students' needs & 11,13 & 1 \\
\hline No previous concerns & 6,14 & 1 \\
\hline Access to adequate teaching resources & 4 & 1 \\
\hline Fear of the unknown / general apprehension & 12,2 & 1 \\
\hline Transition from teaching children to adults & 13 & 2 \\
\hline Being faced with so many different student needs & 13 & 2 \\
\hline
\end{tabular}

Table 6.8: Student's ELT-Related Concerns in February 2009

\begin{tabular}{|l|c|c|}
\hline Future Concerns in february 2009 & Respondent \# & Total Frequency \\
\hline Meeting the needs of ES/FL students & $8,9,11$ & 3 \\
\hline Developing own teaching materials & $5,6,10$ & 3 \\
\hline No concerns & $2,4,13$ & 3 \\
\hline Finding work & 1,14 & 2 \\
\hline Managing workload & 3,10 & 2 \\
\hline Being ready to teach own ESL class & 7,12 & 2 \\
\hline Size of ESL classrooms & 7 & 1 \\
\hline Able to make use of SLA theory and research in class & 8 & 1 \\
\hline Being an effective teacher & 11 & 2 \\
\hline
\end{tabular}


Table 6.7 shows that the most frequently cited concerns for September 2008 were:

(1) The relationship they were going to have with their host teacher (4 total);

(2) Being nervous about the performance aspect of teaching ( 3 total);

(3) Being able to answer ESL students' questions (2 total); and

(4) Meeting students' needs (2 total)

Table 6.8 shows that in February 2009, the most frequently cited concerns about the future were:

(1) Meeting the needs of ES/FL students (3 total);

(2) Developing own teaching materials ( 3 total);

(3) Finding work ( 2 total); and

(4) Being ready to teach own ESL class (2 total)

It appears that a movement from inward-focused concerns (how will I perform in front of a large group of students?) to outward-focused concerns (will I be able to meet the needs of my future students?) has occurred between the first practicum placement in September and the second placement in February. However, we need to keep in mind that, as Table 6.7 and Table 6.8 show, respondent 11 indicated that she was concerned about meeting her students' needs both in September and in February, as she looked ahead to the future.

In fact, looking at Table 6.7, we can see a duality at play regarding the concerns of respondent 11, who was concerned about being able to answer ESL students' questions while at the same time feeling concerned about meeting the needs of her soon-to-be practicum students. Thus respondent 11 can be seen to have both inward- and outward-focused concerns prior to starting her first practicum. This finding lends support to Conway and Clark's (2003) position that learning-to-teach is not a linear process that always begins with inward-focused concerns and then progresses outwardly to reflect concerns about students.

What is interesting about the 14 TLs' reported concerns in September 2008 is that the most frequently cited concern, relationship with their host teacher, cannot be neatly categorized as either an outward or inward focused concern, but rather can be viewed as both. Significantly, 
all four TLs who reported relationship with host teacher as their greatest concern were all novice teachers: they came into the CTESL program with no previous language teaching experience.

Worth noting is that, similar to relationship with host teacher, some concerns, such as being able to make use of SLA theory and research in class may appear inward-focused but in fact relate to what Conway and Clark (2003) have termed development of self-as-teacher. This means that rather than focusing on concerns about self for survival (how can I create a good lesson plan), TLs are focused on their own development as teacher learners.

Finally, Table 6.7 and Table 6.8 show an almost equal ratio of outward-focused concerns (such as meeting the needs of ESL students) and inward-focused concerns (such as finding employment). These findings suggest that, similar to the TLs surveyed in Clark and Conway's (2003) study, the 14 CTESL students in this study were equally prone to outward and inward focused concerns at both the beginning and middle stages of their practicum. As such, the assertion that Clark and Conway (2003) make that the process of learning to teach does not involve a linear progression from concerns for self to concern for others, but rather is cyclical and bi-directional, is supported.

\section{Investigating the case of an Outlier: Respondent 2}

As indicated in Chapter 3, Silverman and Marvasti (2008) recommend qualitative researchers increase the validity of their findings by "actively seeking out and addressing anomalies and deviant cases" (p.259-264). Rather than cherry-picking data that supports a researcher's initial research hypothesis or their emerging theories, a critical examination of all 
data, known as comprehensive data treatment, is needed (p.259-264). For this reason, in the following section, I investigate the case of an outlier ${ }^{25}$ : respondent 2.

An interesting feature of the data shown in Box plot 2 on page 116 is the answer of respondent 2, the only CTESL student with no PLTE who was not emphatic about the value of observing host teachers. Briefly, I will share additional information about respondent 2 that may account for his less emphatic response compared to that of his peers who also came into the program with no PLTE. Here is that additional information:

Table 8.1: Additional Information on Respondent 2

\begin{tabular}{|c|c|}
\hline Gender & Male \\
\hline Age range, & 50 plus \\
\hline $11 \%$ & Not English \\
\hline PITE: & None \\
\hline Type of student & Post-graduate \\
\hline $\begin{array}{l}\text { How often } \\
\text { respondent } \\
\text { strongly agreed } \\
\text { or disagreed }\end{array}$ & $\begin{array}{l}1 \text { time only; } 13 \text { answers out of } \\
15 \text { were all } 2 \text { s and } 3 s\end{array}$ \\
\hline $\begin{array}{l}\text { Responses to } \\
\text { open-ended } \\
\text { questions. }\end{array}$ & $\begin{array}{l}\text { Extremely brief: } \\
3 \text { words; } 2 \text { words; } 1 \text { word; } 5 \\
\text { words }\end{array}$ \\
\hline
\end{tabular}

I provide this additional information because respondent 2 is distinct from his peers in more than just one area of the questionnaire. In addition to his response to question 18 , he is the only student to only somewhat agree with question 15 , which included the statement that the practicum placement is an essential part of the CTESL program. All other students indicated

${ }^{25}$ I understand the term outlier is associated with quantitative studies of an experimental nature. However, I am using the term in a far more general sense, similar to journalist Malcolm Gladwell in his 2008 book "Outliers". 
strong agreement or agreement. It is important to note that his responses to all 15 likert-scale questions are all $2 \mathrm{~s}$ and $3 \mathrm{~s}$, with the exception of question 21 and 22 . As well, his responses to the four open-ended questions in the final section of the questionnaire were the briefest of all 14 student teachers surveyed: 3 words in his answer to the first open-ended question; 2 words for the second; 1 word for the third; and 5 words for the fourth. All other 13 respondents were much more elaborate in their answers, many wrote short paragraphs for each response.

Obviously any theories I have about why this mature male student with no previous teaching experience responded to the questionnaire in the manner he did are purely speculative. However I believe that outliers present interesting and potentially important cases to investigate. I offer the following two theories in the event that other scholars may find them interesting:

1. Respondent 2 may not be an emphatic or very expressive individual, which might explain why he answered emphatically to only 1 question out of 15 ; this may also help explain the brevity of his responses to four open-coded questions at the end of the questionnaire.

2. Gender may play a significant role in how emphatic respondents are: the two least emphatic respondents of all 14 student teachers surveyed are male: respondent 2 and respondent 6 . This fact led me to add up all the emphatic responses of female and male respondents separately. The results ${ }^{26}$ are fascinating:

\begin{tabular}{|l|l|}
\hline Male Respondents ( 3 total) & Female Respondents $(11$ total) \\
\hline The average number of times a male & The average number of times a female \\
respondent responded emphatically on the & respondent responded emphatically on the \\
questionnaire was $\mathbf{1 . 7}$ & questionnaire was $\mathbf{5 . 7}$
\end{tabular}

\footnotetext{
${ }^{26}$ The median for emphatic responses (instances where respondents circled 1 or 6 , indicating strong agreement or strong disagreement) for each gender was calculated by tracking the total number of emphatic responses per respondent and then adding these totals with totals of other respondents in the same gender group. These group totals were then divided by the number of members in each group. The total of all emphatic responses by females was 63 (from a total of 11 females). The total emphatic response for males was 5 (from a total of 3 males). Interestingly, the most emphatic male respondent who responded emphatically 3 times equated to the least emphatic female respondent who responded emphatically 3 times. Neither age nor PLTE influenced how emphatic female respondents were.
} 
Note that the frequency rate of emphatic responses cannot be attributed to PLTE.

Consider the following table:

\begin{tabular}{|l|l|}
\hline Female respondents with PLTE (2 total) & Male respondents with PLTE (2 total) \\
\hline $\begin{array}{l}\text { Alima, who had 5 years' PLTE, gave a total } \\
\text { of five (5) emphatic responses }\end{array}$ & $\begin{array}{l}\text { Marek, who had 4 years' PLTE, gave a total } \\
\text { of one (1) emphatic responses }\end{array}$ \\
$\begin{array}{l}\text { Karen, who had 4.5 years' PLTE, gave a total } \\
\text { of nine (9) emphatic responses }\end{array}$ & $\begin{array}{l}\text { Respondent 14, who had 3.5 years' PLTE, } \\
\text { gave a total of three (3) emphatic responses }\end{array}$ \\
\hline
\end{tabular}

\section{Stage 2 Questionnaire: Importance of the 6-point Scale}

Employing a six-point scale on the Stage 2 questionnaire to include strongly agree and strongly disagree options proved beneficial in this study. These two options allowed me to measure how intensely CTESL students felt about each statement. Several statements were responded to with intensity, indicating that TLs felt strongly about the topic at hand. As indicated on the previous page, results from six-point scale likert questions led to the discovery that, in my study, male participants were far less emphatic in their responses than their female peers.

Had I included only a 4-point scale, I would not have picked up on the intensity of each TL's response; I might not have been led to investigate the same emerging areas of importance that I had done in Stage 3 and 4 of data collection. Specifically, the six-point scale helped me to indentify the importance of PLTE in this study which I then explored further in Stage 3 and 4.

\section{TLs' interest in Curriculum Design and Acknowledgement of Researcher Bias}

When designing the questionnaire for Stage 2 data collection, I had not anticipated an interest in curriculum design with respect to respondents' ELT-related career aspirations. Thus, when reading the responses of Respondent 1 and 5, I was intrigued to discover that they weren't interested in teaching but rather were interested in curriculum design. I realized that my question 
of what aspirations do you have for your future as an English language teacher revealed a biased assumption that all TLs completing the CTESL program would be interested in teaching $\mathrm{ES} / \mathrm{FL}$ in the future.

\section{TLs' Motivation for Certification: Distinet from B. Ed Students?}

The diversity of responses that students gave when asked about their primary motivation for obtaining the CTESL (as seen in Table 6.5) is worth exploring further. Table 6.5 illustrates how some of the responses given, such as overseas travel opportunities, extend beyond the practical dimensions associated with certification processes, whereas other responses, such as professional development, are clearly linked to teaching. Worth re-considering is the fact that the first response belonged to a CTESL student who came into the program with no PLTE; the second response came from a student with 3.5 years' PLTE. Also, worth noting is that Alima, who indicated self-development was a central motivation for obtaining the CTESL, had 5 years' PLTE.

With no data on the primary motivations of student teachers enrolled in Ontario B. Ed. programs, I would, at some point, like to know if the reasons provided by B.Ed. student teachers are as diverse as the CTESL group surveyed, outlined in Table 6.5. Stopping to consider the specific pre-selection process that B. Ed. students go through in Canada before they even start their program (i.e., needing to select primary/junior or intermediate/senior during the initial application process), it makes sense that TLs' main reasons for obtaining a B. Ed. might constitute a less diverse range of answers than the CTESL group and may be more professionspecific. Given the diverse range of contexts associated with teaching ES/FL, and given the fact that CTESL applicants do not need to indicate their professional intentions regarding what type of ESL program they hope to teach in, I think the above speculations hold some merit. 
In support of this theory is the practicum course instructor's estimation that:

... probably 50 per cent of those who are doing it [the CTESL program] as a concurrent [with their undergrad degree] are really still unsure as to whether or not they'll actually go into teaching. . They may just be unclear as to what they're going to do in general and whether teaching is one of those options available to them (Interview with Sarah, p.12, January 23, 2009).

Note that Sarah distinguishes between TLs who are doing the CTESL program as part of their final year of studies in an undergraduate program and those who have already completed their undergraduate degree and have returned to university specifically for the CTESL program.

The distinction between undergraduate and postgraduate students is important for two reasons. First, data from Stage 2 of my study shows that the only two students who indicated a strong interest in curriculum design and far less interest in teaching ES/FL were both undergraduate students between 20 and 24 years old.

There is another reason why this distinction between undergrad and postgrad students is significant. The CTESL program described in this study is unique to other programs offered at Ontario universities and colleges because of the undergrad and postgrad distinction. While there is one other CTESL program offered in the same city (as the program featured in this study), this second program is offered at a college, and, more importantly, is for post-graduate students only. This means that students going into this college program have made the decision to return to school to specialize in ES/FL teaching. In this way they form a very different group to the undergraduate students in this study who were already enrolled in their undergraduate degree when they opted to do the CTESL program while completing their final year of study.

Again, this distinction is important when we consider the nature of the majority of B. Ed. programs in Canada that admit only post-graduate students in a specific area of public school teaching, such as primary/junior and intermediate/senior. When B. Ed. TLs begin their 
practicum, it is likely that they have already begun to visualize what type of student they hope to teach in the future. Of course, they may change their minds later and pursue qualifications to teach a different age range of students. But the point is that there is a specialized focus and premeditated aspect to $B$. Ed. programs different to the CTESL program featured in this study.

\section{PLTE and the Significance of Hindsight Reflection}

Hindsight reflection is a unique form of reflection that emerged in this study and is specifically associated with TLs who came into the CTESL program with several years' PLTE. As I have not encountered this term in LTE or GTE literature, it merits further discussion here.

Hindsight reflection is distinct from reflection in action, reflection on action and reflection for action in the following ways:

1. A certain amount of time has passed between the original teaching event(s) and the "aha" moment the teacher in question experiences of how she/he might have better met the needs of his/her former students;

2. The present "aha" moment is based on new theoretical knowledge and/or observations that are novel to the TL in question and resonates with him or her in particular way;

3. Hindsight reflection allows for a more objective stance about the former teaching event(s) in question because of the marriage between new theoretical knowledge as it is applied to former practice, rather than mere reflection on practice alone;

While hindsight reflection is distinct from reflection in-, on-, and for-action, certain points are understandably interrelated. For example, imagine that either a pre-service or inservice teacher with PLTE has recently engaged in hindsight reflection about aspects of their formal teaching practice. They do so as a result of a professional development activity of some kind, such as attending a conference workshop or reading a thought-provoking TESL-based journal article. Having had the "aha" moment, they find themselves reflecting for action: how can they adjust their future practice to accommodate for these new insights? Then, while 
teaching, the practitioner may find him/herself reflecting in action, mindful that he/she has just put to use this new information and is monitoring, in a natural, way, the impact that this has on his/her students. Afterward, he/she may then reflect on action to assess if and how the hindsight reflection benefited his/her students and teaching practice.

\section{Refection across a Continuum: Different Stages of Teacher Development}

As outlined in Chapter 2, Larrivee (2008) suggested that reflection can be seen to operate on a continuum, involving surface, pedagogical, and critical levels of reflection. Given that PLTE has been established as the most significant independent variable in this study, the following $\mathrm{A}, \mathrm{B}$, and $\mathrm{C}$, points on the continuum below are worth reflecting on:

Figure 8.1: Three Teacher Learners Reflecting Across a Continuum

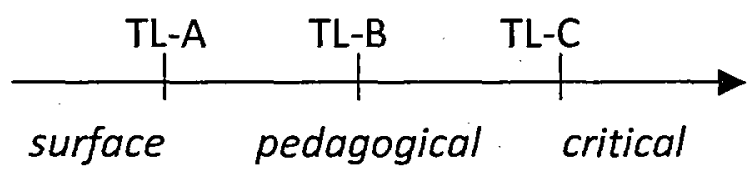

In the above illustration, $\mathrm{A}, \mathrm{B}$, and $\mathrm{C}$ are markers for different types of pre-service teachers. Note that these are theoretical examples only, provided for the purpose of further discussion. Teacher learners $\mathrm{A}, \mathrm{B}$, and $\mathrm{C}$ are not meant as conclusive examples of the learning-to-teach process.

\section{Teacher Learner A (TL-A):}

Student A comes into the program with no PLTE and wants to acquire the CTESL because this certificate will help them realize their goal of travelling around the world; they are not interested in pursuing teaching as a career. As such, student A might not be inclined to engage in reflection beyond the surface-level of $O K$, that lesson seemed to go well. 


\section{Teacher Learner B (TL-B):}

Student B comes into the program with no PLTE but with an interest in teaching ESL here in Ontario (or teaching EFL in a particular country that they have a personal connection to); they might be more inclined to engage in both surface and pedagogical reflection.

\section{Teacher Learner C (TL-C):}

Student C may come into the program with no PLTE or several years' PLTE but sees teaching $\mathrm{ES} / \mathrm{FL}$ as a definite career option and has a natural pre-disposition toward reflecting on their own learning-to-teach processes and the learning of others.

The illustration of Teacher Learner C is not intended to suggest that all CTESL students with PLTE will engage in both pedagogical and critical level reflection. A teacher learner could enter the program with several years' PLTE and not be motivated to become critically reflective about his or her practice. Conversely, a student could come into an LTE program with no PLTE but have clear career aspirations and therefore be more likely to reflect beyond the surface level; he or she may well begin to engage in critical reflection.

My central position here is that teacher learners who come into an LTE program with several years' PLTE are more likely to engage in reflection beyond surface level simply because they have an existing repertoire of previous teaching moments to draw from that, in turn, can facilitate an intentional move toward critical reflection. However this does not mean that all TLs with PLTE are able or willing to do so. Connected to this idea is the fact that - as this study has demonstrated - TLs with PLTE may be inclined to engage in hindsight reflection during their program study. 


\section{CHAPTER 9: Conclusion}

In this chapter I revisit the research questions posed in Chapter 1 and summarize findings related to those questions. Following this, I acknowledge a number of limitations inherent in this case study. I then discuss implications for future LTE research and pedagogy.

\section{Research Questions Revisited}

1. With respect to their teaching concerns, how closely do the experiences of this group of CTESL students resemble Conway and Clark's (2003) model of teacher development?

2. What are their ELT-related career aspirations? Related to this, what are their primary motivations for obtaining the CTESL?

3. Do the CTESL students see value in their practicum placements? If yes, how so?

4. What are their appraisals of the four different types of practicum course reflection: face-to-face, online, individual, and collective?

5. Do features such as age, gender, and previous language teaching experience (PLTE) appear to influence how receptive individual CTESL students are to the four types of reflection outlined above?

\section{Research Question \# 1: Concerns of CTESL Students?}

As discussed in Chapter 6 and 8, findings from Stage 2 indicate that the 14 CTESL students in this study reported having both inward and outward focused concerns both prior to and during their practicum placements. These findings support the argument put forth by Conway and Clark (2003) that learning to teach is not a linear process but rather is bi-directional and cyclical. Further, certain concerns that CTESL students reported having, such as relationship with their host teacher and being able to make use of SLA theory and research in their future classes can be categorized as a particular type of inward-focused concern, associated in part or in full with development of self-as-teacher (Conway \& Clark, 2003). 


\section{Research Question \# 2: Aspirations of CTESL Students?}

As indicated in Chapter 1, researchers and teacher educators alike need to identify how invested CTESL students are in their long-term development as ES/FL teachers. From the outset of this thesis, I have asserted that if critical reflection is indeed essential to ongoing professional development, and if reflective practice is indeed an integral part of both LTE and GTE programs because of this established connection, we need to determine how invested CTESL students are in pursuing ES/FL teaching as a career. If TLs are only partially invested, then the reflective model of teacher education may lose some of its potency.

The 14 CTESL students surveyed provided a range of answers when asked: what aspirations do you have for your future as an English language teacher? The majority of CTESL students (10 out of 14) indicated they hoped to continue to teach English after graduation. Out of these ten, three respondents indicated that they aspired to become good teachers. For the remaining four TLs who did not express an interest in teaching ESL or EFL, three of them expressed an interest in curriculum design and one of them indicated she was undecided. However, this undecided student, respondent 4 (Alima), later indicated during the one-on-one interview that she was increasingly - "more and more so" - considering teaching ESL as a career. From these findings, it can be argued that reflective language teaching, with its link to long-term professional development, is likely relevant for at least 11 of the 14 respondents who expressed an interest in pursuing ELT as a career.

\section{Research Question \# 3: Value of the TESL Practicum?}

As emphasized in Chapter 1, the issue of how ES/FL teachers develop at the pre-service level is still a topic "little understood" (Crookes, 2003). Equally important is the fact that "the practicum remains an under-theorized and under-researched area" (p.2). For this reason, I set out 
to learn more about the practicum experiences of CTESL students in Stage 2, 3, and 4. One area in particular that I wanted to document was the value that these TLs placed on their practicum experiences and what aspects in particular they found most valuable. Because student teachers' voices are underrepresented with regard to their practicum experiences (Ralph, Wimmer, \& Walker, 2008), I made sure to extensively quote TLs throughout this thesis.

When asked to comment on which two or three aspects of their practicum course and placement they found most valuable, answers from the 14 CTESL students were fairly homogenous. The majority of the group, 11 out of 14 CTESL students, reported that observing their host teachers was of great value to them. And the majority of the group, nine out of 14 CTESL students, reported that practice teaching was of great value to them. Worth remembering is that seven out of the 11 students who reported significant value in observing their host teacher also reported value in practice teaching; hence for seven students, observation and practice teaching were of equal value.

Findings from the questionnaire data also revealed that three out of the 14 respondents indicated that being in a "real" classroom and interacting with and observing ESL students was of significant value to them. Worth noting is that all three respondents were novice teachers. Their appreciation for having access to "real" ESL classrooms lends support to my argument that TLs with no PLTE do not have a repertoire of previous classroom images to draw from and thus are likely to be that much more appreciative of the opportunity to observe their host teaches and ESL learners in action when compared to their peers with PLTE. However, this does not mean that TLs with PLTE do not value the hands-on, "real" aspect of their practicum placements; we know that one experienced language teacher in this study, Alima, clearly valued the "real-life" aspect of the practicum experience. My suggestion here is that TLs with PLTE may be less emphatic about the value of observing their host teachers and ESL classrooms than novice TLs. 
The fact that three respondents found discussing with their CTESL peers to be of great value is significant for two reasons. First, this finding demonstrates that collaborative learning was indeed encouraged during the CTESL practicum course and did indeed take place. Second, this finding demonstrates that while three students found the opportunity to share their practicum experiences with other TLs to be particularly valuable, for the most part, the greatest value drawn from the practicum experience was first-hand observation and practice teaching. In other words, for the 14 CTESL students surveyed, there was no greater source of learning than the first-hand experience of being in an ESL classroom. Thus Elaine's assertion that "experience is really the only teacher" would seem to reflect the predominant view among her peers.

\section{Research Question \# 4: TLs' Appraisal of Different Types of Reflection?}

Individual reflection: All 14 CTESL students indicated that they had been given adequate opportunities to engage in personal reflection. Further, 13 out of 14 CTESL students indicated that they had found individual reflection to be useful to them while completing their practicum course and attending their practicum placements. Data from Stage 3 provided additional details on why Alima, Marek, Karen, and Elaine found individual reflection beneficial.

Collective reflection: All 14 CTESL students indicated that they had been given adequate opportunities to engage in reflection with their peers. In addition, all 14 CTESL students indicated that talking about their practicum experiences with other students was useful. Data from Stage 3 and 4 provided further details on why in-person discussions with CTESL peers were considered to be so beneficial. Recall that Alima - who came into the programme with 5 years' PLTE - was equally emphatic about the value of collaborative reflection and learning with peers as Elaine, who came into the program with no PLTE, had been. 
In-person reflection vs. online reflection: Online reflection was the least preferred form of the four types of reflection. More than $1 / 3$ of those surveyed (5 out of 14 CTESL students) indicated that they did not find online discussion with peers via Web-CT to be beneficial. Only 3 students agreed that the online discussions were helpful and 6 students indicated that they found these discussions only somewhat helpful. Data from Stage 3 provided insight into why online reflection was the least preferred form of reflection and why some TLs did find it beneficial. Worth re-considering is Marek and Karen's point that online discussions allow for more time to reflect and involve a different type of reflection than in-person discussions. Recall also that Alima, though she much preferred in-person discussions, did feel that including online discussions as part of the practicum course curriculum was pedagogically sound, stating that “there are other students who don't feel comfortable having discussions in class, and it [the online discussion] works for them. It's about addressing a wide spectrum of learning styles in your classroom and being respectful of all of the differences" (Interview with Alima, p.11, February 24, 2009).

\section{Research Question \# 5: Significant Features?}

As demonstrated in Chapter 6, the most significant feature in this study, influencing three separate aspects of CTESL students' practicum experiences, was previous language teaching experience (PLTE). Here are those three aspects of the practicum experience:

1. PLTE has an impact on the difficulty that CTESL students experienced linking educational theory with practice (question 13); those with no PLTE experienced more difficulty making this link;

2. PLTE has an impact on how intensely CTESL students valued observing their host teachers (question 18); those with no PLTE were more emphatic about this value; and

3. PLTE has an impact on the amount of feedback desired by CTESL students (question 19); those with no PLTE desired more feedback. 
Worth revisiting is the connection between PLTE and the occurrence of hindsight reflection, discussed at length in Chapter $\mathbf{8}$. This is particularly important because, from my perspective, hindsight reflection is a natural catalyst for critical reflection. In this study, hindsight reflection was associated with TLs who came into the CTESL program with PLTE but with no previous teacher training specific to teaching ES/FL to adults. All 3 TLs who volunteered in Stage 3 and 4 of this study provided clear evidence of having engaged in hindsight reflection. Hindsight reflection was easily identified by language such as I wish I knew then what I know now (Alima); I would have done some things differently (Marek); and I thought back to my teaching and thought about stuff that I would change (Karen). Although it is not my position that all teacher learners who enter LTE programs with PLTE will naturally be inclined toward hindsight reflection, I feel that the potential impact that PLTE has on pre-service teachers' experience of LTE programs, practicum placements and reflective practice merits further study.

\section{The Reflective Process for Novice vs. Experienced Teachers}

Although reflection-on-action and reflection-for-action were described in Chapters 2 and Chapter $\mathbf{5}$ as being very much interconnected, it is equally important to be able to view them as distinct, at least theoretically. Their distinction ties into a central idea of this thesis: that for novice teachers, reflecting on their developing practice may be less difficult than reflecting for their future practice, simply because novice teachers have yet to develop their own repertoire of previous teaching moments to draw from when planning (reflecting for) future lessons or anticipating student problems. This may help explain why, in this study, novice TLs valued observing their host teachers slightly more than their CTESL peers who had PLTE. By observing their host teachers, the novice TLs in this study were able to expand their knowledge-base of what language teaching actually looks like in practice. I am not suggesting that novice teachers 
do not have any teaching knowledge-base to draw from and are therefore "blank slates". Rather, I am suggesting that, compared to more experienced language teachers, novice teachers' understanding of practical, everyday ES/FL classroom issues is inclined to be limited to theory and their own experiences as language learners.

At the same time, viewing reflection-on and for-action as being interconnected remains important. Returning to one of the reflective questions that Sarah posed in Stage 1: Are you always seeking out best practices for any given situation? (Interview with Sarah, p.9, January 9, 2009), we can see that the words seeking out and any given situation can be interpreted as reflection on-, for-, as well as in- action. The common thread for reflection-on and for-practice, according to all four participants in stage 3 of my study, is the notion that teachers reflect in order to improve their practice. According to Marek, Alima, Karen, and Elaine, it is important for novice and an experienced teacher alike to reflect on their practice in order to seek out best practices for future teaching moments.

On the topic of reflective teaching, it is worth considering that many experienced teachers do reflect in the actual moment of teaching - known as reflection-in-action or reflection-inpractice - by making the decision to, say, adjust aspects of their lesson to better meet the needs of a particular student or group of students as they become aware of those needs in that particular moment. Thus best practices for more experienced teachers might entail being sensitive to and adapting to students' needs whenever possible in the moment of teaching. Worth noting is that reflection-in-action is associated with experienced teachers rather than novice teaches, as the former are more likely have "already established a repertoire" of previous teaching experiences to draw from and are accustomed to running their own classrooms (Farrell, 2007, p.182). 
Equally important to consider is the heavy cognitive load that many novice TLs face in their first few weeks and months of teaching. Because their cognitive load is likely much heavier than that of TLs with several years' PLTE, the likelihood that that novice TLs will be able to step back from their practice to reflect in the moment of teaching in order to pursue best practices is arguably quite slim. For this reason, I believe that video recordings of practice teaching are tremendously valuable, particularly for novice TLs. The recording can be stopped and replayed at any point, allowing for TLs to get a more accurate sense of what occurred actually during their practice teaching, which can then help them reflect more objectively about their future practice.

I would like to emphasize that while experienced teachers may be more likely than novice teachers to reflect-in-action, this does not mean that the process is automatic. It is possible, of course, that a teacher can teach for 20 years and not be reflective about his or her practice either before, during, or after teaching, as Crookes (2003) has noted. It is also possible that while in-service teachers and pre-service teachers with PLTE may possess the ability to be reflective, they may not necessarily see value in reflective teaching (be willing to reflect) and therefore will not reflect, beyond the surface level, on their practice. In other words, although the three TLs with PLTE who volunteered in Stage 3 and 4 of my study saw value in reflective practice and all three engaged in hindsight reflection, this does not mean that the same holds true for all TLs with PLTE.

Which form of reflection is more desirable: for-action, in-action, or on-action? From my perspective, while the reflective process can be easily compartmentalized for purposes of theoretical discussion, in actual practice, this is not the case. It is my position that all forms of reflection are valuable but that reflection-in-action is less likely to be experienced by novice teachers. When reflection on-action is done in an objective and purposeful manner, I would argue that it is inevitably connected to reflection-for-action. Novice teachers who want to 
improve their developing practice to become "a good teacher" and who see value in the concept of reflective teaching will no doubt engage in reflection-on-action as well as for-practice. However, as Elaine noted in Stage 3, this process may initially take a lot of time, simply because novice teachers do not have a repertoire of previous teaching experience to draw from. This "missing" repertoire would include experience with lesson planning, pacing, lesson cohesion, as well as being aware of different ESL learners' needs and teaching contexts, among other things. Interestingly, Elaine indicated that both her host teachers told her that when they had first started teaching, lesson planning was quite difficult for them. In fact, they mentioned to Elaine that they had "planned for hours and hours before they got to class" in the early stages of their career, but that, with experience, the planning process become much easier. This anecdote lends support to the idea that reflection-for-practice becomes easier with time as well as experience for teachers who genuinely want to reflect upon and improve (reflect for) their practice.

\section{Reflection: Not always Constructive}

Though I have clearly taken a positive stance on reflective teaching throughout this thesis, I would like to acknowledge a potentially counter-productive aspect of reflection. Both Karen and Alima, in Stages 3 and 4, indicated that not all types of reflection are helpful to the teacher learner. Alima indicated that when she first started teaching, if things did not go well in class, she would take it personally and "fret about it for hours on end". Alima indicated that with experience, she learned "to not take it so personally and to start thinking about it from a big picture perspective". With more teaching experience, Alima said that it become easier to be more objective and take herself "outside of the situation" when she reflected. According to Alima, it is this more objective, de-personalized form of reflection that is desirous, rather than succumbing to endless "fretting". Similarly, Karen indicated that "there is a fine line between 
reflecting and over-analyzing" and that with the latter, it can cause teachers to "feel less confident" about their teaching practice, which, of course, is counter-productive.

I would also like to acknowledge that while recent scholars like Farrell (2007) and Crookes (2003) have highlighted the importance of collaborative reflection, I understand that some teachers are still able to develop as reflective practitioners without sharing their reflections with others. However, I would like to point out the obvious: if teachers who favour a solitary, intrapersonal form of reflection do not share their reflections, other practitioners will never be able to benefit from the ideas, insights, and perspectives that these teachers have gleaned from their practice. Sharing aspects of one's reflective teaching practice need not be limited to joining a teacher development group; it could involve sharing insights about reflective teaching at conferences and workshops.

\section{Limitations of Study}

There are several limitations of this case study that need to be addressed. First, the small sample size of 14 CTESL students in Stage 2 and 4 CTESL students in Stages 3 and 4 means that my findings cannot be generalized to other LTE program settings. Further research involving a larger sample size in general and a larger sample size of male respondents is needed. Another limitation of this study is the fact that, unlike the study that Conway and Clark (2003) undertook, I did not attempt to measure the concerns of CTESL students at two separate. points in their practicum placements. Rather I asked respondents to indicate, when they completed the questionnaire in February 2009, what their concerns had been in September 2008. It is possible that their recollection of how they felt six months earlier was not as reliable as how they did indeed feel at that time. 
A third limitation is that the host teachers' perspectives are entirely missing from this study, as are the perspectives of the ESL learners themselves. Although the scope of my research did not allow me to investigate either of these areas, it is important to recognize that their perspectives on the TESOL/TESL practicum experience are worth documenting. In particular, the perspective of host teachers, as Crookes (2003) notes, is an under-researched area worthy of further study, particularly given the important role that they play in LTE programs.

Finally, a fourth limitation of this study is the fact that my decision not to invite four M.A. students to participate meant that the full portrait of the CTESL program featured in this study has not been provided (assuming of course, that some or all of the four M.A. students would have volunteered to participate, at least in Stage 2). Though these four TLs did not participate in this study, I would like to mention that all four of them came into the program with PLTE. Given the significance of PLTE in this study and the constructivist model of teacher learning that the CTESL program is based on, the absence of input from this third group of student, the M.A. student with PLTE, is therefore a limitation.

\section{Implications for LTE Programs and Research}

There are a number of implications for further LTE-related research and programs. First, the CTESL program featured in this study was different from the college institution in the same city; the latter only admitted post-graduate students and favoured an immersion practicum experience. Future research could involve a comparative case study that looks at both programs to determine if post-graduate TLs at the college program appear more invested in ELT-related careers and how their immersion practicum experiences compare.

Further research on reflective language teaching might involve a follow-up study with TESOL graduates in their first year of in-service teaching. Areas of investigation might involve 
the impact their LTE program has had on their current practice, as well as perceptions and evidence of reflective practice in their role as in-service teachers compared to pre-service teachers; their ongoing development as teacher learners; whether they have actively sought out opportunities to collaborate and share with co-workers and other professionals in the field; and what obstacles, such as time or workplace environment, work against the actualization of reflective practice and collaboration with other teachers.

An area of research that is not related to my original five research questions but that I feel could be researched further is the finding that male respondents in this study were decidedly less emphatic when responding to the 15 likert scale questions in Stage 2 than their female peers. Could gender play a role in how emphatic respondents are when asked to comment on questions that they are personally connected to, such as the practicum experience for CTESL students? I believe this unanswered question warrants further research.

In terms of additional implications, it is imperative to consider that GTE has long influenced the content, design, and educational theories underlying LTE programs (Crandall, 2000). It therefore makes sense that the differences between B.Ed. students and TESOL students be critically examined. We need to bear in mind that LTE and GTE, while sharing many points in common, are also very different. As discussed in the previous chapter, B.Ed students are required to indicate, during the initial application process, what age group they hope to work with upon graduation, whereas for TESOL student teachers, this is not the case. Thus B.Ed students come into GTE programs with a specialized point of focus and have an idea of what type of learners they hope to work with in the future, whereas CTESOL student teachers do not.

Further to this, teaching children in the public school system is remarkably different to teaching ESL to recently landed adult immigrants in a community centre or teaching EAP at university. The field of ESL teaching is multi-layered, with many specialized areas of practice. 
Scholars and teacher educators alike need to stop and consider how reflective models of teaching practice that form an integral part of language teacher education programs are different, or need to be differentiated, from reflective models advocated in B. Ed programs.

An implication for both future pedagogy and research is the complex aspect of online learning, evident from Stage 2 and Stage 3 data in this study. As both Sarah in Stage 1 and Alima in Stage 3 noted, technology is an unavoidable component of ES/FL teaching and should therefore be addressed in the CTESL curriculum. Yet, we need to remember that online learning was the least preferred form of reflection among the 14 CTESL students surveyed in Stage 2. It appears that something in the application of its use may be missing. Could it be that the merits on online discussion need to be more explicitly stated to TLs, specifically that, as Marek noted, this forum allows for more time to reflect on and respond to the comments of one's peers? Or, will teacher educators simply have to accept that some TLs will not enjoy online learning even if they are able to recognize its pedagogical value? One thing remains clear: given that online learning is increasingly becoming part of the post-secondary learning experience, research needs to be undertaken that looks into the impact this increased online presence has on students who, like Alima, identify with being "very much an in-person, face-to-face communicator" and who "do not like doing things online".

The goal of creating an online learning experience with links to reflective teaching may be pedagogically ambitious in the sense that not all teacher learners will see value in it. However it is possible that grounding this course requirement in a real-world application might make a difference for TLs who do not like online learning. Rather than creating an insular and temporary online learning environment for pre-service teachers, teacher educators may want instead to ask CTESL students to critically review or reflect upon the usefulness of an existent online ES/FL 
discussion forum. TESL-L ${ }^{27}$, with over 30,000 members and averaging 3 posts each day on a wide range of topics related to English language teaching, might be an ideal place to start. Given the vastness of the postings, the online experience on this list-serve may need to be scaffolded for students at first, with the teacher educator selecting a particular post and thread in advance for CTESL students to examine and discuss. Once TLs are familiar with this online learning environment, independent or collaborative evaluation of any number of archived posts by inservice language teachers could then take place. Interestingly, TESL-L contains several special interest sub-lists, such as TESLCA-L, which focuses exclusively on connections between computer technology and TESL. Rather than directing students toward the larger TESL-L, it may be more pedagogically appropriate to directing them toward TESLCA-L.

Differentiating between "fretting endlessly" and being able to reflect more objectively is arguably a skill that teachers need to learn how to develop. For this reason alone, it makes sense that teacher educators explicitly address the topic of reflective teaching and share information on what exactly reflective teaching means to different scholars and practicing teachers. In particular, teacher educators may want to provide TLs with meta-reflective tools to help them begin to reflect more objectively and with a clear purpose, and to help them avoid simply "fretting" about what went "wrong" in their practice teaching. As noted in Chapter 2, it is not enough to simply encourage reflective teaching, because without a conceptual framework for what reflective teaching might look like in practice, reflective teaching does not mean very much.

Presenting pre-service teachers with a conceptual map of surface pedagogical critical levels of reflection and then providing examples of surface-level, pedagogical-level, and

\footnotetext{
${ }^{27}$ Note that this idea is apparently not unique to this thesis. When consulting the TESL-L guidelines, I noticed a section that specifically addresses teacher educators. They are instructed not to require their student teachers to post to the website as part of an assignment. In other words, student teachers can "lurk" on the website, but they cannot be asked to participate in or initiate a post. Postings must be completely voluntary. Student teachers would therefore need to take on the role of observer only if directed to the website by their course instructor.
} 
critically reflective questions as a reference point might prove beneficial. As indicated above, given the dual focus on computer technology and long-term professional development in many LTE programs, asking TLs to critically examine the online discussion posts of in-service teachers on large list-serves such as TESL-L might also be appropriate. Student teachers can be encouraged to analyze and discuss the reflective foci of different practicing teachers on TESLrelated online forums. Addressing the issue of reflection-on and for-practice and providing narrative examples of what this might look like in practice is another possibility. Also, addressing Karen's point that not all teachers reflect in the same way and that the preferred medium of reflection (intrapersonal, interpersonal, in-person, online) will vary from practitioner to practitioner might also be beneficial. Above all, teacher educators cannot simply advise student teachers to "be reflective" without providing some reference point and discussion of what this might look like in practice.

Given the significance of previous language teaching experience (PLTE) in this study, seen to affect three separate aspects of the TESL practicum experience, language teacher educators may want to acquire background information on program applicants. Again, this is not to suggest that all TLs with PLTE will be inclined to reflect beyond the surface level. Rather it is to say that TLs with PLTE have an existent repertoire of teaching images, moments, and experiences to draw from. In other words, compared to the novice teacher, they already have a reference point for language teaching to reflect upon. Will all TLs with PLTE use these previous teaching experiences to reflect more critically upon their past, present, and future practice? We cannot know. But teacher educators can certainly encourage critical reflection through metareflective practices, as outlined above.

Background information on TLs could encompass both length and context of previous teaching experiences. Scholars have suggested that this type of information gathering is needed: 
"Just as teacher might do a needs analysis to discover where there students' interests and needs lie, teacher educators can discover the more immediate interests and needs of their student teachers" (Numrich, 1996, p.149). In loop input fashion, I would add to the above the importance of individual strengths and life experiences that both ESL learners and TLs bring into classrooms.

Teacher educators who support a constructivist model of teacher learning may find it worthwhile to administer, at the outset of their course, a simpler version of the questionnaire used in this study. Information gathered about pre-service TLs can be used to help the teacher educator understand the unique aspects of each group of pre-service teachers engaged in actively constructing their individual and collective knowledge-bases. In other words, teacher educators may benefit from knowing who their student teachers are as people, not just learners.

The purpose of this study was not to evaluate the effectiveness of the CTESL program or the practicum course, but rather to document the lived experiences of teacher learners completing the second of two practicum placements. When reporting on the fact that CTESL students were generally not enthusiastic about having online discussions with their peers, I do not see this as a critique of the practicum course. Rather, I am reminded that, in an effort to expose students to a range of reflective practices within the context of an LTE or GTE program, there will invariably be some activities that students like more and some that are decidedly less popular. As Scrivener (1994) indicates, ES/FL teachers should be mindful that "trying things out" and learning from what goes well and what does not is an inevitable part of the learning cycle for not just ES/FL learners, but ES/FL teachers as well. I would add teacher educators to this loop input equation, particularly within the context of viewing reflective teaching as a life-long process.

As Crandall (2000) observed almost 10 years ago, there is somewhat "disparate research on teacher learning" and, as this research agenda is still somewhat young, there are "clearly great 
and useful possibilities for inquiry into, and understanding of, the antecedents, processes, environments, and impacts of teacher learning in language teaching" (p.407). It is my hope that in the not so distant future, the absence of teacher learners' voices at the LTE pre-service level will be more comprehensively addressed. Within the context of viewing teacher educators as teacher learners, I also look forward to research that investigates "if and how teacher educator themselves engage in continuous reflection to advance or improve their teaching practices" (Mueller \& Skamp, 2003, p. 429). And yes, I look forward to noting an absence of terms such as master teacher or anecdotes about "mother birds" who find it "difficult to trust the fledglings". (Bold \& Chambers, 2009, p.22). 


\section{References}

Bailey, K. M., Curtis, A., \& Nunan, D. (2001) Pursuing professional development: The self as source. Boston: Heinle \& Heinle.

Bailey, K. M. (1990). The use of diary studies in teacher education programs. In J. C. Richards, \& D. Nunan (Eds.), Second language teacher education (pp. 215-226). New York: Cambridge University Press.

Bartlett, L. (1990). Teacher development through reflective teaching. In J. C. Richards, \& D. Nunan (Eds.), Second language teacher education (pp. 202-214). New York: Cambridge University Press.

Beaumont, J. (2004). Passing as a teacher: An ethnographic account of entering the TESOL profession. Ed.D. dissertation, Columbia University Teachers College, United States: New York. Retrieved October 5, 2008, from Dissertations \& Theses: Publication No. AAT 3135321.

Bloomberg, L.D., \& Volpe, M. (2008). Completing your qualitative dissertation: A roadmap from beginning to end. Thousand Oaks, CA: Sage Publications.

Bold, C., \& Chambers, P. (2009). Reflecting meaningfully, reflecting differently. Reflective Practice, $10(1), 13-26$.

Brandt, C. (2006). Allowing for practice: A critical issue in TESOL teacher preparation. ELT Journal, $60(4), 355-364$.

Brinton, D. \& Holten, C. (1989). What novice teachers focus on: The practicum in TESL. TESOL Quarterly, 23 (2), 343-350. 
Brinton, D. \& Holten, C. (1995). "You shoulda been there": Charting novice teacher growth using dialogue journals. TESOL Journal, 4 (4), p.23-26.

Brock, M. N., Wong, M. M. W, \& Wu, B. (1993). Collaborative diary keeping. In Freeman, D., \& Cornwell, S. (Eds.), New ways in teacher education (pp.10-13). Virginia: TESOL Inc.

Carter, B. (2008). Teacher-learners' voices: Not the same old song. Innovation in Language Learning and Teaching, 2 (1), 33-46.

Conway, P.F., \& Clark, C.M. (2003). The journey inward and outward: A re-examination of Fuller's concerns-based model of teacher development. Teaching and Teacher Education, 19 (5), 465-82.

Crandall, J. (2000). Language teacher education. Annual Review of Applied Linguistics, 20, 34-55

Crookes, G. (2003). A practicum in TESOL: Professional development through teaching practice. Cambridge: Cambridge University Press.

Cruickshank, D. \& Applegate, J. (1981). Reflective teaching as a strategy for teacher growth. Educational Leadership, 38, 553-4.

Davies, M. B. (2007). Doing a successful research project using qualitative or quantitative methods. New York: Palgrave Macmillan.

de Vaus, D. (2002). Surveys in social research. New York: Routledge.

DeMarrais, K. (2004). Qualitative interview studies: Learning through experience. In K. DeMarrais, \& S. D. Lapan (Eds.), Foundations for research: Methods of inquiry in education and the social sciences (pp. 51-68). New Jersey: Lawrence Erlbaum Associates.

Drew, C.J., Hardman, M.L., \& Hosp, J.L. (2008). Designing and conducting research in education. Thousand Oaks, CA: Sage Publications 
Farrell, T.S.C. (2007). Reflective language teaching: From research to practice. New York:

Continuum Press.

Ferguson, G., \& Donno, S. (2003). One-month teacher training courses: Time for a change? ELT Journal, 57 (1), 26-33.

Freeman, D., \& Cornwell, S. (1993). New ways in teacher education. Virginia: TESOL Inc.

Freeman, D., \& Johnson, K. (1998). Re-conceptualizing the knowledge-base of language teacher education. TESOL Quarterly, 32 (3), 397-417.

Ghaye, A. \& Ghaye, K. (1998). Teaching and learning through critical reflective practice. London: David Fulton Publishers.

Goethals, M. S., Howard, R. A., \& Sanders, M. M. (2004). Student teaching: A process approach to reflective practice - a guide for pre-service and in-service teachers. New Jersey: Pearson Education.

Hays, P. A. (2004). Case study research. In K. DeMarrais, \& S. D. Lapan (Eds.), Foundations for research: methods of inquiry in education and the social sciences (pp. 217-234). New Jersey: Lawrence Erlbaum Associates.

Hutchinson, S. R. (2004). Survey research. In K. DeMarrais, \& S. D. Lapan (Eds.), Foundations for research: methods of inquiry in education and the social sciences (pp. 51-68). New Jersey: Lawrence Erlbaum Associates.

Johnson, B., \& Christensen, L. B. (2000). Educational research: Quantitative and qualitative approaches. Boston: Allyn and Bacon.

Johnson, B., \& Christensen, L. B. (2004). Educational research: Quantitative, qualitative, and mixed approaches. Boston: Pearson Education. 
Johnson, K. E. (1992). Tapping experienced teachers' knowledge during the TESOL practicum. Guidelines, 14 (2), 43-53.

Johnson, K. E. (1994). The emerging beliefs and instructional practices of pre-service English as a second language teachers. Teaching and Teacher Education, 10 (4), 439-452.

Johnson, K. E. (1996). The vision versus the reality: The tensions of the TESOL practicum. In D. Freeman, \& J. C. Richards (Eds.), Teacher learning in language teaching (pp. 30-49). New York: Cambridge University Press.

Kitchen, J., Stevens, D. (2008) Action research in teacher education. Action Research, 6 (1), 7-28. Kleiber, P. B. (2004). Focus groups: More than a method of qualitative inquiry. In K. DeMarrais, \& S. D. Lapan (Eds.), Foundations for research: methods of inquiry in education and the social sciences (pp. 87-102). New Jersey: Lawrence Erlbaum Associates.

Knowles, J.G., Cole, A.L., \& Presswood, C.S. (1994). Through pre-service teachers' eyes: Exploring field experiences through narrative and inquiry. New Jersey: Prentice Hall.

Krueger, R. A., \& Casey, M. (2009). Focus groups: A practical guide for applied research. Thousand Oaks, CA: Sage Publications.

Kvale, S. (1996). Interviews: An introduction to qualitative research interviewing. Thousand Oaks, CA: Sage Publications.

Larrivee, B. (2008). Meeting the challenge of preparing reflective practitioners. The new educator, $4(1), 87-106$.

Lee, V.S. (2004). Teaching and Learning through inquiry: A guidebook for institutions and instructors. Sterling, VA: Stylus Publishing. 
Merriam, S. B., \& Simpson, E. L. (1994). A guide to research for educators and trainers of adults. Florida: Krieger Publishing.

Merriam, S. B. (1998). Qualitative research and case study applications in education. San Francisco: Jossey-Bass Publishers.

Miles, M. B., \& Huberman, A. M. (1994). Qualitative data analysis. Thousand Oaks, CA: Sage Publications.

Mueller, A., \& Skamp, K. (2003). Teacher candidates talk: Listen to the unsteady beat of learning to teach. Journal of Teacher Education, 54 (5), 428-440.

Nardi, P. M. (2006). Doing survey research. Boston: Pearson Education.

Numrich, C. (1996). On becoming a language teacher: Insights from Diary Studies. TESOL Quarterly, 30 (1), 131-153.

Parker, R. (1991). Product vs. process in language teaching education: shifting the focus of course design. In Sadtono, E. (Ed), Language teacher education in a fast-changing world. Singapore: SEAMEO Regional Language Centre.

Ralph, E., Wimmer, R., \& Walker, K. Clinical and practical education in the professions: The student voice. In Collected essays on learning and teaching (CELT), volume 1, (pp.55-60). Edmonton: University of Alberta Press.

Richards, J. C. \& Crookes, G. (1988). The practicum in TESOL. TESOL Quarterly, 22 (1), 9-27.

Richards, J. C and Ho, B. (1998). Reflective teaching through journal writing. In J.C. Richards (Ed), Beyond training: Perspectives on language teacher education (pp.153-170). New York: Cambridge University Press. 
Richards, J. C. (1998). Beyond training: Perspectives on language teacher education. New York: Cambridge University Press.

Richards, J. C. (1990). The language teaching matrix. New York: Cambridge University Press. Richards, J.C., \& Farrell, T. (2005). Professional development for language teachers: Strategies for teacher learners. Cambridge: Cambridge University Press.

Richards, J. C., \& Lockhart, C. (1994). Reflective teaching in second language classrooms. New York: Cambridge University Press.

Romano, M. (2005). Assessing and meeting the needs of pre-service teachers: A programmatic perspective. Action in Teacher Education, 27 (3), 40-54.

Sarasin, L.C. (1998). Learning style perspectives: Impact in the classroom. Madison, WI: Atwood. Publishing.

Schon, D. A. (1983). The reflective practitioner: How professionals think in action. New York: Basic Books.

Schon, D. A. (1987). Educating the reflective practitioner. San Francisco, CA: Jossey-Bass.

Scrivener, J. (1994). Learning teaching: A guidebook-for English language teachers. Oxford: Macmillan Heinemann English Language Teaching.

Senior, R. M. (2006). The experience of language teaching. New York: Cambridge University Press. Sheilds, C.L., \& Janopoulas, M. (1995). A flexible and practical practicum. The Teacher Trainer, 3 (1), 11-16.

Silverman, D., \& Marvasti, A. (2008). Doing qualitative research: A comprehensive guide. Thousand Oaks, CA: Sage Publications. 
Stewart, D. W., Shamdasani, P. N., \& Rook, D. W. (2007). Focus groups: Theory and practice. Thousand Oaks, CA: Sage Publications.

Stoynoff, S. (1999). The TESOL practicum: An integrated model in the U.S. TESOL Quarterly, 33 (1), 145-151.

Tabachnick, B. R. \& Zeichner, K. M. (1991). Reflections on reflective teaching. In Tabachnick, B. R. \& Zeichner, K. M (Eds.) Issues and practices in inquiry-oriented teacher education (pp.1-21). London: Falmer Press.

Ur, P. (1996). A course in language teaching: Practice and theory. New York: Cambridge University Press.

Whitson, G \& Bodycott, P. (1991). Using feedback and reflections as tools in bridging the theorypractice link in language teacher training at the primary level. In Sadtono, E. (Ed), Language teacher education in a fast-changing world. Singapore: SEAMEO Regional Language Centre.

Woodward, T. (1991). Models and metaphors in language teacher training: Loop input and other strategies. Cambridge: Cambridge University Press.

Yates, R. \& Muchisky, D. (2003). On reconceptualising teacher education. TESOL Quarterly, 37 (1), 135-147. 


\section{Appendices}

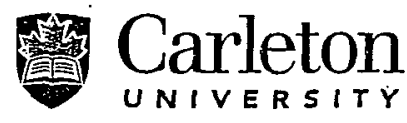

Canada's Capital University
Carleton University Research Office

5 th Floor Tory Building

1125 Colonel By Drive

Ottawa, ON K1S 586 Canada

Tei: (613) $520-2516$

Fax: (613) 520-2521

unw.carleton.ca/cu/research/curo/

\section{Ethics Clearance Form}

This is to certify that the Carleton University Research Ethics Committee has examined the application for ethical clearance. The committee found the research project to meet appropriate ethical standards as outlined in the Tri-Council Policy Statement: Ethical Conduct for Research Involving Humans and, the Carleton University Policies and Procedures for the Ethical Conduct of Research.

\section{$X$ New approval \\ Date of approval \\ Researcher \\ Status \\ Department \\ Supervisor \\ Title of project} - Renewal of original approval

\section{Original date of approval:}

\author{
21 November 2008 \\ Michelle Wardman \\ M.A. student \\ School of Linguistics and Applied Language Studies \\ Professor David Wood \\ The TESOL Practicum: Building a Community of Practice?
}

Ethics approval expires on: 31 May 2009

\section{All researchers are governed by the following conditions:}

Annual Status Report: You are required to submit an Annual Status Report to either renew clearance or close the file. Failure to submit the Annual Status Report will result in the immediate suspension of the project. Funded projects will have accounts suspended until the report is submitted and approved.

Changes to the project: Any changes to the project must be submitted to the Carleton University Research Ethics Committee for approval. All changes must be approved prior to the continuance of the research.

Adverse events: Should any participant suffer adversely from their participation in the project you are required to report the matter to the Carleton University Research Ethics Committee. You must submit.a written record of the event and indicate what steps you have taken to resolve the situation.

Suspension or termination of approval: Failure to conduct the research in accordance.with the principles of the Tri-Council Policy Statement: Ethical Conduct for Research Involving Humans and the Carleton University Policies and Procedures for the Ethical Conduct of Research may result in the suspension or termination of the research project.



For the Chair of the Carleton University Research Ethics Committee

Prof. Antonio Gualtieri 
Appendix B: Situating my Role as Researcher

I have completed the following questionnaire (that was administered to participants in Stage 2) for theoretical purposes only. I include it here to illustrate my situated knowledge of the CTESL program featured in this study. Note the year change on page 2 that shows September 2007.

\section{Section 1: Background Information}

Please circle (O) the answers that apply to you and fill out the box section when it applies.

Q1. What is your gender?

Female Male

Q2. Please circle the age group you belong to:



Q3. Which kind of student are you? Please check off the section that applies to you.

- Undergraduate (4-year degree student)

- M.A.

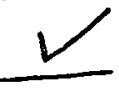

- Post-graduate (have already completed undergraduate degree)

Q4. What is your first language?

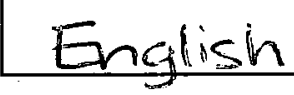

Q5. Do you speak any languages other than English? If yes, please complete the chart. If No:

\begin{tabular}{|c|c|}
\hline Language (Ex: French) & Overall Fluency (Ex: Intermediate) \\
\hline 1. French & Intermediate \\
\hline 2. Jafanese & Beginner \\
\hline 3. & \\
\hline
\end{tabular}

Q6. What is your primary reason for obtaining the CTESL?

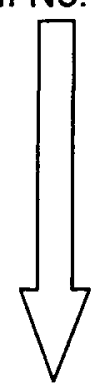

$$
\text { To obtain TESL Ontario Certification }
$$


Q7. Did you have any previous language teaching experience when you started the CTESL program in September 2008 ?

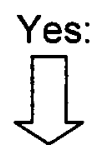

Q8. How many years of language teaching $20 \pi$ f experience did you have in September 2008 ? Please check the section that applies to you.

Less than 1 year

1 to 2 years

2 to 3 years 3 to 4 years More than 5 years
No: Please proceed to Section 2, page 3



Q9.

Indicate the type of language teaching experience you had coming into the CTESL

Program (circle all that apply).

- ESL (here in Canada or any English-speaking country such as England or the USA)

- EFL (in any country where English is not a first language such as Japan or China)

- Other (please explain)

Q10. Do you currently hold any teaching certificates? If yes, please circle all that apply.

- B.Ed. If no, please proceed to Section 2

6. CELTA

- Other (please indicate name and duration of certification) 


\section{Section 2: Your Practicum Experiences So Far}

Directions: Please circle a number from 1 to 6 that best reflects your feelings toward each statement. $1=$ strongly agree and $6=$ strongly disagree.

$\begin{array}{cccccc}1 & 2 & 3 & 4 & 5 & 6 \\ \text { Strongly Agree } & \text { Agree } & \text { Somewhat Agree } & \text { Somewhat Disagree } & \text { Disagree } & \text { Strongly Disagree }\end{array}$

11. In this course, I have had adequate opportunities to engage in personal reflection.
(1).
2
3
4
5
6

12. In this course, I have had adequate opportunities to reflect with my peers.
1
(2)
3
4
5
6

13. In this course, I have had difficulty linking educational theory with my practicum teaching.
1
2
3
4
(5)
6

14. In this course, I have been provided with practical teaching resources (such as lesson Less $50^{\mathrm{p}}$ in the piacticum in the practicum 1 course but

in the Merhedologid course

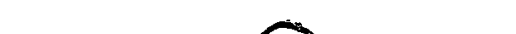

2

(3)

4

5

6

15. The practicum course is an essential part of the CTESL program at Carleton.
1
(2)
3
4
5
6

16. The practicum placement is an essential part of the CTESL program at Carleton.
(1)
2
3
4
5
6

17. During my practice teaching, I sometimes feel pressure to teach a particular way.
3
2
3
4
(5)
6 


\begin{tabular}{llcccc}
1 & 2 & 3 & 4 & 5 & 6 \\
Strongly Agree & Agree & Somewhat Agree & Somewhat Disagree & Disagree & Strongly Disagree \\
\hline-- & -
\end{tabular}

18. I value the opportunity to observe my host teacher(s) teach in their classroom.
1
(2)
3
4
5
6

19. I would like to have more feedback from my host teacher regarding my teaching.
1
2
(3)
4
5
6

20. I feel free to experiment and try out new ideas in my practice teaching.
1
(2)
3
4
5
6

21. I seldom learn anything new when listening to my classmates talk about their practicum.
1
2
3
4
5
(6)

22. In this class, I feel comfortable sharing my practicum experiences with other students.
(1)
2
3
4
5
6

23. Talking about my practicum experiences with other students is useful.
1
(2)
3
4
5
6

24. The online Web-CT discussion group is useful. * Not applicable to M.A. Studerits

5

6 year

25. In this course, I have found individual reflection to be useful.

1

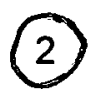

3

4

5

6

Please proceed to Section 3 (the final section) 
225

Section 3: Perspectives on the Practicum Course and Practice Teaching

Please complete this section in as much detail as you feel comfortable. Your responses will give me valuable insight into the practicum experiences of CTESL students here at Carleton. Please write on the back of this page if you require more space.

Q26. Which 2 or 3 aspects of this practicum course do you find the most valuable? (Example: observing your host teacher, discussing with peers on Web-CT, practice teaching, etc.) - Observing host teachers as well as EsL learners and being a "fly on the will" to see what goes on in cither Est teachers" clissmouns.

- Micro-teaching in the Methodology course, beat use I got to sa. ing classmates in action (I realize this is not the same thing as the practicum (course, but it's what I valued tie most). - The informal and insightful discussions that two k place in the practicums course (aten stading/hearing about different practicum placement experiences).

Q27. Thinking back to September 2008 , what concerns, if any, did you have at that time about your first practicum teaching experience? Please explain.

Concern that ing host teacher would not be easy to work with and might net be open to me trying out new ideas/approucles with her/ his students.

Q28. Looking ahead to the future, what concerns, if any, do you have about teaching English?

Finding work that is meaningful to me, pays weill, and keeps me challenged.

Also, finding work in a supportive, collaborative wat environment Cog., teachers are happy to share teaching materials rather than "guarding thern"/being solo fingers").

Q29. What aspirations do you have for your future as an English language teacher?

To continue teaching EsL here in Canada.

Specifically, Ind like to teach at the post-secondary level. I id also like to contivive to develop as a professional and keep my teaching afresh". 


\section{Appendix C: Carleton}

Thank you for completing this questionnaire. Your participation will help me gain insight into the practicum experiences of CTESL students here at Carleton.

\section{Acknowledgement of Voluntary Participation:}

I have read the letter of February 9, 2009. I agree to participate in Michelle Wardman's study on the practicum experiences of CTESL students by completing this questionnaire. I understand that my name and any information that I have written down in this questionnaire will remain strictly confidential. With the exception of graduate students who may assist Michelle in coding anonymous data collected from the questionnaires, I understand that only Michelle and her supervisor will have access to the information in the questionnaires.

I also understand that my participation in any stage of this study is voluntary.

Name:

Signature: Date:

\section{Information on the 30-40 minute Follow-Up Interview:}

I understand that $I$ can further participate in this study by agreeing to participate in a $30-40$ minute interview, to be conducted by Michelle Wardman in February and March 2009. I understand that all information shared in the interview will remain strictly confidential.

Please indicate your willingness to be contacted for an interview:

Yes, I am willing to be contacted for a 30-40 minute follow-up interview

No, I am not willing to be contacted for a 30-40 minute follow-up interview.

Contact information (to send you a summary of the results of my study and/or to contact you to arrange an interview):

Email: @connect.carleton.ca Phone number:

\section{Section 1: Background Information}

Please circle (O) the answers that apply to you and fill out the box section when it applies.

Q1. What is your gender?

Female Male

Q2. Please circle the age group you belong to:
Under 20
$20-24$
25-29
$30-34$
35-39
40-44
45-49
50 plus 
Q3. Which kind of student are you? Please check off the section that applies to you.

- Undergraduate (4 -year degree student)

- Post-graduate (have aiready completed undergraduate degree)

Q4. What is your first language?

Q5. Do you speak any languages other than English? If yes, please complete the chart. If No:

\begin{tabular}{|l|l|}
\hline Language (Ex: French) & Overall Fluency (Ex: Intermediate) \\
\hline 1. & \\
\hline 3. & \\
\hline
\end{tabular}

Q6. What is your primary reason for obtaining the CTESL?

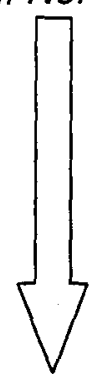

Q7. Did you have any previous language teaching experience when you started the CTESL program in September 2008?<smiles>[Te]=C1CCCCC1</smiles>

Q8. How many years of language teaching experience did you have in September 2008? Please check the section that applies to you.

Less than 1 year

1 to 2 years

2 to 3 years

_. 3 to 4 years

4 to 5 years More than 5 years
No: Please proceed to Section 2, page 3



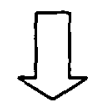

Q9. Indicate the type of language teaching experience you had coming into the CTESL Program (circle all that apply).

- ESL (here in Canada or any English-speaking country such as England or the USA)

- EFL (in any country where English is not a first language such as Japan or China)

- Other (please explain) 
Q10. Do you currently hold any teaching certificates?

If yes, please circle all that apply.

- B.Ed.

If no, please proceed to Section 2

- CELTA

- Other (please indicate name and duration of certification)

\section{Section 2: Your Practicum Experiences So Far}

Directions: Please circle a number from 1 to 6 that best reflects your feelings toward each statement. $1=$ strongly agree and $6=$ strongly disagree.

$\begin{array}{cccccc}1 & 2 & 3 & 4 & 5 & 6 \\ \text { Strongly Agree } & \text { Agree } & \text { Somewhat Agree } & \text { Somewhat Disagree } & \text { Disagree } & \text { Strongly Disagree }\end{array}$

26. In this course, I have had adequate opportunities to engage in personal reflection.
2
2
3
4
5

6

27. In this course, I have had adequate opportunities to reflect with my peers.
2
2
3
4
5
6

28. In this course, I have had difficulty linking educational theory with my practicum teaching.
2
2
3
4
5
6

29. In this course, I have been provided with practical teaching resources (such as lesson plan ideas) that I can use as a teacher in the future.
1
2
3
4
5
6

30. The practicum course is an essential part of the CTESL program at Carleton.
1
2
3
4
5
6

31. The practicum placement is an essential part of the CTESL program at Carleton.
2
2
3
4
5
6

32. During my practice teaching, I sometimes feel pressure to teach a particular way.
4
2
3
4
5
6 
$\begin{array}{llcccc}1 & 2 & 3 & 4 & 5 & 6 \\ \text { Strongly Agree } & \text { Agree } & \text { Somewhat Agree } & \text { Somewhat Disagree } & \text { Disagree } & \text { Strongly Disagree }\end{array}$

33. I value the opportunity to observe my host teacher(s) teach in their classroom.
1
2
3
4
5
6

34. I would like to have more feedback from my host teacher regarding my teaching.
1
2
3
4
5
6

35. I feel free to experiment and try out new ideas in my practice teaching.
1
2
3
4
5
6

36. I seldom learn anything new when listening to my classmates talk about their practicum.
1
2
3
4
5
6

37. In this class, I feel comfortable sharing my practicum experiences with other students.
1
2
3
4
5
6

38. Talking about my practicum experiences with other students is useful.
1
2
3
4
5
6

39. The online Web-CT discussion group is useful.
1
2
3
4
5
6

40. In this course, I have found individual reflection to be useful.
1
2
3
4
5
6

Please proceed to Section 3 (the final section) 


\section{Section 3: Perspectives on the Practicum Course and Practice Teaching}

Please complete this section in as much detail as you feel comfortable. Your responses will give me valuable insight into the practicum experiences of CTESL students here at Carleton. Please write on the back of this page if you require more space.

Q26. Which 2 or 3 aspects of this practicum course do you find the most valuable? (Example: observing your host teacher, discussing with peers on Web-CT, practice teaching, etc.)

Q27. Thinking back to September 2008, what concerns, if any, did you have at that time about your first practicum teaching experience? Please explain.

Q28. Looking ahead to the future, what concerns, if any, do you have about teaching English?

Q29. What aspirations do you have for your future as an English language teacher? 


\section{Appendix D: Recruitment Letter given to CTESL Students}

\section{Carleton \\ U N I V R S T Y}

February 9, 2009

Dear student,

My name is Michelle Wardman and I am a Carleton MA student completing my second year here at SLaLS. I am here today to give you a brief overview of my thesis project and to find out if you would be interested in participating in my study.

Specifically, I am interested in understanding the learning processes that you as CTESL students go through while completing your practicum placements. I would like to discover whether or not you find certain types of reflection (individual, group, online and face-to-face) more useful than others in the process of meeting the requirements for this course and developing your teaching practice. I would also like to understand your main reason for obtaining the CTESL (your shortterm and long-term goals) and to get a sense of your prior language learning and teaching experiences.

To begin with, participation in any stage of my study is voluntary. You may choose to participate in none of the stages of my study. It will not affect your grade in this class. You may choose to participate only in stage 2 by completing the 20 minute questionnaire. Or you may decide that you are interested in completing the questionnaire as well as being contacted by me for a 30 minute follow-up interview. The choice is entirely yours. If you do decide to volunteer, please note that all information you disclose will be kept confidential. Your name will never appear in any part of my thesis.

If you would like to volunteer, please complete the questionnaire distributed at the end of this class today. If you do not wish to volunteer, simply return the incomplete questionnaire in the envelope provided.

Thank you for your time today.

Michelle Wardman 
Appendix E: Information and Consent for CTESL Student

\section{Carleton}

U I VER SITY

INFORMATION AND CONSENT FOR RESEARCH PARTICIPATION, Stage 2

Researcher: Michelle Wardman (MA student), Faculty of Arts and Social Sciences, Carleton University

Supervisor: Dr. David Wood, Faculty of Arts and Social Sciences, Carleton University

Dear student,

This information letter explains: 1) the purpose of my thesis study; 2) the procedures I will follow for stage 2 of my study; 3 ) voluntary participation; 4) issues related to confidentiality and anonymity; and 5) potential benefits and risks to each participant.

1) Purpose: To gain insight into the practicum experiences of CTESL undergraduate and postgraduate students at Carleton University. I would like to understand the learning processes that CTESL students go through while completing their practicum placements. I would like to discover whether or not you find certain types of reflection (individual, group, online and face-to-face) more useful than others in the process of meeting the requirements for LALS 4206 and while developing your teaching practice. I also wish to understand your reasons for obtaining the CTESL (i.e., short-term and long-term goals) and to get a sense of your prior language learning and teaching experiences.

2) Procedure: The information letter that you are currently reading relates to stage 2 of my study. This stage of my study involves participants completing a 20-minute questionnaire. If you would like to volunteer, please sign the consent section on page 2 of this letter and complete the questionnaire distributed at the end of this class today. Please put the questionnaire back in the envelope in which it came. If you do not wish to volunteer, simply return the incomplete questionnaire to its original envelope.

3) Participation: Participation in any stage of this study, including the first stage, is voluntary. You are free to withdraw from the study at any time, up until March 6, 2009. If you choose to withdraw from the study before this time, you will be asked if you want any or all of the data collected up to the point of withdrawal to be destroyed and excluded from the study and thesis. Once I have completed my thesis, you will have the opportunity to read about my findings in greater detail.

4) Confidentiality and Anonymity. Any information you disclose on the questionnaire will be kept confidential. Your name will never appear in any part of my thesis. I will protect your identity by using a pseudonym. Every attempt will be made to ensure that any information you give me remains non-attributable. Questionnaires and accompanying notes will be kept in a secure, locked filing cabinet in my apartment. Representatives of the Carleton University Research Ethics Committee may review any records under the supervision of the researcher for audit purposes. Once my thesis is complete, I will black 
out your name and contact information on the questionnaire and accompanying notes. I will shred these documents once I have established no further research use for them.

5) Potential Benefits and Risks: In the process of completing this questionnaire, you may gain insight into how your practicum placements have informed and shaped your teaching practice. You may enjoy the process of stepping back and appraising what type of reflection has worked best for you in this course. The risk of completing the questionnaire is that your identity may be inferred by your instructor or fellow classmates when comments from Section 3 of the questionnaire are included in my thesis. Depending on the nature of your practicum experience, another potential risk is that an unpleasant memory of your practicum placement may surface while you complete the questionnaire. Should this happen, please keep in mind that you are not required to finish completing the questionnaire, nor do you have to submit what you have completed.

If you have any questions about this stage of my study, or stage 3 or 4 , please feel free to contact me, Michelle Wardman, by email, at mwardman@connect.carleton.ca. You can also contact my supervisor, Dr. David Wood at david wood@,carleton.ca or 613-520-2600 ext. 6684.

\section{CONSENT}

I have read the information letter and voluntarily agree to take part in Stage 2 of this research project. I will be provided with a copy of this form for my reference.

This project has been reviewed and has received ethics clearance by the Carleton University Research Ethics Committee. If I have any questions about my rights as a research participant, I may contact the Chair of Carleton University's Research Ethics Committee.

Professor Antonio Gualtieri, Chair

Carleton University Research Ethics Committee

Carleton University

1125 Colonel By Drive

Ottawa, Ontario

K1Y $1 \mathrm{~J} 7$

Telephone: 613-520-2517

Email: ethics@carleton.ca

Name of Participant:

Signature of Participant: Date:

Signatures of researcher and supervisor:

Researcher: Date:

Supervisor: Date: 